\title{
Automatic and Probabilistic Foehn Diagnosis with a Statistical Mixture Model \\ MAster's Thesis
}

in Atmospheric Sciences

Submitted to the

FaCulty of Geo- And Atmospheric Sciences

of the

UNIVERSITY OF INNSBRUCK

in Partial Fulfillment of the Requirements for the Degree of MASTER OF SCIENCE

by

DAVID PLAVCAN

Advisors

Ao.Univ.-Prof. Dr. Georg J. Mayr

Univ.-Prof. Dr. Achim Zeileis

Innsbruck, January 2014 



\section{Abstract}

The goal of this study was to develop an objective and probabilistic foehn diagnosis method. Unsupervised classification with mixture models was used. Mixture models separate data by estimating parameters of (Gaussian) probability density functions which are assumed to describe the distributions of a variable. Reasonable concomitants can be added to improve the fits. Results are compared with a previous (semi-)automatic method and with manual expert classification.

For a station in a topographically simple foehn valley (Ellbögen in the Wipp Valley, Austria), mixture models use speed as primary variable to separate foehn and down-valley winds. Using only speed at this valley station gives already an accurate foehn event frequency. Adding the difference of potential temperature to an upstream crest station (Sattelberg) and relative humidity as concomitant variables, improves the temporal accuracy of analyzed foehn events. These results outperform the previous method clearly and match for most cases perfectly the human expert classification.

For a station in complex topography at the intersection of two valleys (Innsbruck University) the same approach works for a tighter direction sector but thus misses foehn deflected by the topography. Foehn not coming from the direct upwind direction can be diagnosed with a mixture model with difference in potential temperature to the upstream station Ellbögen when foehn is diagnosed there. Many other tested combinations of concomitants could not improve this simple model. Results of this model are more accurate than those of the previous method, although a few up-valley wind cases are misclassified as foehn.

Resulting foehn frequencies are 18.61\% at Ellbögen (from 1 January 2000 till 1 January 2013) and 5.65\% at Innsbruck University (from 1 January 2002 till 1 January 2012), when periods shorter than one hour are eliminated, which are mostly misclassified convective outflows. Foehn increases the average annual temperature by $1.00 \mathrm{~K}$ at Ellbögen and by $0.31 \mathrm{~K}$ at Innsbruck. The daily and annual distribution of foehn frequencies at Innsbruck is strongly connected to the differences of average temperature by foehn and no-foehn. This leads to highest foehn frequencies in the afternoons with typical onsets around 12 UTC and ending around 18 UTC. At Ellbögen this dependency is less pronounced. 


\section{Contents}

Abstract $\quad$ i

Contents

1 Introduction $\quad 1$

1.1 Motivation . . . . . . . . . . . . . . . . . . . 1

1.2 Winds in Complex Terrain . . . . . . . . . . . . . . . . . . 1

1.2.1 Current Foehn Theories and Observations . . . . . . . . . . 2

1.2 .2 Diurnal Mountain Winds . . . . . . . . . . . . . . . 5

1.2.3 Potential Temperature as Tracer for Foehn . . . . . . . . . . . 8

1.3 Development of Foehn Diagnosis Methods . . . . . . . . . . . . . . . 9

1.3.1 Manual and Subjective Methods . . . . . . . . . . . . . . 9

1.3.2 Objective and Semiautomatic Methods . . . . . . . . . . . 11

1.4 Current Foehn Climatology for Wipp Valley and Innsbruck . . . . . . 13

1.5 Unsupervised Classification . . . . . . . . . . . . . . . . . . . 14

1.6 Goals and Outline . . . . . . . . . . . . . . . . . . 15

2 Location and Data $\quad 17$

2.1 Wipp Valley Area . . . . . . . . . . . . . . . . . . . . . . . 17

2.2 Data Availability and Quality . . . . . . . . . . . . . . . 19

3 Methods and Results for a Foehn Valley Station (Ellbögen) 23

3.1 Article . . . . . . . . . . . . . . . . . 23

3.2 Additional Results . . . . . . . . . . . . . . . . . . . 32

3.2.1 Wind-sector at Valley and Mountain Station . . . . . . . . . . 32

3.2.2 Scaling of Speed Distribution . . . . . . . . . . . . . . . . 32

3.2.3 Further Tested Models . . . . . . . . . . . . . . . . . 33

4 Methods and Results for a Complex Location (Innsbruck) 35

4.1 Problems Resulting from the Complex Location . . . . . . . . . . . . 35

4.2 Classification Schemes for Different Measurement Setups . . . . . . . 37

4.2.1 Upstream Foehn Valley Station . . . . . . . . . . . . . . 37 
4.2.2 Upstream Crest Station . . . . . . . . . . . . . . . . . . 44

4.2 .3 Only Valley Station . . . . . . . . . . . . . . . . . 48

4.3 Case Studies . . . . . . . . . . . . . . . . . . . 50

4.3.1 Classical Foehn Case 25 April 2012 . . . . . . . . . . . . 50

4.3.2 Foehn Case with deflected foehn on 07/08 November 2011 . . 52

4.3.3 Weak Foehn Cases on 04/05 December 2011 . . . . . . . . . 53

4.3.4 Misclassification of Up-valley Wind 02 April 2012 . . . . . . 54

5 Climatology of Föhn for Ellbögen and Innsbruck $\quad 57$

5.1 Postprocessing . . . . . . . . . . . . . . . . . . . 57

5.2 Annual Foehn Days . . . . . . . . . . . . . . . . . . . . 58

5.3 Annual and Daily Foehn Frequency Distribution . . . . . . . . . . 58

5.4 Temperature Effects . . . . . . . . . . . . . . . . . . 61

5.5 Foehn Begin and Ending Times . . . . . . . . . . . . . . . 62

5.6 Comparison: Deflected - Direct Foehn . . . . . . . . . . . . . . 64

$\begin{array}{lll}6 & \text { Discussion and Conclusion } & 67\end{array}$

$\begin{array}{ll}\text { Bibliography } & 71\end{array}$

$\begin{array}{ll}\text { Acknowledgments } & 77\end{array}$

$\begin{array}{ll}\text { Curriculum Vitae } & 79\end{array}$ 


\section{Chapter 1}

\section{Introduction}

\subsection{Motivation}

Foehn winds occur in all mountain regions around the world and affect weather and climate. According to WMO (1992), foehn is defined as 'a wind (which is) warmed and dried by descent, in general on the lee side of mountain'. Although the term "foehn" originates from the European Alps, such winds occurs in all mountain regions around the world. Some popular examples are Chinook (Rocky Mountains), Bora (Dinaric Alps), Mistral (Rhone Valley, southern France) and Zonda (Argentina). A full list of all foehn-type wind names for different regions of world can be found in Richner and Hächler (2013). The reason for the modification "in general on the lee side of mountain", is that this definition also includes gap flows (Mayr et al. 2007). Foehn winds occur also downstream of gaps with a level floor, e.g. in Shelikof Strait, Alaska (Lackmann and Overland 1989).

Many of these foehn winds affect human activities. Most dangerous are turbulence and wind sheer of this winds for aviation (e.g. Dörnbrack 2006). Foehn also influences air quality, snow melting, temperature and wind speeds in valleys.

Because of this importance, foehn climatologies are important. For creating these climatologies, a method to diagnose foehn is necessary, which can be applied with a minimum of effort. Foehn diagnosis are also useful for forecast verification and are an important input for other studies, concerning e.g. air quality and foehn mechanism.

\subsection{Winds in Complex Terrain}

Diagnosing foehn winds requires distinguishing them from other winds, especially from those caused by complex topography. The dominant wind systems in mountains are radiatively driven mountain winds (Defant 1910) which develop on almost 
every undisturbed clear day.

\subsubsection{Current Foehn Theories and Observations}

The current concepts which are used to describe foehn flows could be summarized into two main mechanisms. Some authors propose that gravity waves play a crucial role in the formation of downslope windstorms (e.g. Klemp and Lilly 1978; Peltier and Clark 1979), while others explain the foehn flow with hydraulic theory (e.g. Long 1953, 1954; Smith 1985; Armi 1986; Durran 1986; Klemp and Durran 1987). All these theories are summarized in detail by Jackson et al. (2013).

\section{Mountain Waves}

How a flow interacts with obstacles depends on its speed and stability and on the shape of the barrier. All these properties can be summarized into the nondimensional mountain height $\hat{H}=N H / U$, where $N$ is the Brunt Väisälä frequency (the eigenfrequency of atmosphere), $H$ is the mountain height and $U$ the upstream wind component perpendicular to the mountain. For $\hat{H} \gg 1$ the flow is blocked and the air moves around the obstacles, while for small non-dimensional mountain heights $(\hat{H} \leq 1)$ the whole layer will flow over the barrier. In the second case, many patterns are possible, depending on the exact value of this number and the structure of the atmosphere (see Jackson et al. (2013)). Flow over very small scaled mountain heights $(\hat{H} \ll 1)$ can be even described by linear theories, while in general such flows are not linear. This concept assumes similar air mass at both sides of obstacle.

To describe downslope windstorms, nonlinear effects are important, such as formation of a critical layer by breaking of vertically propagating mountain waves on lee (Clark and Peltier 1977; Peltier and Clark 1979, 1983; Clark and Farley 1984). When non-dimensional mountain height exceeds a threshold, waves overturn and break above the lee slope. In this wave breaking region a stagnate, mixed layer forms. Because the wind speed becomes almost zero at this critical level and thus equal to the phase speed of the standing mountain waves, the waves cannot propagate upward and are absorbed or reflected downward. If this layer is at a suitable altitude, the downward reflected wind energy leads to strong wind speeds and gusts on the surface. Additionally the mixing of the critical layer through wave braking leads to warming, and thus to a reduction of pressure in lee.

This behavior was studied in many numerical simulations. The authors found that waves began to break in their simulations, when the non-dimensional mountain height exceeds values of 0.85 to 1.1, depending on the simulation setup (Huppert and Miles 1969; Smith and Grønås 1993; Lin and T.A. 1996). Below this values linear mountain waves are observed. If this scaled mountain height is increased above 




Figure 1.1: Schematic illustration of a continuously stratified flow over a mountain (taken from Smith (1985)). Shown are isentrops/streamlines. $H_{o}$ indicates the altitude of the dividing stream line.

these values, additional upstream blocking of the lover flow occurs, which is also a nonlinear characteristic of many foehn events. However, many authors (Farmer and Armi 1999; Cummins 2000; Farmer and Armi 2001; Armi and Farmer 2002) pointed problems with these simulations (Afanasyev and Peltier 2001a,b) out, like initial and boundary conditions and turbulence parametrization.

\section{Hydraulic Theory}

An other concept which is used to describe the foehn flow is the shallow water theory. Long showed in theory (Long 1953) and in experiment (Long 1954), that a simple two layer model can describe the asymmetrical case of a flow over a mountain. In this setup, a inversion separates the upper passive layer from from the lower active layer which can be described with shallow water equations (see e.g. Jackson et al. (2013)). An important property of this flow is its hydraulic Froude Number $F r^{2}=U^{2} /\left(g^{\prime} h\right)$, where $U$ is the wind speed, $g^{\prime}$ the reduced gravity and $h$ the fluid/air depth of the layer. Upstream the flow is relatively slow, thick and so subcritical $(F r<1)$, on the crest it transitions into a supercritical $(F r>1)$, relatively fast and thinning flow till a small part of kinetic energy dissipates in a hydraulic jump, where the flow adjusts to subcritical downstream conditions.

Smith (1985) adjusted this concept into one with stratified fluid flow, which based on observations and numerical simulations and is more representative for the real atmosphere (see Fig. 1.1). He assumed that on the lee, above the foehn flow, a very turbulent, mixed region with stagnate air exists. This relatively warm layer separates and decouples the flow below it, and thus enables the lower one to become 
hydraulic character and accelerate. The streamline which surrounds the turbulent region is called dividing streamline.

Durran (1986) confirmed in numerical simulations the importance of that inversion which decouples the lower foehn flow from upper layers. This low level inversion forces the flow to become supercritical and thus is essential for the acceleration of the flow in lee. In simulations without that inversion no downslope windstorm developed. Also he showed that in such a setup with two separated layers nonlinear effects occurs even for $\hat{H} \approx 0.3$.

For the formation of the important well mixed, turbulent layer, two formation mechanism are proposed: In numerical simulations many authors (e.g. Clark and Peltier 1977) see breaking mountain waves as reason for the formation of this layer. In contrast to this, Farmer and Armi (1999) saw in their oceanic measurements shear instabilities responsible for the mixing.

\section{Friction}

In contrast to early studies which assumed that friction is negligible, newer numerical simulation showed that friction is important (e.g. Richard et al. 1989; Georgelin et al. 1994; Olafsson and P. 1997). Boundary layer effects are important for absorbing of (mountain wave) energy and so they limit the downwind extent of foehn.

\section{Observations}

Many observations and measurement campaigns were operated on foehn during the past century:

Lee waves were first observed aloft in the in the northern lee of the Giant Mountains (Poland) by sailplanes (Küttner 1938).

The Alpine Experiment (1982, ALPEX) showed that upstream blocking is characteristic for foehn and is the main reason for temperature differences between lee and upstream (Seibert 1982).

For the most famous downslope windstorm in Boulder (11 January 1972), a hydraulic supercritical foehn layer was found, which was observed below the mountain waves, decoupled by an inversion (Lilly 1979).

Bora observations showed also that during strong events a inversion is located at mountain crest level, which indicates the importance of hydraulic dynamics (Yoshino 1976). It was also found that the strongest winds are located downstream of gaps (Gohm and Mayr 2005).

Detailed observations of foehn events in Wipp Valley during the Mesoscale Alpine Program (MAP, Mayr et al. 2004, 2007) showed that the presence of a stagnate, nearly well-mixed layer above the foehn flow is a distinguishing feature 
(Armi and Mayr 2007). Some shallow foehn cases were observed without synoptic cross barrier wind component at crest level (and consequently without mountain waves), driven just by air masses with different temperatures across the mountain, which cause a hydrostatic pressure gradient (Mayr and Armi 2008).

Foehn flows observed in Owens Valley during the Terrain-Induced Rotor Experiment (T-REX, Grubišić et al. 2008) also could descend only so far downwards that the potential temperature in the valley was at least as high as the temperature of upstream air at crest level (Mayr and Armi 2010; Armi and Mayr 2011). It could be observed that shear-layer instabilities mixed the aloft layer to decouple the flow aloft from the foehn flow. The length of the single wave response varied with the distance between crest and hydraulic jump and did not match the free-oscillation wave length.

\subsubsection{Diurnal Mountain Winds}

By diagnosing foehn, the main task is to distinguish it from the dominating radiatively driven mountain winds. These winds are driven by differential heating and cooling of valley and plain, which cause a diurnal cycle of pressure differences (Hann 1879; Defant 1910). They were summarized by Defant (1949) in his well known schematic diagram (Fig. 1.2), which is still today the most important reference (e.g. Whiteman 2000; Markowski and Yvette 2010). An overview to all this relevant mountain winds is shown in Fig. 1.3, which will be discussed in this section. All explanations refer to undisturbed fair weather conditions with weak synoptic forcing.

\section{Slope Winds System}

Slope winds are caused by horizontal temperature differences between the slope and the center of the valley (Whiteman 2000). This difference results from radiative heating and cooling of the boundary layer over slopes.

Downslope winds occur during night (compare (e) $-(\mathrm{g})$ in Fig. 1.2). After sunset air above the slope surfaces cools and becomes denser than the air in center of the valley. This leads to a negative buoyancy force which causes a downward motion. The depth of the flow layer increases downward to typical values of 3 to $100 \mathrm{~m}$. Maximal wind speeds reach typical values of 1 to $4 \mathrm{~m} \mathrm{~s}^{-1}$.

Upslope winds occur during the day when the slopes are heated by the sun (see (a) - (c) in Fig. 1.2). The air at the slopes becomes warmer and less dense than the air in center of valley, which leads to a positive buoyancy force and upward air motion. Due to this temperature difference also a horizontal pressure gradient develops, with a force towards the slope. This pressure gradient forces the flow to 

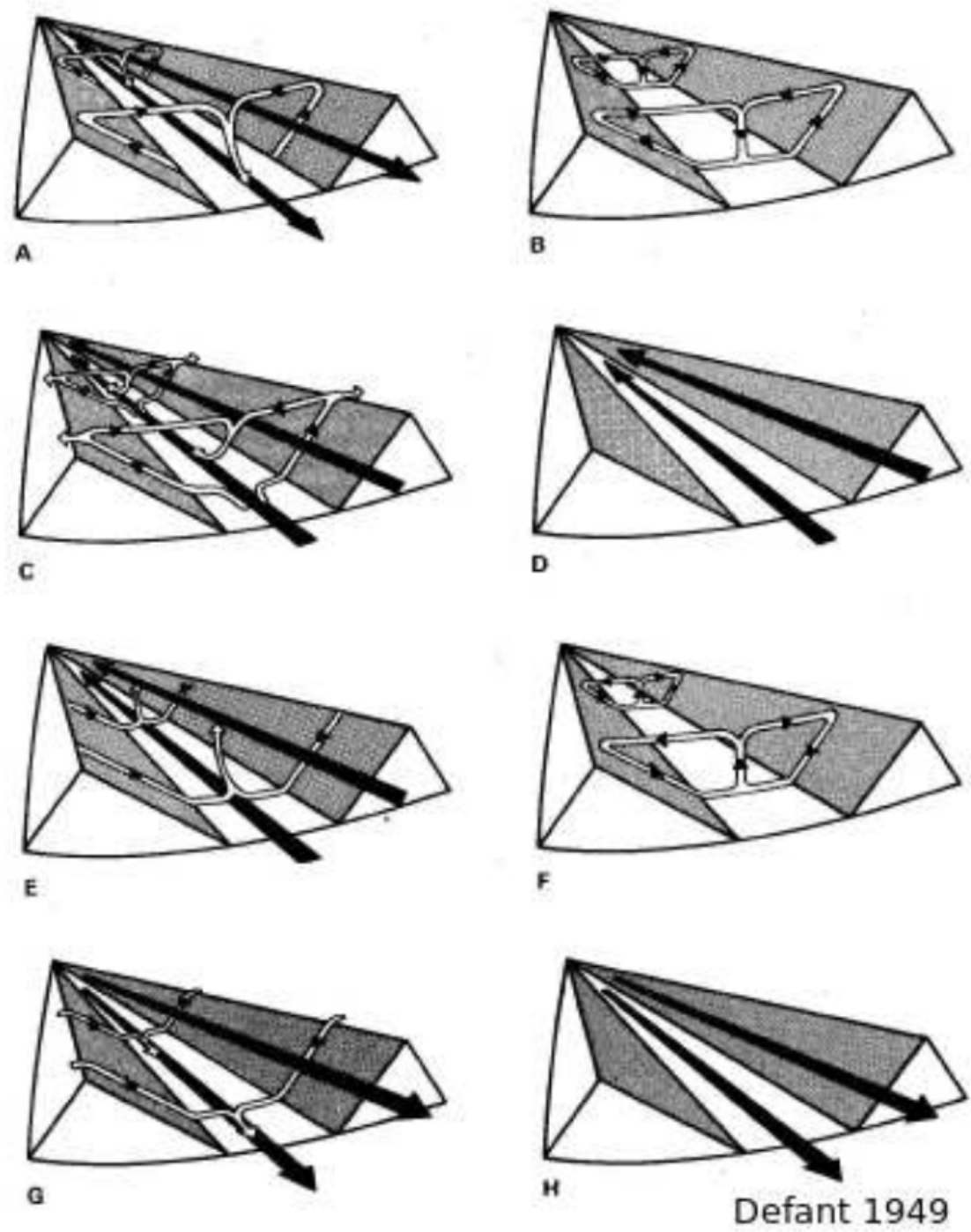

Figure 1.2: Schematic illustration of diurnal cycle of valley and slope winds on a clear day after Defant (1949). (a) Sunrise at morning: Onset of upslope winds (white arrows) and continuation of down-valley winds (black arrows). The valley is colder than the plain. (b) Forenoon: Strong upslope winds and transition from down-valley to up-valley winds. Same temperature and pressure in valley and plain. (c) Noon and early afternoon: stagnating upslope winds and fully developed up-valley wind. The valley is warmer and the pressure is lower than in the plain. (d) Late afternoon: slope winds have stopped completely and upvalley wind continues. Same temperature and pressure distribution as before. (e) Evening: Onset of downslope winds and weakening up-valley wind. Temperature still warmer and pressure lower in valley than at plain. (f) Early night: Downslope winds and transition from up-valley to down-valley wind. Equal temperature and pressure distribution. (g) Middle of night: Downslope and down-valley winds. Valley is colder and has higher pressure than the plain. (h) Late night to morning: Down-valley winds persist. Same temperature and pressure distribution as before. 


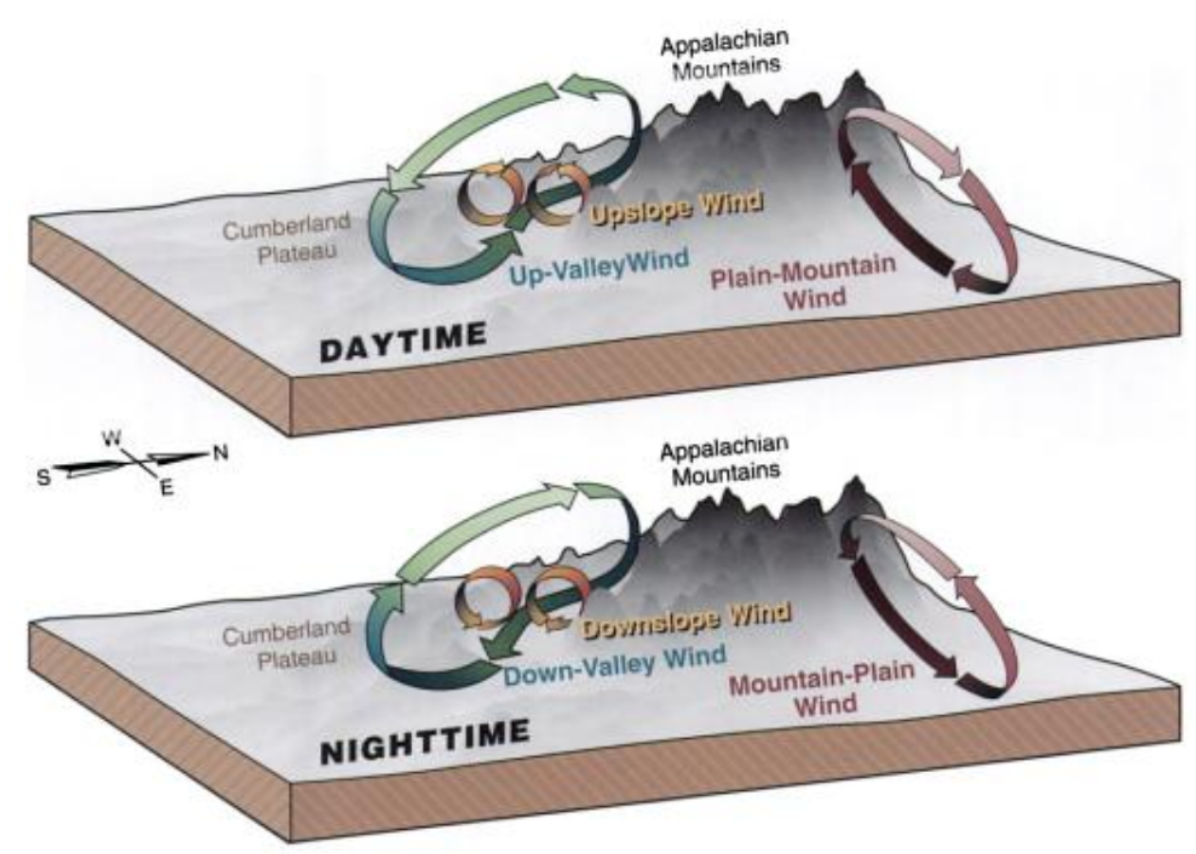

Figure 1.3: Schematic illustration of three wind systems found over mountainous terrain (the fourth wind system, cross-valley flow is not shown). They are shown for the Appalachian Mountains and the Tennessee Valley (taken from Whiteman (2000)).

stay at the slopes and not to rise vertically upwards. The depths of the flow layer increase upwards to typical values of 20 to $200 \mathrm{~m}$. Maximal wind speeds reach typical values of 1 to $5 \mathrm{~m} \mathrm{~s}^{-1}$.

\section{Valley Winds System}

The along-valley wind system can be explained by the so called topographic amplification factor (TAF) introduced by Wagner (1932b). It is also known as area-height distribution (Steinacker 1984) and the valley volume effect (e.g. Whiteman 2000). The TAF is based on the fact that the same daytime energy input (or nighttime loss) leads to a larger heating (or cooling) in the valley than over the plain, caused by the smaller valley atmosphere volume compared to the flat plain. This explains the larger temperature and pressure amplitudes in valleys compared to flat regions. The valley winds react more slowly to the radiative forcing than the slope winds, because the volume to be heated/cooled is larger for the valley than for the slope boundary layers. The circulation is closed by a compensating flow above the valley wind with opposite direction.

The down-valley winds form during night (see (f) - (h) in Fig.1.2), when the valley air cools below the temperature of the plain. The resulting hydrostatic pressure gradient accelerates the flow and leads to the onset of the down-valley wind. It persists still some hours after sunrise, till the valley reaches the same temperature as 
the plain. Afterwards, the pressure gradient shifts and the down-valley wind change into the up-valley wind (see (b) - (d) in Fig.1.2).

The transition times and strength of valley winds depend strongly on the season, but also on plenty other factors. In winter down-valley winds are dominant, while up-valley winds only occur for few hours in afternoon and are much weaker than in summer (Dreiseitl et al. 1980; Whiteman 2000; Zängl 2004). On days with snow covered valley floor the down-valley winds can often persist the whole day (Whiteman 2000). Up-valley winds reach their maximum speed on late summer afternoons.

\section{Mountain-Plain Winds System}

Mountain-plain winds are caused by temperature differences between a mountain massif and the surrounding plains (Whiteman 2000). The elevated mountain massif cools more strongly during night and warms faster during day. So during nighttime a wind blows downwards from the mountain massive towards the plain and vice versa during daytime (see Fig. 1.3). In case of the Alps, the upward wind ("Alpine pumping ") reaches speeds from 1 to $4 \mathrm{~m} \mathrm{~s}^{-1}$ and has an extent of $\sim 80 \mathrm{~km}$ into the Alpine foreland (Weissmann et al. 2005).

\subsubsection{Potential Temperature as Tracer for Foehn}

The main property of foehn is the descent of air on the lee side of obstacles. A conservative value along such streamlines is the potential temperature $\theta$, under the assumption of dry adiabatic processes. It is used in some foehn classifications methods as a tracer for foehn-air. The potential temperature is defined as

$$
\theta=T\left(\frac{p_{0}}{p}\right)^{\frac{R_{d}}{c_{p}}}
$$

where $T$ is the temperature in Kelvin, $p$ the pressure in $\mathrm{hPa}, p_{0}=1000 \mathrm{hPa}$ the standard pressure, $R_{d}=287.05 \mathrm{~J} \mathrm{~kg}^{-1} \mathrm{~K}^{-1}$ the gas constant for dry air and $c_{p}=1004.67 \mathrm{~J} \mathrm{~kg}^{-1} \mathrm{~K}^{-1}$ the specific heat for constant pressure.

However this assumption of only dry adiabatic processes matches just an idealized case. In reality the potential temperature of a descending air parcel from crest to valley can be modified by several processes (cf. Vergeiner (2004)):

(1) Evaporation: On foehn cases with moist air upstream upstream, strong winds can advect a part of the precipitation and precipitation-causing clouds across the crest towards the lee (foehn-wall). This liquid moisture evaporates during the descent of the first few hundreds meters and thus decreases the 
potential temperature by $0.33 \mathrm{~K}$ per $100 \mathrm{~m}$ (Vergeiner 2004). In some extreme situations this precipitation can even reach the valley ("Dimmerfoehn").

(2) Radiation: The amount of warming due to divergence of the radiation flux for typical time scales about $1 \mathrm{~h}$ is very low ( $\approx 0.1 \mathrm{~K}$; Vergeiner 2004).

(3) Vertical turbulent mixing: During the movement and descent further downstream from the crest potential warmer air from aloft is mixed into the foehn flow. Thus, this entrainment causes a continuous increase of potential temperature of foehn flow (Vergeiner 2004).

(4) Horizontal turbulent mixing: During night radiatively cooled air from foehn-free side valleys is mixed into the foehn flow which can lead to a decrease in potential temperature of several degrees.

Consequently, the difference of potential temperature between two stations

$$
\Delta \theta=\theta_{\text {crest }}-\theta_{\text {valley }}
$$

may assume values different from zero during foehn.

\subsection{Development of Foehn Diagnosis Methods}

During the last century different methods for foehn diagnosis were used. This section provides an overview from the first subjective approaches to the modern almost automatic analysis methods.

\subsubsection{Manual and Subjective Methods}

The traditional still widely used method is the so-called three-point method summarized first by Conrad (1936) in the "Handbook of Climatology". Observational time series data have to be analyzed for the following three criteria to determine the onset of a foehn event:

(1) Wind direction from the mountain crest with increasing wind speed,

(2) rapid increase of temperature

(3) and decrease in relative humidity.

Opposite signals of 2 and 3 with a wind shift characterize the end of the foehn.

Many authors used those criteria for foehn diagnosis (Pollack 1911; Berg 1951; Obenland 1956; Frey 1957; Reiter 1958; Widmer 1966; Zanella 1982; Seibert 1982; 
Gutermann 1970). Many of them used additional criteria, such as a pressure gradient across the mountain towards the foehn location (Pollack 1911; Frey 1957; Zanella 1982), the presence of "typical foehn clouds" (Berg 1951; Reiter 1958) or a certain wind direction on a suitable mountain station (Widmer 1966; Seibert 1982).

Seibert (1985) developed flow diagrams for analyzing the onset and end of foehn for Innsbruck, in which all criteria of Conrad (1936) are included. She included additional criteria for wind at mountains and gusts at valley. For difficult cases also the weather situation should be checked to see whether it is favorable for foehn.

She also mentioned that authors who did not consider the three-point method achieved questionable results (Seibert 1985). For example Ungeheuer (1952), classified foehn in Bad Tölz only with a single wind criterion. He demanded just a south wind with a minimum wind speed of $2 \mathrm{~m} \mathrm{~s}^{-1}$ which persists for at least one hour. With this method he got on average 113 foehn days per year!

Ekhart (1949) classified foehn in Innsbruck also just by a single wind criterion. He declined temperature and humidity criteria, because the definition of "warm" and "dry" was too relative in his opinion. So he counted a foehn day, when the mean wind direction in Innsbruck was between southeast and southwest with a strong variability, which indicates a strong gustiness, a characteristic property of foehn. He mentioned that Innsbruck is the single station at which foehn can be classified "objectively" with this method. The reason for this is, that Innsbruck lies in the east-west oriented Inn Valley, into which the south-oriented Wipp Valley drains (see also section 2.1 and Fig. 2.1). Because of this special location, strong, gusty south winds occurs here just by south foehn.

Schütz and Steinhauser (1955) used temperature and humidity criteria for their foehn investigations, but ignored the wind conditions. They searched for a generally applicable criterion for foehn classification and used for the first time the conservation of potential temperature along the descending foehn flow. They found that foehn descends through passes, located below the weather station at the peak of Sonnblick mountain to the valleys and classified foehn when the vertical temperature gradient was at least $0.7 \mathrm{~K}$ per $100 \mathrm{~m}$ between Sonnblick and valley stations. Additionally, the relative humidity has to be below 70\%. After a manual examination, the authors were convinced that with these two criteria they found almost all foehn cases and that they have (almost) no positive misclassification. It should be noted, that in those times there was no clear foehn definition like today. It was common to include the so called anticyclonic or free foehn (antizyklonaler or freier Föhn). This "foehn" describes the situation when air is descending under the influence of an anticyclone (Ficker 1943), which does not match the current definition discussed in chapter 1.2. Because of this changed definition, the classification method of Schütz and Steinhauser (1955) can not be used today any more. 
The Austrian weather service Zentralanstalt für Meteorologie und Geodynamik (ZAMG) introduced 1952 a three-stage foehn-scale, which enables classifying foehn that does not reach the station. This foehn-scale is still today in use at Austrian climate stations (translated from Seibert 1982; Reiter 1958):

\section{0... "föhnig" (foehn aloft, but not reaching the valley)}

Moderate or strong south winds at the mountains, which do not penetrate to the valleys. This foehn situation can be recognized from a valley station as follows:

a) by clouds: foehn wall at the main alpine crest, break-up of the cloudcover, Altocumulus lenticularis clouds, clouds moving from south or southwesterly directions

b) especially good visibility and far objects appearing near,

c) less white light, causing darker and deeper colors of the environment, especially of the mountain slopes and blue of the sky.

\section{1... light foehn}

Temporal occurrence of south winds also in the valleys, gusts do not reach storm speed. Clear increase in temperature and decrease in humidity. Clouds and optical appearance as in $\mathbf{0 .}$

\section{2...strong foehn}

Lively to stormy south winds with strong gustiness, persisting for several hours. Other appearance as in $\mathbf{1}$.

Seibert (1982) discussed the problems of this foehn-scale. Especially the stage $\mathbf{0}$ is very arbitrary, because e.g. clear visibility and lenticularis clouds do not occur at every foehn event.

\subsubsection{Objective and Semiautomatic Methods}

The first approach to automatize the foehn diagnosis was made by Gutermann (1970) for the station Bad Ragaz in the Swiss Rhine Valley and Altdorf in Reuss Valley. He used a supervised learning approach! First he analyzed foehn cases manually and formed two groups with "foehn" and "no foehn". He then applied Fisher's discriminant analysis for each month. Suitable classifiers were a wind index (a combination of direction and speed) and anomalies of temperature and relative humidity for each of the three climate observations per day. Many additional variables were tested but did not improve the results. His method achieved good results on independent 
testing data. He analyzed on average 101.5 climate observations with foehn per year in Bad Ragaz and 56.5 in Altdorf for the period 1939-1968. The disadvantage of this method is the large amount of initial work necessary to manually classify the training data-set. This may be the reason why the method remained fairly unknown.

With increasing availability of measurement data from automatic weather stations, automatic methods have become more important. Vergeiner (2004) developed a new, so-called objective foehn classification (OFC; Drechsel and Mayr 2008) during MAP. This classification is based on physically meaningful criteria, which have to be fulfilled to classify a measurement as foehn. For this the wind at valley and mountain station must came from a predefined wind-sector from the crest direction with a minimum speed of mostly $2 \mathrm{~m} \mathrm{~s}^{-1}$. Additionally to those "classical" requirements, a so called $\theta$-criterion (see also 1.2.3) was introduced. The difference in potential temperature between the valley and a mountain station $\left(\Delta \theta=\theta_{\text {crest }}-\theta_{\text {valley }}\right)$ must be below a estimated threshold for diagnosis of foehn. Determining this threshold is a semi-automatic process. It is found at a curvature maximum in the $\Delta \theta$ distribution (with already fulfilled wind criteria). The threshold has to be specified for each location before the OFC can be applied automatically for foehn detection. This OFC was applied for South foehn in the Wipp Valley and the Inn Valley (Föst 2006), for North foehn in the Inn Valley (Haas 2006), for North foehn in South Tyrol and the Aosta Valley (Verant 2006) and the Chinook in Bolder (Kneringer 2011).

With a very similar method, Dürr (2008) analyzed South foehn in northern Alpine valleys in Switzerland. In addition to the criteria used in the OFC, Dürr used relative humidity and gusts. First he defined a foehn wind sector manually for each valley station. The other thresholds were estimated by a statistical analysis of so called "south wind cases without south foehn" (south wind at valley stations and north wind at crest station and some other predefined conditions). From this sub data-set (consisting only of down valley wind cases) the 90th percentile for the distributions of wind speed and gusts and the 10th percentile for the distributions of relative humidity and the difference in potential temperature to a station at the main crest $(\Delta \theta)$ were taken as limits which were used to separate those down-valley winds from foehn. Hereby the limit for the relative humidity was extremely low, so that it had to be modified. For onset of foehn all of those criteria have to be fulfilled, while for the continuation of foehn the wind speed is not used in order to bridge over short lulls in foehn-calms.

Since all of these methods are deterministic and do not include the uncertainty of the diagnoses, Strobl (2009) modified the OFC to a "Probabilistic Foehn Classification" (PFC) for lower gap flows. He used this probabilistic approach because it is difficult to distinguish especially the lower gap flows from radiatively driven down-valley winds. He first analyzed the daily cycle of the valley wind systems un- 


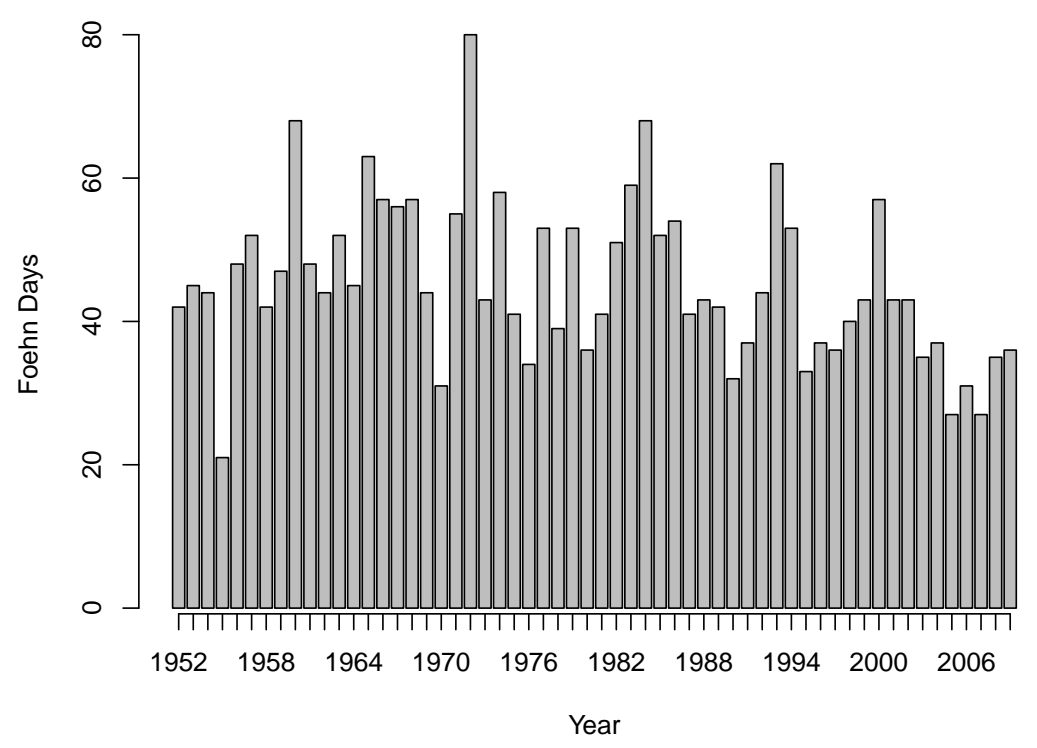

Figure 1.4: Series of days with foehn in Innsbruck, based on climate observations at three times per day (Ortner 2010).

der undisturbed synoptic conditions for the whole year. Then he approximated the annual cycle of onset and ending times of the radiatively down-valley winds. As next step the (original) OFC was applied. A speed distribution of foehn winds was estimated from analyzed foehn winds for times when on average no down-valley winds occurs. The probabilistic extension was applied only for times when climatologically the wind in valley is downward. On those times the foehn probability was calculated by the ratio of the previous estimated speed density during foehn divided by the whole speed density from foehn wind sector. Because of the laborious estimation of the annual valley wind cycle this method was just applied to the Upper Inn Valley and the Wipp Valley.

\subsection{Current Foehn Climatology for Wipp Valley and Innsbruck}

Ortner (2010) summarized a 138 years long foehn series for Innsbruck, based on several classification methods presented in section 1.3. Since the applied diagnosis methods are not homogeneous, the series in Fig. 1.4 shows only the period since 1952, with a subjective classification, based on climate observations by the threestage method (see subsection 1.3). On average 45.5 days with foehn (stage 1 or 2) were observed in Innsbruck during this period. 

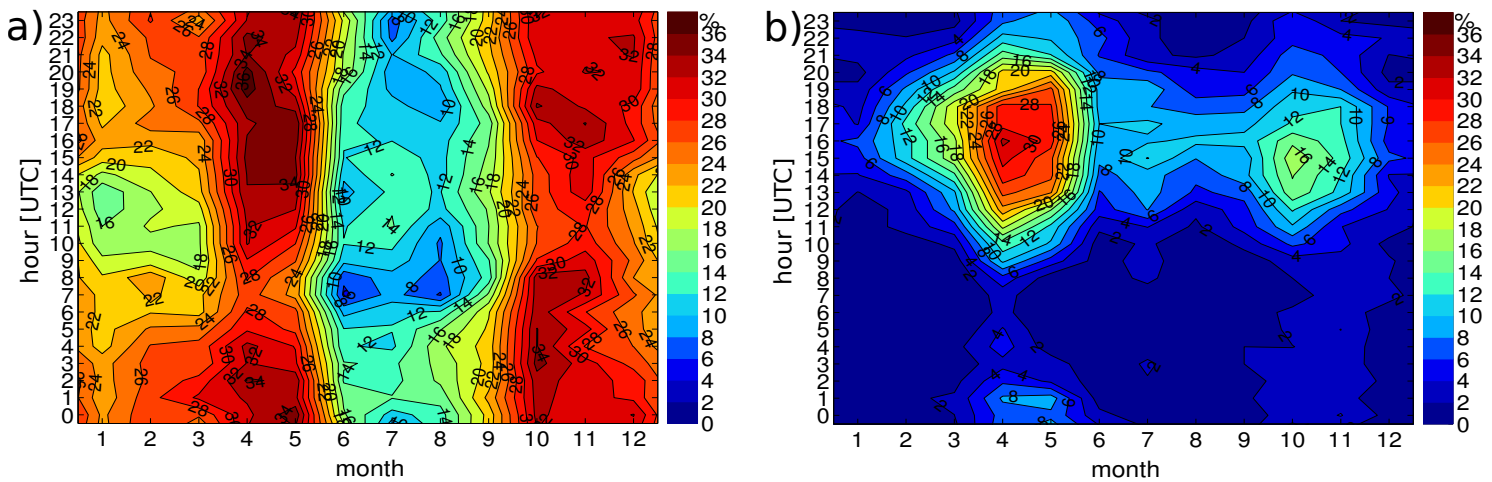

Figure 1.5: Seasonal and daily distribution of foehn frequencies for Ellbögen (a) and Innsbruck University (b). The period from September 1999 through August 2004 was used for this visualization. Taken from Föst (2006).

Föst (2006) analyzed the seasonal and daily distribution of foehn (see Fig. 1.5) with five years of data. In Wipp Valley, foehn frequency has two well pronounced maxima in spring and autumn, with clear a minimum during the summer months. The daily cycle is weak except of winter, where a minimum is analyzed during noon. In Innsbruck the seasonal cycle is very similar to Ellbögen, but the daily cycle is here dominant with low foehn occurrence at night and a maximum on late afternoon. Seibert (1985) found a very similar pattern for Innsbruck.

\subsection{Unsupervised Classification}

Statistical science distinguishes between supervised and unsupervised learning methods (Hastie et al. 2009). Supervised methods are used when a data sample is available with response measurements (training data) to which a statistical model can be fitted (e.g. regressions like Model Output Statistics). If the response is unknown, unsupervised methods can be used.

Since the favorable automatic foehn classification method should work without manually pre-classified foehn (in contrast to Gutermann (1970)), an unsupervised method is needed. In this case it is unknown whether a measurement belongs to the group foehn or no foehn. The statistical method has to separate the measurements into those groups.

Hastie et al. (2009) summarized some popular methods which can solve such a classification problem, such as cluster analysis. The goal of cluster analysis is to form groups, in which the elements are more similar to each other than to those from another group. Three types of algorithms can solve this problem: combinatorial algorithms, mixture models and mode seeking.

The authors describe those algorithms as follows (Hastie et al. 2009): The 
combinatorial algorithms directly group the observations without any underlying probability model. Mixture models assume that data from a population which is independent and identically distributed and is described by a probability density function. Each of these density functions describes one component/cluster of the data. The mixture model estimates the parameters of those functions by maximum likelihood or corresponding Bayesian approaches. Mode seekers use a non-parametric perspective to estimate directly distinct modes of the probability density function. Observations "closest" to each mode define the individual clusters.

Direct verification of unsupervised classification is not possible, because in general the result is unknown and no test data-set is available. So it has to be proved manually whether the results are sensible.

\subsection{Goals and Outline}

All the foehn diagnosis methods summarized in the section 1.3.2 have in common that their applications work automatically and objective, while (parts of) the estimations of thresholds happen manually and subjectively. An additional disadvantage of the newer methods (Vergeiner 2004; Drechsel and Mayr 2008; Dürr 2008) are the hard criteria, which can not catch the whole band of foehn characteristics which occur at a certain location. Hereby mainly the $\theta$-criterion is crucial, because many mechanism (see section 1.2.3) make it impossible to find here a clear apportionment to other wind systems. The first attempt to handle the uncertainty of the diagnosis with the PFC (Strobl 2009) is cumbersome for wide application because the estimation of the annual cycle of nocturnal down-valley wind periods is complicated and time-consuming.

Consequently, an improved objective foehn classification should be the goal for this work, which reduces the above mentioned shortcomings as much as possible. The major aim of this study is to develop a classification method which reduces the amount of manual work and enables a fast and easy application to many foehn locations. Additionally this method should give information about the (un-)certainty of the diagnosis. It would be also desirable to improve the accuracy of the former methods.

As a novel approach unsupervised learning methods from statistical science should be tried. In particular, a mixture model should be tested for foehn diagnosis. It has to be tested whether this statistical model is suitable for such foehn analysis, and which input variables are necessary. Additionally it should be tested, if a minimalist approach for automatic foehn detection just by using information from a valley station is possible. Investigations should begin in a valley with frequent foehn and simple topography, before they are extended to more complex sites. 
Chapter 2 presents the chosen location for this investigation, and analyzes data availability and quality. Chapter 3 contains an article accepted for publication in the Journal of Applied Meteorology and Climatology (Plavcan et al. 2014), which describes mixture models in general and its application to the Wipp Valley. The method and application for the more complex location Innsbruck follows in chapter 4 . Chapter 5 contains a detailed foehn climatology for both stations. Finally, the advantages and disadvantages of mixture models for foehn classification are discussed in chapter 6 . 


\section{Chapter 2}

\section{Location and Data}

The ideal area for developing and testing new automatic foehn diagnosis methods should have frequent foehn and stations at crest and valley with long measurement series. The Wipp Valley in the central Alps fulfills these criteria. Additionally, it provides a topographically more compley situation at its exit.

\subsection{Wipp Valley Area}

The Wipp Valley (Fig. 2.1) with the Brenner Pass (1370 m amsl) connects the southern and northern Alps. The pass itself is deeply incised into the main alpine crest, with a width of only a few hundreds of meters at its bottom ("lower gap"; see Fig. 2.2). A much wider upper gap is located above around $2200 \mathrm{~m}$ amsl. The crest station Sattelberg (SAT) is located there. Because of this much wider gap, also the air volume which flows through it during foehn is much lager, so that the lower gap plays usually a marginal role (Armi and Mayr 2007). The crest altitude $(\approx 3500 \mathrm{~m}$ amsl) forms the border between the "shallow gap flow" below and the "deep foehn flow" above (Mayr et al. 2007).

$21 \mathrm{~km}$ downstream (north) from the crest station Sattelberg the foehn valley station Ellbögen is located in the south-north orientated Wipp Valley. $10 \mathrm{~km}$ further, the station Innsbruck follows in the $500 \mathrm{~m}$ deeper Inn Valley (altitudes of stations are given in Table 2.1). This valley is orientated west-east and hence perpendicular to the Wipp Valley. At the delta, the Wipp Valley flows over a steep step into the Inn Valley. The mountain range ("Nordkette") norther of the Inn Valley has a mean altitude of approximately $2.4 \mathrm{~km}$ amsl. This topography splits the foehn flow into two parts, one which moves towards the east and the other to the west. In some cases the (south-)foehn is even deflected downwards at the Nordkette, and reaches the valley floor in Innsbruck as a northerly wind (Seibert 1985; Zängl 2003; Föst 2006). 


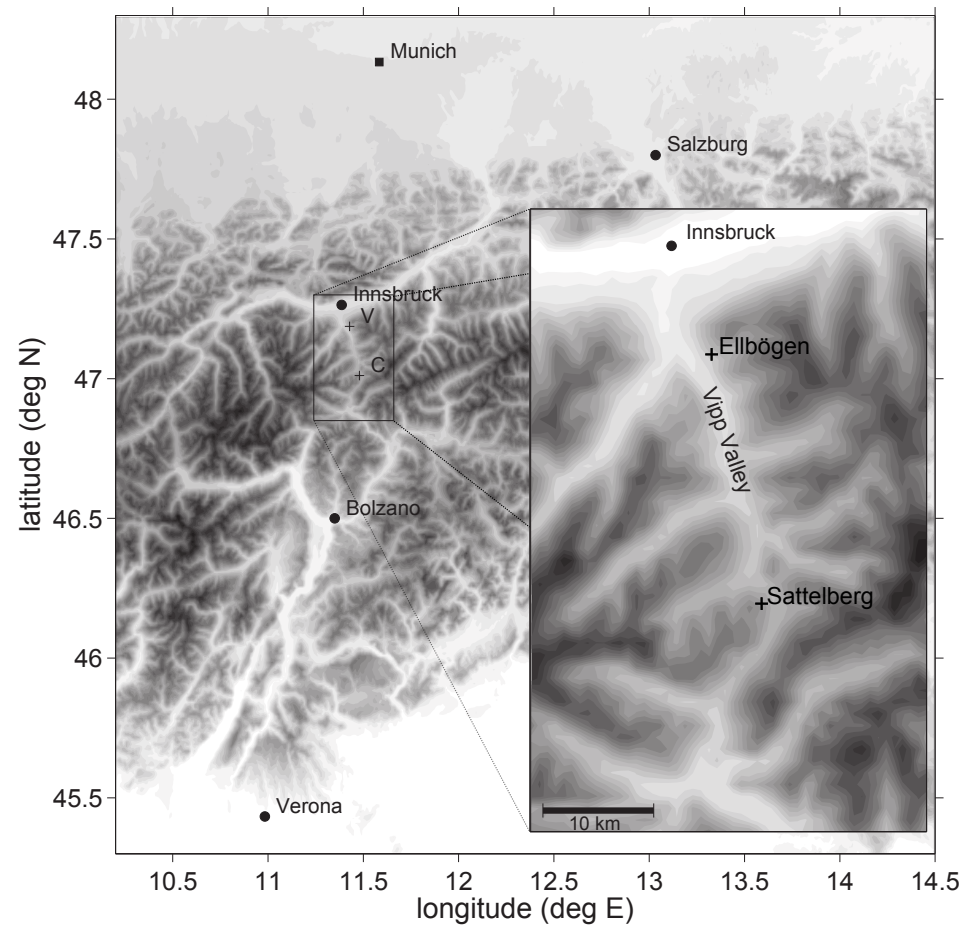

Figure 2.1: Topographic map of the central part of the Eastern Alps with insert of detail with used stations in Wipp Valley and Inn Valley. For more station details see Table 2.1.

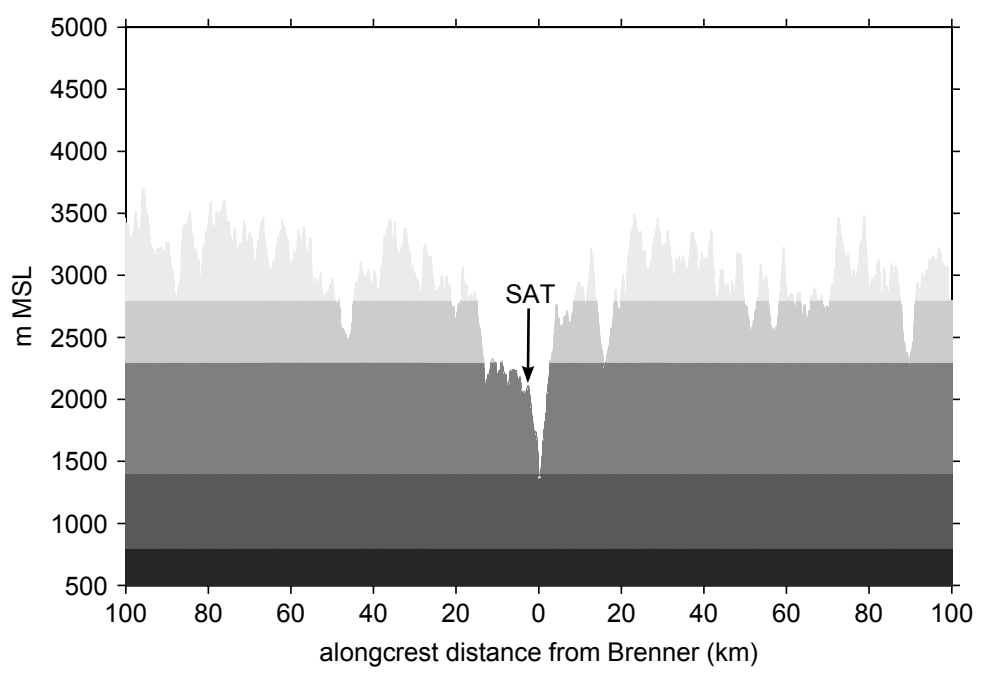

Figure 2.2: Cross-section at $30: 1$ aspect ratio looking north along the crest of the Alps showing the Brenner Pass as the lowest pass and the mountain station Sattelberg (SAT, arrow). Adapted from Armi and Mayr (2007). 
Another special feature associated with the topography of this location is the the so called "pre-foehnal west-wind" (Seibert 1985). This is a strong down-valley wind of cold air located in the upper Inn Valley, which occurs often when foehn is established aloft in the Wipp Valley, but can not descend to Innsbruck because of stable stratification. This wind is not just caused by a south-north pressure gradient which is associated with south foehn synoptical weather conditions, but mainly due to the sinking of the foehn flow through a gap between two mountains located just east of northern part of the Wipp Valley. The warming associated with this sinking, causes a local pressure minimum east of Innsbruck, which in turn drives the downvalley wind (Zängl 2003), which may often reach speeds of weaker foehn events in Innsbruck.

Table 2.1: Summary of used stations with abbreviations, altitude above see level and geographic coordinates. All stations are provided by the Institute of Meteorology and Geophysics at University of Innsbruck.

\begin{tabular}{lcccc}
\hline \hline Station name & Abbreviation & Altitude $[\mathrm{m}$ amsl] & Longitude & Latitude \\
\hline Sattelberg & SAT & 2108 & 11.2846 & 47.0040 \\
Ellbögen & ELB & 1080 & 11.2540 & 47.1114 \\
Innsbruck & IBK & 580 & 11.2311 & 47.1550 \\
\hline
\end{tabular}

\subsection{Data Availability and Quality}

For this whole study, three automatic weather stations (see Table 2.1) were used. The data at stations Sattelberg and Ellbögen are available for a 14 year period (13 September 1999 to 18 June 2013), at Innsbruck for 11 years (25 October 2001 to 18 July 2012). All data were processed as 10-minute averages.

All stations were calibrated before the measurement period of MAP started. This process, including all calibration factors is described in detail by Pippan (2000). During autumn 2009 new temperature and humidity sensors were installed at all three stations without any additional calibrations on top of the ones provided by the manufacturer. So the calibration factors for temperature and humidity were just applied till 2009 on the raw data. The pressure calibration function was used for the whole period because those sensors were not changed.

Additionally, the wind direction shifts at the mountain station Sattelberg and at Innsbruck were corrected manually. Because of the canalization of wind through the gap where the station Sattelberg is located (see Fig. 2.2 and 2.1), just winds from north and south are observed (except for weak slope winds). This can be 


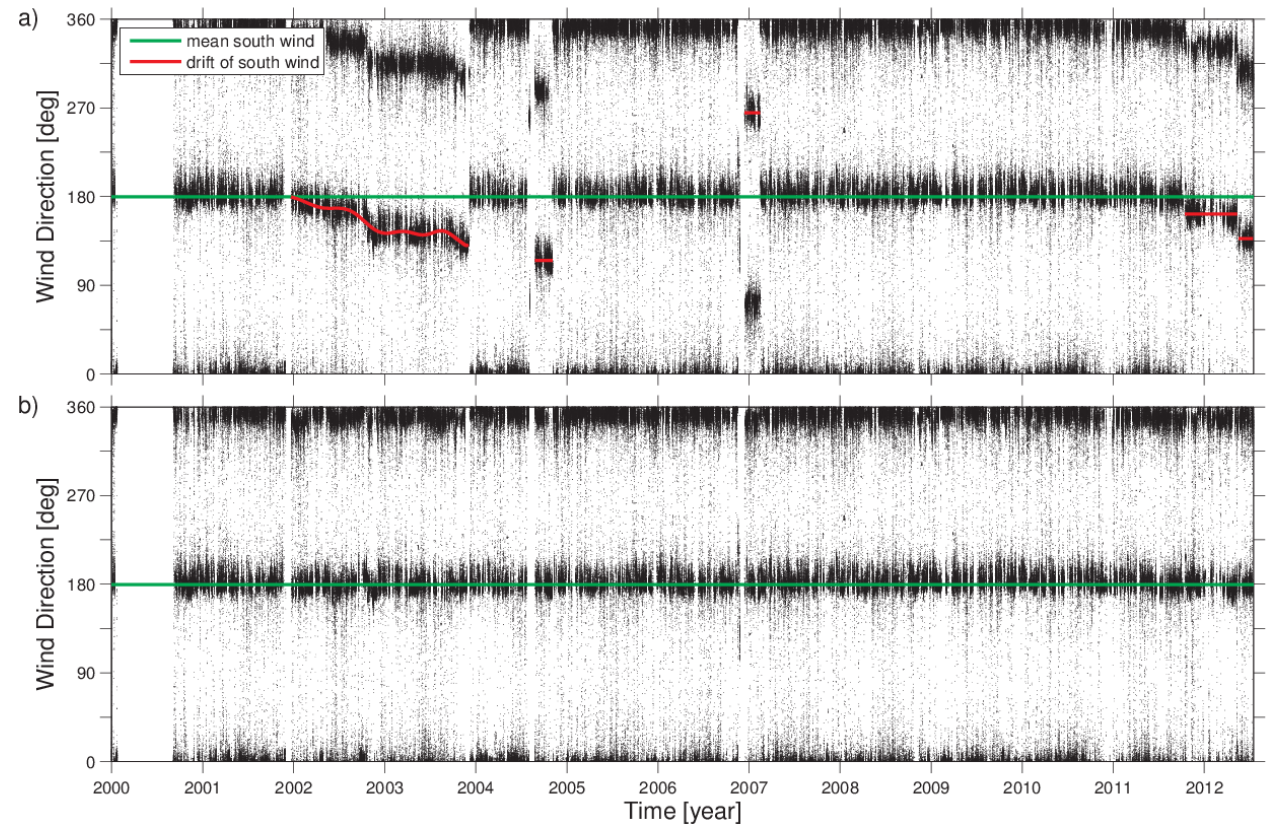

Figure 2.3: Raw (a) and corrected (b) 10-minutes averaged data of wind direction at crest station Sattelberg. The green lines represent the mean south wind direction $\left(\approx 180^{\circ}\right)$. The red line marks times when the direction drifted away and corrections were applied.
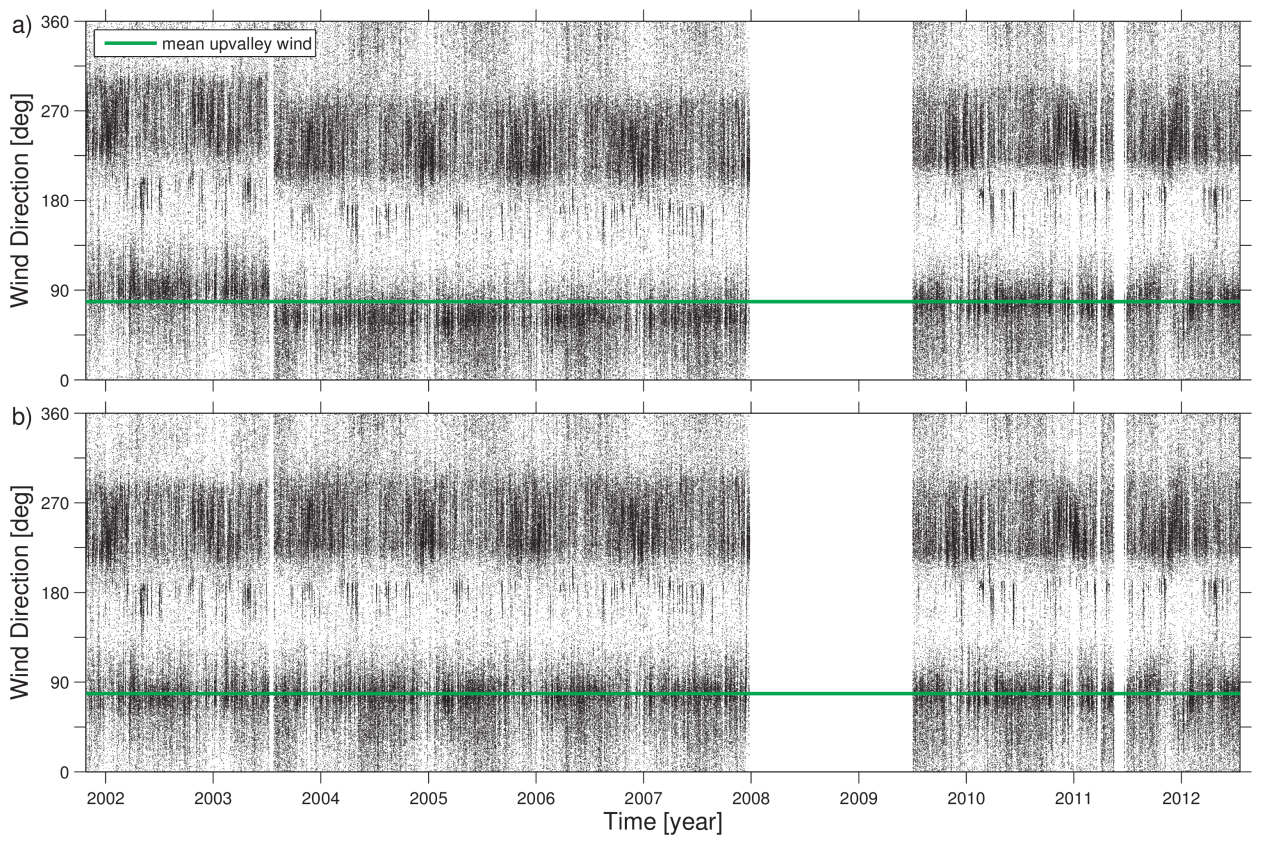

Figure 2.4: Same as Fig 2.3, but for the station Innsbruck. The green line represents the mean up-valley wind direction of the currant sensor. 


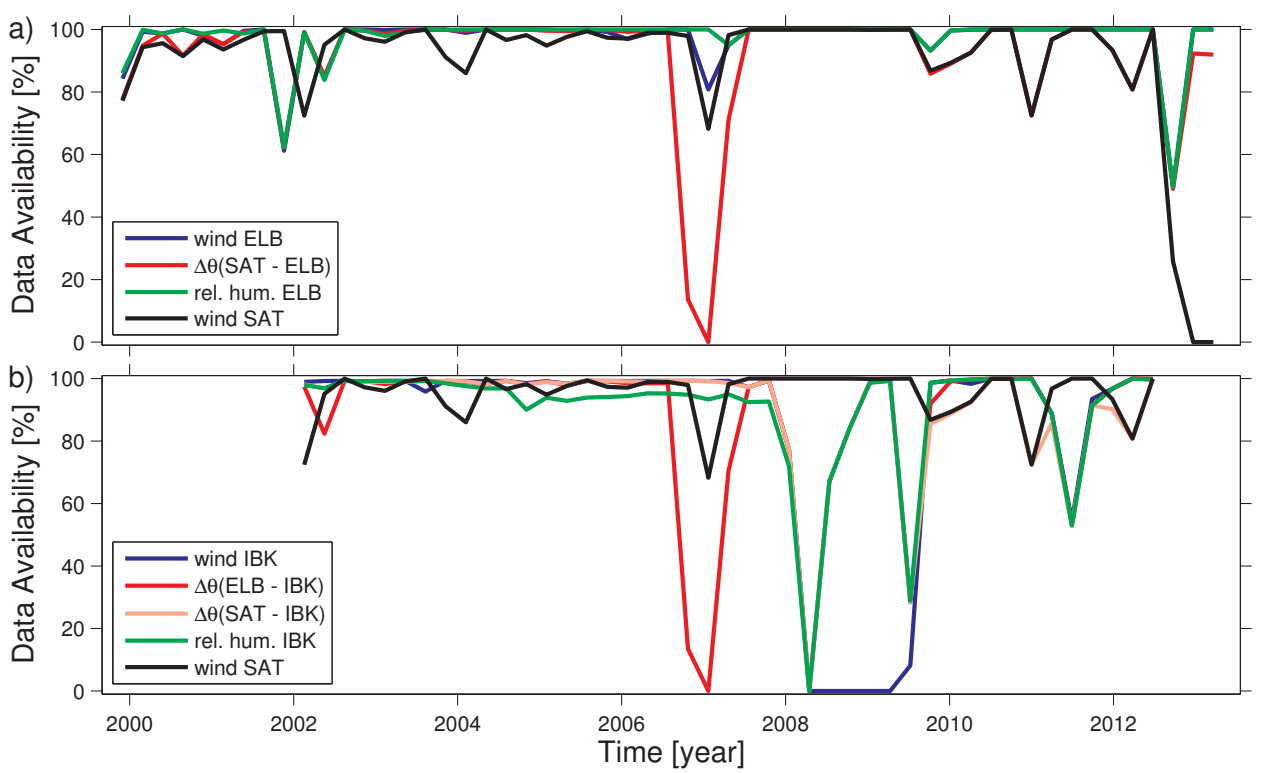

Figure 2.5: Time series of availability from different variables (averaged over 3 months) used for classification of foehn in Ellbögen (a) and Innsbruck (b). Wind summarizes availability of direction and speed. $\Delta \theta$ includes availability of pressure and temperature at bout (rest/upstream and valley) stations.

seen in Fig. 2.3 where all wind direction measurements are plotted. During some periods the wind direction sensor was shifted (supposedly by strong winds) and the average "south" direction moved to other directions. For the first period (2002 2004) a polynomial function was fitted for this "south" direction. The difference to the average (i.e. true) south direction $\left(179^{\circ}\right)$ were added to correct that shift. On the other, much shorter periods the wind did not shifted continuously but in steps of several degrees. Here just the average differences were added/subtracted because after those shifts the direction remained nearly unchanged. For the identification of the south direction, longer periods of constant direction were compared with numerical weather prediction model (NWP) analysis maps. Hereby the data of transition times at beginning and ending of these shifted periods were eliminated. At station Innsbruck, the direction was corrected by the same method by using up-valley wind direction instead of south wind.

Fig. 2.5 shoves data availability of parameters used for foehn classification. Data for foehn diagnosis in Ellbögen are present for $91 \%$ of the whole period for mixture model approaches (excluding wind at Sattelberg). The only longer gap is from 2006 to the beginning of begin 2007 when the pressure measurement failed. In such a case when pressure of one station is missing $\theta$ could be calculated by using the barometric relation. Since the remaining period of available data is sufficiently long for testing foehn classification methods and a complete climatology is not the main goal of this study, this calculation was not done. At Innsbruck, the data availability is much 
lower with around 80\%. Especially between 2008 and 2010 wind measurements are missing for a very long period including temporary absence of all sensors.

Table 2.2 summarizes overall data availability for both stations and different combinations of variables, as used in many mixture models. It is obvious that with increasing amount of variables the data availability decreases. Especially the gusts in Innsbruck are available for only one quarter of the the time, which makes them unusable. So for comparison of different models always the minimum available dataset, with intersection of all variables (except gusts) have to be used. But for the final climatology all available data corresponding to the necessary variables of the chosen best model will be used.

Table 2.2: Overall availability of different variable combinations used in mixture models for foehn diagnosis at both valley stations. Variables are abbreviated after the SYNOP code ( $T$ temperature, $p p p$ pressure, $f f$ wind speed, $f x$ gusts, $d d$ wind direction). Variables without station indications are from respectively valley station where foehn is being classified. The most important models are listed for the corresponding data availability, whereby it's names beginning with "M" are for Ellbögen and with "MI" for Innsbruck.

\begin{tabular}{lccc}
\hline \hline Variables & Ellbögen & Innsbruck & corresponding models \\
\hline$T, p p p, d d, f f, r h$ & $93.56 \%$ & $81.63 \%$ & M1 \\
$+T(S A T), p p p(S A T)$ & $91.19 \%$ & $79.54 \%$ & M2, M3 \\
$+f f(S A T), d d(S A T)$ & $84.06 \%$ & $76.91 \%$ & OFC, MIS27, MIS35 \\
$+f x(E L B / I B K)$ & $91.19 \%$ & $24.61 \%$ & \\
$+T(E L B), p p p(E L B)$ & - & $76.33 \%$ & MIE19, MIE31 \\
\hline
\end{tabular}




\section{Chapter 3}

\section{Methods and Results for a Foehn Valley Station (Ellbögen)}

This chapter contains a published article, which describes the general method (mixture models), used in this work and the application to the Wipp Valley. Since the articel has space only for the three best of all tested models, the other ones are presented in the subsequent subsections.

3.1 Article 


\title{
Automatic and Probabilistic Foehn Diagnosis with a Statistical Mixture Model
}

\author{
David Plavean, Georg J. Mayr * \\ Institute of Meteorology and Geophysics, University of Innsbruck, Innsbruck, Austria \\ ACHIM ZEILEIS \\ Department of Statistics, Faculty of Economics and Statistics, University of Innsbruck
}

\begin{abstract}
Diagnosing foehn winds from weather station data downwind of topographic obstacles requires distinguishing them from other downslope winds, particularly nocturnal ones driven by radiative cooling. We present an automatic classification scheme to obtain reproducible results that include information about the (un)certainty of the diagnosis. A statistical mixture model separates foehn and no-foehn winds in a measured time series of wind. In addition to wind speed and direction, it accommodates other physically meaningful classifiers such as the (potential) temperature difference to an upwind station (e.g. near the crest) or relative humidity. The algorithm was tested for the central Alpine Wipp Valley against human expert classification and a previous objective method (Drechsel and Mayr 2008), which the new method outperforms. Climatologically, using only wind information gives nearly identical foehn frequencies as when using additional co-variables. A data record length of at least one year is required for satisfactory results. The suitability of mixture models for objective classification of foehn at other locations will have to be tested in further studies.
\end{abstract}

\section{Introduction}

Foehn is 'a wind (which is) warmed and dried by descent, in general on the lee side of a mountain' (WMO 1992). As such it is as ubiquitous as the mountain ranges of the earth. Diagnosing when foehn blows requires distinguishing it from other downslope flows, which can be nontrivial. An accurate diagnosis is a prerequisite for studies dealing with mechanisms, climatologies and effects of foehn, e.g. on air quality. This paper describes a method to objectively diagnose both foehn occurrence and the (un)certainty of the diagnosis.

The conceptual model of foehn that fits best the results of the latest large field campaigns (Mesoscale Alpine Programme MAP, Mayr and Armi (2008); Terrain-Induced Rotor Experiment TREX, Armi and Mayr (2011)) is depicted in Fig. 1a. The descent of upstream air is possible when the virtual potential temperature of the descending upstream air mass is equal or lower than the air in the downstream valley. Since absolute humidity normally decreases away from the surface, relative humidity in the descended and compressed foehn air is lower than in the air it replaces downstream. Exceptions occur, e.g. in the Appalachians (Gaffin 2002, 2007).

Other wind systems, which flow down topography and might be mistaken for foehn are downslope/down-valley flows from nocturnal radiative cooling (Defant 1949; Whiteman 2000) depicted in Fig. 1b, and shorter-lived events like frontal passages (Prandtl 1944) or convective outflows.

The traditional method for detecting foehn (Conrad 1936) from observation data at a single (valley) station (location V in Fig. 1) is to analyze temporal changes of temperature, relative humidity and wind. At onset wind speed must increase and direction must be down the local terrain, and for many locations temperature should increase and relative humidity decrease. This method normally requires a human expert, making results non-reproducible and very time-consuming. And even a human expert has difficulty distinguishing weaker foehn flows from radiatively driven downslope flows.

Gutermann (1970) pioneered the (semi-)automated and objective foehn diagnosis. He used a wind index which combines speed and directional information together with anomalies of temperature and relative humidity. The statistical method was Fisher's (linear) discriminant analysis in combination with a long dataset with (manually) classified foehn.

Diagnostic accuracy increases with the availability of a second station further upslope at (or near) the crest (location $\mathrm{C}$ in Fig. 1) with which one can exploit the physical differences between foehn and downslope winds. During foehn (Fig. 1a) the upstream air mass descends so that potential temperatures at stations $\mathrm{V}$ (valley) and $\mathrm{C}$ (crest) will almost ${ }^{1}$ be identical $\left(\Delta \theta=\theta_{\text {crest }}-\theta_{\text {valley }} \approx 0\right)$. In con-

\footnotetext{
${ }^{1}$ Small differences may occur due to e.g. imperfect sensor calibra-
} 


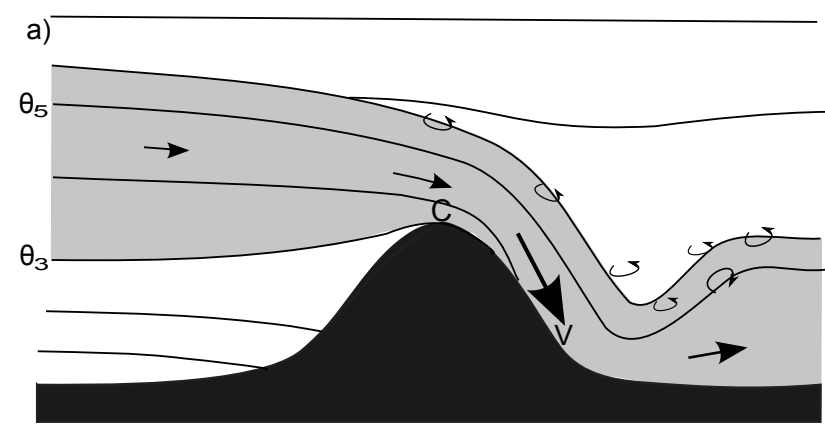

b)

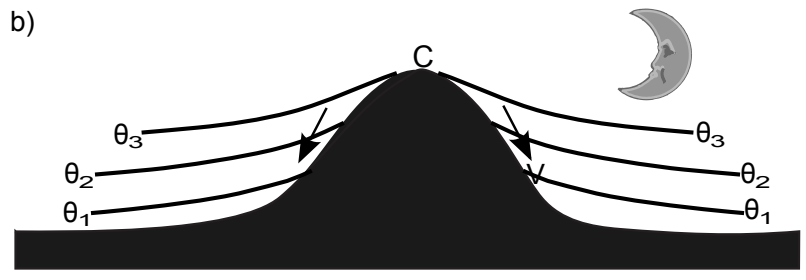

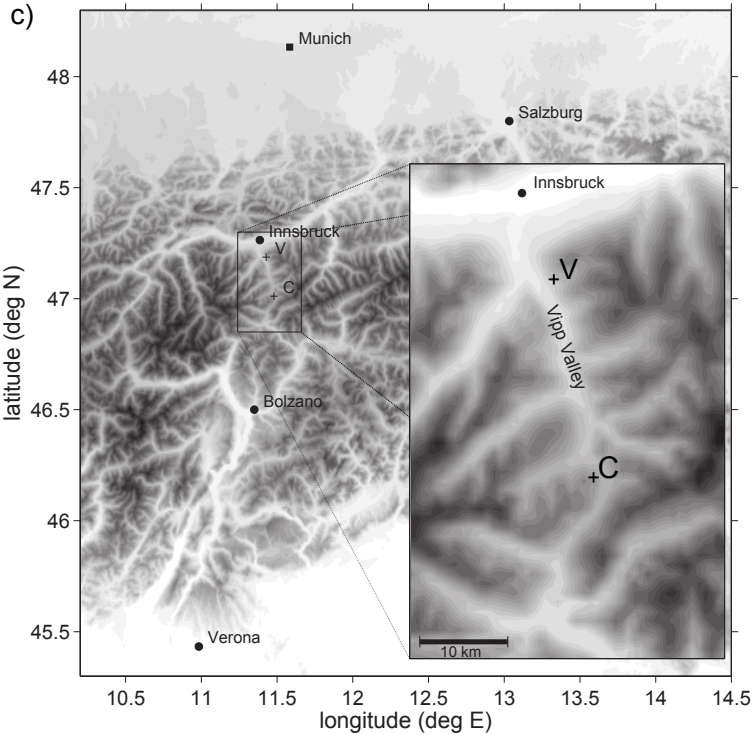

FIG. 1. Schematic representation of (a) foehn and (b) radiatively driven downslope flow, respectively. In (a) dark gray shading indicates the foehn layer and the arrows indicating qualitatively the flow direction and speed. Turbulent mixing at the ground and at the upper edge of the foehn flow is indicated by curved arrows. The light gray shaded area above the foehn flow indicates the mixed residual layer. The solid lines in both parts are isentropes. (c) Topographic map of the eastern Alps with detailed insert of the test region Wipp Valley. C depicts the crest station Sattelberg $(2.1 \mathrm{~km}$ amsl, 11.47926 E, 47.01143 N) and V the valley station Ellbögen (1.1 km amsl, 11.42961 E, 47.18802 N).

trast to this, radiative cooling during a nocturnal downslope wind situation (Fig. 1b) leads to stable stratification $(\Delta \theta>0$; Whiteman (2000)). This difference was exploited to separate foehn from nocturnal downslope winds in an objective foehn classification method (OFC), first devoloped during MAP. It is described in detail in Vergeiner (2004) and summarized in Drechsel and Mayr (2008). The method classifies wind of at least $2 \mathrm{~m} \mathrm{~s}^{-1}$ from a downslope sector as foehn when $\Delta \theta$ is below a station-dependent threshold, which has to be semi-manually determined. Having to determine the hard threshold individually for each location is the main drawback of the method. Dürr (2008) developed another automated physically-based classification which additionally includes relative humidity and gusts for Swiss Stations by refining a manual procedure. This method was used to classify the most recent period of a unique 145 year foehn data series for the Swiss station at Altdorf (Gutermann et al. 2012).

Even a human expert using a second station will encounter events that are not clearly distinguishable and that are classified by the OFC without giving an indication of the high uncertainty. An improved objective classification method should consequently avoid both drawbacks by mak-

tion, mixing in of nocturnally-cooled air or evaporation of precipitation into the downstream foehn layer. They are discussed at length in Vergeiner (2004). ing it unnecessary to determine anything except possibly the topographic downslope direction by hand and by moving from a deterministic to a probabilistic diagnosis.

\section{Foehn diagnosis with a statistical mixture model}

Separation of foehn from radiatively-driven downslope winds is a typical classification problem, for which statistical science provides several methods. Since we want the method to be applicable to any location we chose unsupervised classification. A mixture model allows to both estimate the unknown density distribution of foehn and no-foehn cases from the observed and thus known density of all cases and the probability that observation $i$ belongs to one of the two classes (McLachlan and Peel 2000; Hastie et al. 2009). This assumes that the two densities (wind regimes) are statistically distinguishable as in Fig. 2.

In our case, the mixture model for the wind speed distribution $f(s)$ consists of two normally distributed components, downslope wind and foehn:

$$
f\left(s_{i}\right)=\underbrace{(\pi-1) \phi\left(s_{i} \mid \mu_{1}, \sigma_{1}^{2}\right)}_{\text {I downslope wind }}+\underbrace{\pi \phi\left(s_{i} \mid \mu_{2}, \sigma_{2}^{2}\right)}_{\text {II foehn }}
$$

where

$$
\phi\left(s_{i} \mid \mu, \sigma^{2}\right)=\frac{1}{\sqrt{2 \pi \sigma^{2}}} \exp \left\{-\frac{\left(s_{i}-\mu\right)^{2}}{2 \sigma^{2}}\right\}
$$




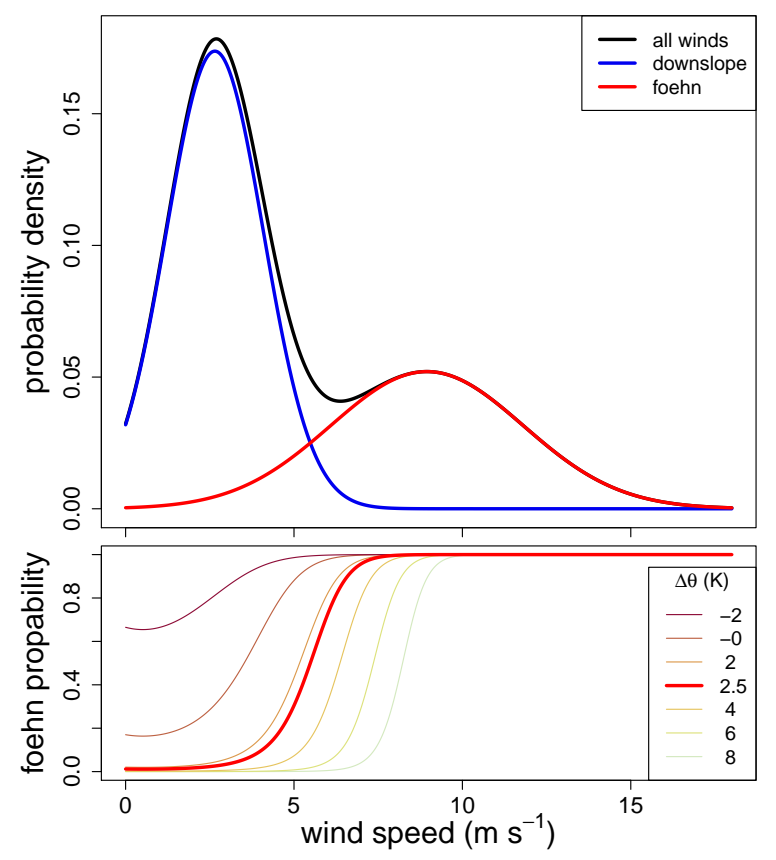

FIG. 2. (top) Distribution of wind speed (black) for winds from the foehn sector at the Wipp Valley station with distributions of foehn (red) and no-foehn (blue) fitted by the mixture model M2 for wind speed with the difference in potential temperature between crest and valley station as concomitant. (bottom) Foehn probability for model M2 as function of wind speed and potential temperature difference $\Delta \theta$ (isolines). The red line represents the mean state for the whole distribution in the top part of the figure.

denotes the Gaussian density function with mean $\mu$ and variance $\sigma^{2} . \pi$ is the prior probability for foehn class and the complementary probability $\pi-1$ is the prior for downslope wind class. We can properly label these two classes since foehn is stronger than nocturnal downslope wind, i.e. $\mu_{2}>\mu_{1}$. Note, that in general any component density can be used in place of the Gaussian or that wind speed can be transformed (e.g. taking the square root) before being used in the mixture model, which, however, did not improve our model.

The probability that one measurement of wind speed $s_{i}$ belongs to the foehn cluster is given by the proportion of the probability density function for foehn to the total wind speed distribution and can be calculated by the ratio of II/(I + II) from the components of Eq. (1).

Additional physically meaningful classifiers such as the potential temperature difference between valley and crest or relative humidity called "concomitant" variables (Dayton and Macready 1986) may be used to improve the estimated distributions. Then the prior probability $\pi$ changes from being constant to a (in our two component case) binomial logit model. The prior for the second component (foehn) is then

$$
\pi(\mathbf{x})=\operatorname{logit}^{-1}\left(\mathbf{x}^{\top} \boldsymbol{\beta}\right)
$$

where the vector

$$
\mathbf{x}=\left(\begin{array}{c}
1 \\
x_{1} \\
x_{2} \\
\vdots
\end{array}\right)
$$

contains the used concomitant variables $x_{i}$ after its first component which is 1 . The corresponding coefficients are written in the vector $\boldsymbol{\beta}$.

We used the FlexMix package (Leisch 2004; Grün and Leisch 2008) in the programming language $\mathbf{R}$ (R Core Team 2013) to fit the mixture model. The only pre-processing was the application of a wind direction filter: Only wind from a $180^{\circ}$ sector centered along the topographic downslope direction could be classified as 'foehn'. The downslope direction can either be determined manually or automatically (Pelletier 2013).

\section{Application}

This automatic classification method was tested for the Wipp Valley in the central Alps (see Fig. 1c). It is a typical foehn valley, orientated perpendicular to a gap in the main crest. The indentation in the crest line increases foehn occurrence (e.g. Jackson et al. (2013)). It was a study area of MAP and has since then been instrumented to allow testing of different foehn classification schemes. We use one crest/gap station at $2.1 \mathrm{~km}$ amsl and one valley station at $1.1 \mathrm{~km}$ amsl, which is $21 \mathrm{~km}$ downstream. 14 years of measurements of wind speed and direction, temperature, relative humidity and pressure averaged over 10-minute intervals are available. Joint data availability is $91 \%$.

Three different mixture models exploiting an increasing amount of measurement information were applied to probabilistically diagnose foehn occurrence at the valley station. The first model (M1) only uses wind speed at the valley station itself. M2 uses the measurements at the crest station to include the potential temperature difference $\Delta \theta$ between crest and valley as the first concomitant variable. Finally, M3 adds relative humidity at the valley station as a second concomitant (cf. Table 1).

The behavior of all three models will be first explored in a case study and then in a foehn climatology over the whole 14-year data set.

\section{a. Case study: Shallow foehn on 27/28 October 2005}

For a subjective (human-expert) verification of these foehn models more than 50 case studies were examined. Most of them, especially the stronger foehn events are well 


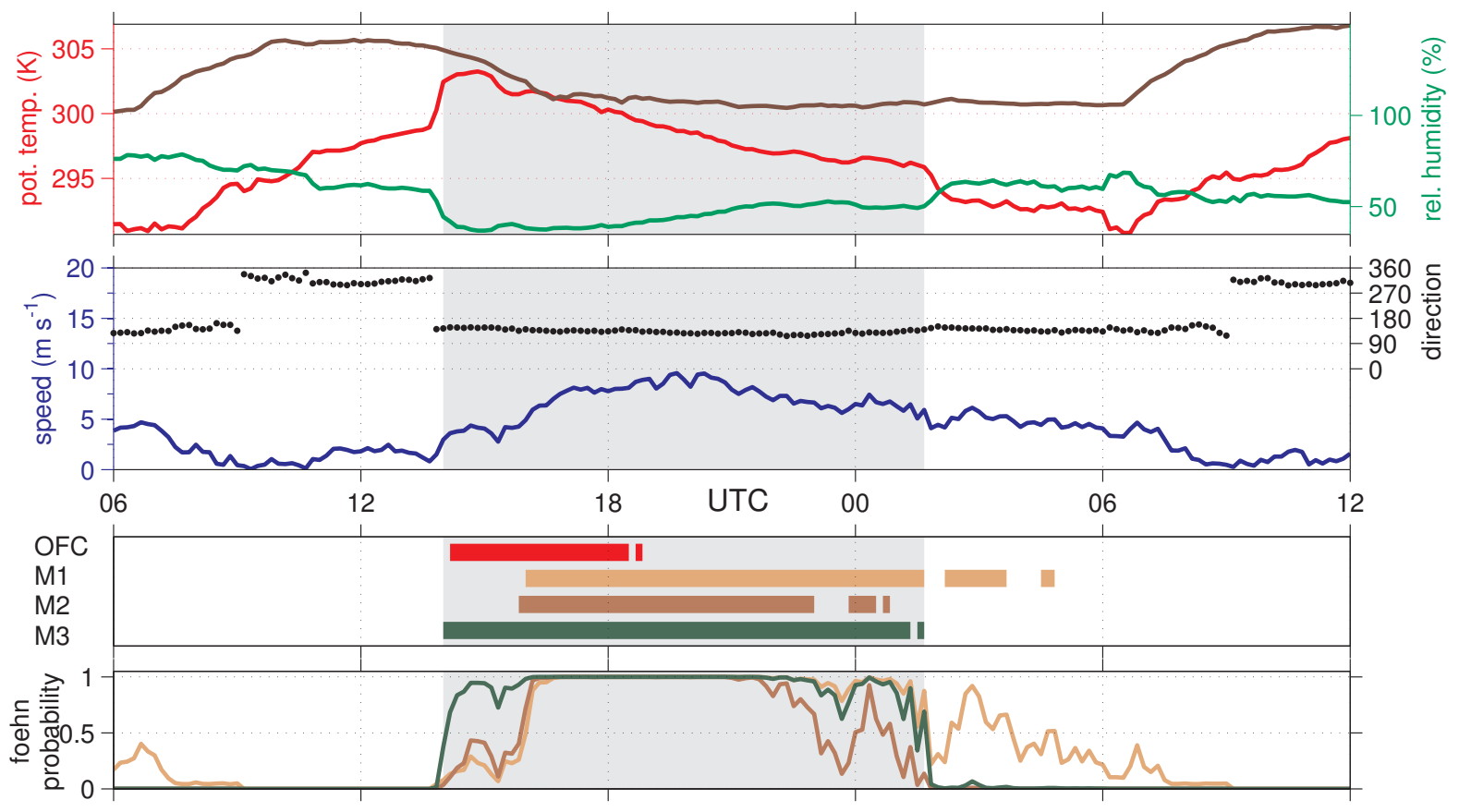

FIG. 3. Time series from 06 UTC 27 October 2005 to 12 UTC 28 October 2005 for the valley station with (first row) potential temperature (red) and relative humidity (green) and the potential temperature of the crest station(brown). Second row: Wind direction (black dotted line) and wind speed (blue line) for valley station. Third row: Periods of foehn diagnosed by each model M1-M3 (cf. Table 1) having a foehn probability $\geq 50 \%$, and the objective foehn classification (OFC). Fourth row: Foehn probabilities from mixture models M1-M3 with same colors as in third row. Manually classified foehn period is shaded light gray in the background of all rows.

captured by all models with only minor differences. For illustration, we present one where the differences between models M1-M3 are especially pronounced and where the ending of the foehn period is difficult to analyze even by a human expert.

On 27 and 28 October 2005 the Alps separated a cold air mass to the south from warmer air to the north, which caused (shallow) south foehn through the lower alpine passes. At the Wipp Valley station, the foehn event started at 1400 UTC 27 October 2005 in our subjective classification (gray shading), shortly after the direction shifted from northwest (=upvalley) to southeast (=downvalley) with a strong increase in temperature and a decline in relative humidity (Fig. 3). It ended the following night at 0150 UTC with reverse but less pronounced signals in temperature and humidity. Notable is the continuous increase of $\Delta \theta$ due to mixing-in of radiatively cooled air since 17 UTC to $4 \mathrm{~K}$ shortly before this foehn event ended. Afterwards, the flow continued to be downvalley and of similar strength but no longer caused by foehn but rather by radiative cooling.

Overall all models captured the core part of this foehn event (compare M1 - M3 in rows 3 and 4 of Fig. 3). By using only wind speed at the valley station, the mixture model M1 misses the onset by a few hours due to low foehn wind speeds and erroneously postpones the ending caused by high radiatively driven speeds. However, by including the information about the uncertainty of the classification, foehn beginning and ending are indicated correctly in row 4 of Fig. 3. Adding the difference in potential temperature between mountain and valley station (M2) avoids the misclassification at the end of the foehn period but shortens the foehn period and still misses the first foehn hours although again the foehn probability correctly increases. Adding the relative humidity at the valley station as further concomitant variable in M3 finally nearly coincides with our subjective classification.

\section{b. Climatological and statistical aspects}

Climatologically, foehn at the valley station is frequent and occurs for about one fifth of the time. All three mixture models analyze the overall foehn frequency ${ }^{2}$ for the investigated 14-year period to within one percentage point

\footnotetext{
${ }^{2}$ using a threshold of $50 \%$ foehn probability
} 
TABLE 1. Summary of mixture models M1-M3 with variables used for fitting (wind speed $s$ and direction $d$, relative humidity $r h$ and difference in potential temperature $\left(\Delta \theta=\theta_{\text {crest }}-\theta_{\text {valley }}\right)$ and relative frequency of no-foehn and foehn classification with two levels of certainty and sum of both levels, each for the 14-year data set at the valley station. Note that wind direction was only used to preprocess data but is not included in the statistical models. Additionally, results for the previous non-probabilistic objective algorithm OFC are shown.

\begin{tabular}{rlrrrrrr}
\hline \hline \multirow{2}{*}{ model } & \multirow{2}{*}{ variables } & \multicolumn{3}{c}{ no foehn (\%) } & \multicolumn{3}{c}{ foehn (\%) } \\
& & $\geq 99$ & $50-99$ & $\sum$ & $\sum$ & $50-99$ & $\geq 99$ \\
\hline M1 & {$[d], s$} & 49.40 & 30.95 & 80.35 & 19.65 & 5.27 & 14.38 \\
M2 & {$[d], s, \Delta \theta$} & 71.78 & 9.61 & 81.39 & 18.61 & 4.30 & 14.32 \\
M3 & {$[d], s, \Delta \theta, r h$} & 71.67 & 8.64 & 80.31 & 19.69 & 4.10 & 15.59 \\
\hline OFC & $s, \Delta \theta, d$ & & & 84.26 & 15.74 & & \\
\hline
\end{tabular}
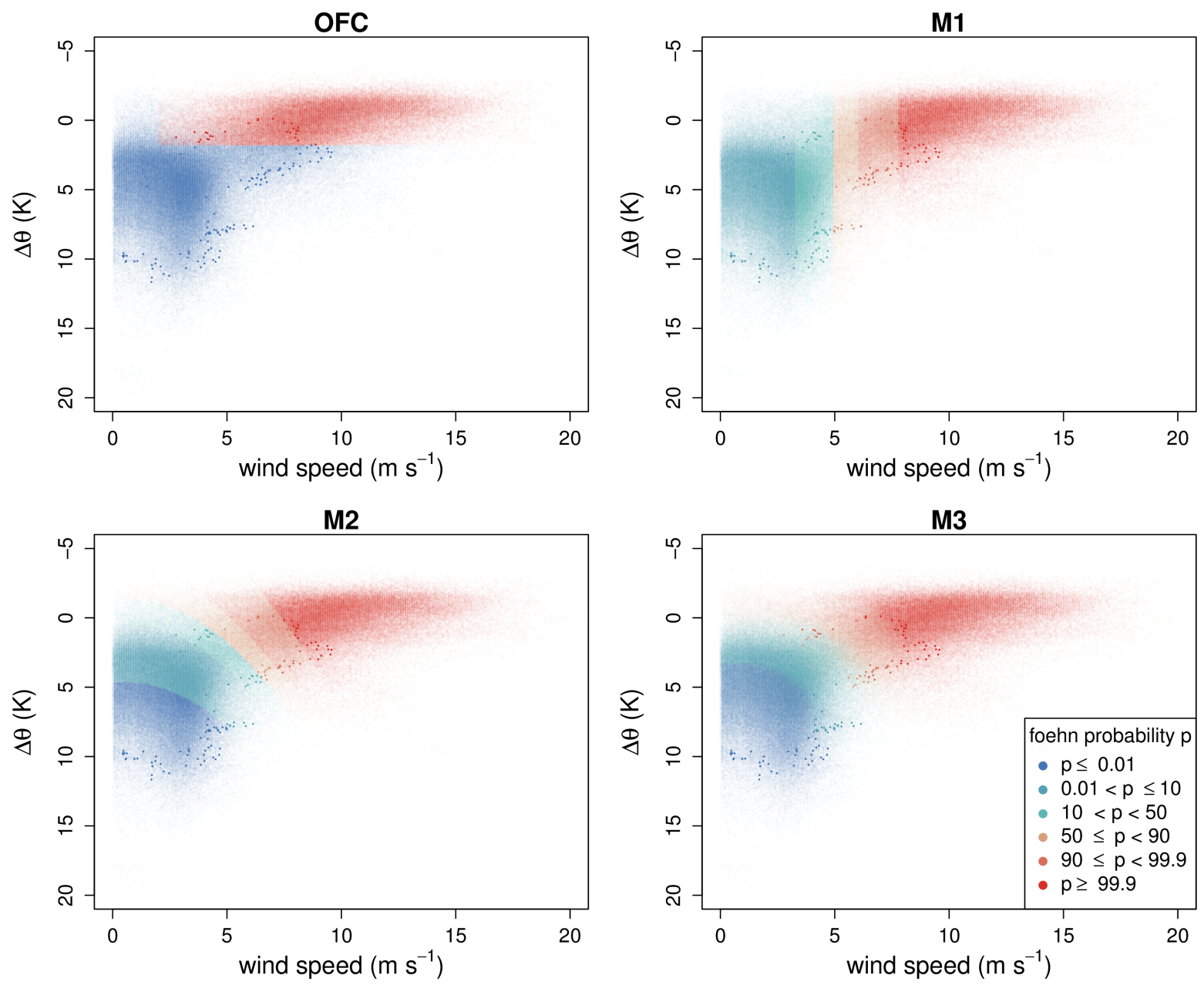

FIG. 4. Likelihood of foehn (colors) for wind speed and potential temperature difference $\left(\Delta \theta=\theta_{\text {crest }}-\theta_{\text {valley }}\right)$ combinations for wind from the $180^{\circ}$-wide foehn wind sector. Each point represents a 10 min mean. Results are shown for the previous objective method OFC (which is deterministic and only has yes/no), and the mixture models M1, M2 and M3 (see also Table 1). The points from foehn wind sector corresponding to the case study shown in Fig. 3 are drawn without transparency. 
(Table 1): using only wind speed gives 19.7\%. Adding potential temperature difference reduces the frequency by one point to $18.6 \%$ (as in the case study), while adding relative humidity in M3 brings the frequency back to the speed-only value of $19.7 \%$. The previous objective method, OFC, on the other hand, found only $15.7 \%$ foehn.

Fig. 4 demonstrates the workings of the mixture models (M1) - (M3) in comparison to the previous objective method (OFC). The point clouds have two maxima. One at low wind speeds and large potential temperature differences $\Delta \theta$ (high static stability), which indicates the down valley winds and another with $\Delta \theta$ near zero and high wind speeds, which indicates foehn. The OFC uses hard thresholds for $\Delta \theta$ and minimum wind speed and misses events of moderate-to-low speeds and moderate stability. Mixture model M1 with wind speed only, on the other hand includes too many of these cases but misses some low speed cases with low stability. If one were to use $50 \%$ probability for a yes/no classification, a line of $4.9 \mathrm{~m} \mathrm{~s}^{-1}$ would separate the classes. The second model M2 divides the classes more appropriately by a curved cut, because now foehn probability also depends on $\Delta \theta$. This can also be seen in the lower part of Fig. 2. At low values of $\Delta \theta$, low wind speeds are sufficient for high foehn probabilities, while for a more stably stratified atmosphere (high $\Delta \theta$ ) much higher speeds are necessary for reaching the deciding probability of $50 \%$. By adding relative humidity in M3 the separation conforms even more closely to the one a human would draw.

\section{Discussion and Conclusion}

The statistical mixture model is a method to diagnose foehn automatically and probabilistically. It eliminates having to select threshold values individually for each location as required by previous automatic methods (Drechsel and Mayr 2008; Dürr 2008) and includes information about how certain the diagnosis is. A data-set with already analyzed foehn periods as in the statistical classification method of Gutermann (1970) is also not needed. Another advantage is the possibility to diagnose foehn for locations with well-established foehn winds, objectively without any mountain station (M1) at the expense of some misses and false positives. For our location, this modified total foehn time by only $0.04 \%$ due to about $7 \%$ temporal misclassifications of either foehn beginning or ending times, compared to the best model M3 (see Table 1 and compare Fig. 4 and case study in Fig. 3). The previous objective method OFC found about one fifth less foehn (Table 1), mostly by ignoring weak nocturnal foehn cases that have a substantial amount of radiatively cooled air mixed in from the slopes and side valleys thus exceeding the hard threshold for potential temperature difference between crest and valley (Fig. 4a).
At farther downstream locations, e.g. wide valleys or plains at edge of mountains, foehn winds might be too weak to be classified by speed (M1) alone. Additional concomitants as in M2 and M3 might help up to a location where the foehn air stream has become too diluted by the surrounding air to be distinguishable (Armi and Mayr 2011; Mayr and Armi 2010).

Prior to the fully automatic classification, one additional piece of information is still required: the selection of the sector of foehn wind direction. Doing this manually only requires having to determine the valley axis direction and selecting an appropriate sector to each side. In our case this was the widest possible of $\pm 90^{\circ}$. This step could be automated using a digital elevation model and a routing algorithm (e.g. Pelletier (2013)). For particular topographies (e.g. edge of mountain), when elimination of other wind systems is required, or when the distinction between different foehn regimes (e.g. south foehn and west foehn) is needed, smaller sectors can be chosen.
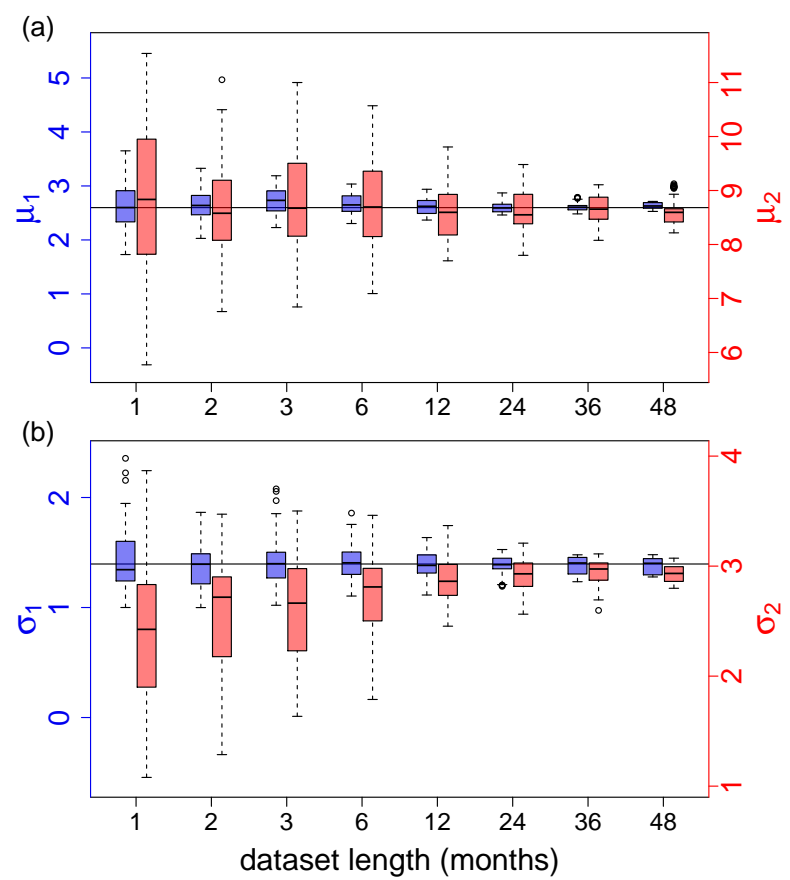

FIG. 5. Effect of data length on parameter estimation of mixture model. Means $\mu_{i}$ (a) and standard deviations $\sigma_{i}$ (b) were fitted separately for 100 contiguous bootstrap samples of different dataset length (months) for mixture model M3 (M1 and M2 are almost identical). Index 1 is for radiatively driven downslope winds (blue; left axis); index 2 for foehn (red; right axis). Note that scaling for each parameter is equal for both indices (ordinates). The black horizontal lines show the parameter values fitted to the whole available data set (152 months). 
Incidentally, the simplest classification setup proved also to be the best when compared against the subjective humanexpert classification of the $50+$ events and overall foehn frequency. Appropriate downslope wind direction, speed and $\Delta \theta$ are the most important inputs for a foehn classification with a last refinement by relative humidity. Similar variables were also found in previous automated methods (Gutermann 1970; Drechsel and Mayr 2008; Dürr 2008). If a crest station is not available, NWP model analysis data at the appropriate height might be used provided the model topography sufficiently resembles the actual topography. The information provided by additional concomitant variables such as gusts, the ratio between gust and 10-minute average speed ('gust factor') or the temporal gradients of temperature and relative humidity, respectively, did not improve the results for data from a single (valley) station. Adding relative humidity to M1 without using $\Delta \theta$ (as for M3) even worsened the classification with too many false positives, because in this constellation the model may include downslope winds with low relative humidity, which can occur in the evening when the wind has just shifted to being downslope and the spread between dry-bulb temperature and dewpoint is still large. For the combination of valley and crest station, adding the difference of mixing ratio between mountain and valley station did not improve the results.

Since wind speed distributions are typically non-Gaussian (cf. Wilks (2011)) but the mixture model in its simplest form in Eq. (1) assumes such a distribution, we remedied a possible violation by first transforming wind speed with logarithm and square root, respectively. However, in all cases considered by us results were worse.

Since weather station records at foehn locations have different length, an important practical question is the required minimum data-set length for the classification to become reliable. Fig. 5 shows the effect of record length on four parameters of the mixture model (cf. Eq. (1)). For each of the record lengths ( 1 month to 4 years) 100 such contiguous samples were randomly drawn from the 14 -year data set and the mixture models fitted only with these measurements. Parameters for no-foehn are already well captured for short periods since radiatively driven flows occur on many nights. Foehn, on the other hand, has a strong seasonal cycle due to e.g. local cold pools (cf. Mayr et al. (2007)) with a pronounced minimum during summer in our investigated area. Therefore short records from summer will provide too small a foehn sample for reliable parameter estimation but the same duration taken in autumn might suffice. To cover the major part of foehn wind distributions, a minimum dataset of one year is required for a station with frequent foehn.

A main purpose of the paper was to introduce mixture models as an efficient way of probabilistically diagnosing foehn. We have started to explore their suitability for other foehn regions of the world. While the automatic algorithm using only wind information is successful for simple foehn locations like the Wipp Valley, other sites might require appropriate concomitants such as M2, M3 here. The application potential of this diagnosis method encompasses, e.g. (unified) foehn climatologies, studies of foehn mechanisms, or verification of foehn forecasts.

\section{Acknowledgments.}

We thank very much the three anonymous reviewers who provided such constructive criticism and suggestions how to improve this paper. This study was supported by the Austrian Science Fund (FWF): L615-N10.

\section{REFERENCES}

Armi, L. and G. J. Mayr, 2011: The descending stratified flow and internal hydraulic jump in the lee of the sierras. Journal of Applied Meteorology and Climatology, 50, 1995-2011.

Conrad, V., 1936: Handbuch der Klimatologie, chap. Die klimatologischen Elemente und ihre Abhängigkeit von terrestrischen Einflüssen, 1146-1166. Bornträger.

Dayton, C. M. and G. B. Macready, 1986: Concomitantvariable latent-class models. Journal of the American Statistical Association, 83, 173-178.

Defant, A., 1949: Zur Theorie der Hangwinde, nebst Bemerkungen zur Theorie der Berg- und Talwinde. Archiv für Meteorologie Geophysik und Bioklimatologie A, 1, 421-450.

Drechsel, S. and G. J. Mayr, 2008: Objective forecasting of foehn winds for a subgrid-scale Alpine valley. Weather and Forecasting, 23, 205-218.

Dür, B., 2008: Automatisiertes Verfahren zur Bestimmung von Föhn in Alpentälern. Arbeitsbericht 223, MeteoSchweiz. URL http://www.meteoschweiz. admin.ch/web/de/forschung/publikationen/alle_ publikationen/ab_223.Par.0001.DownloadFile. tmp/ab223.pdf.

Gaffin, D. M., 2002: Unexpected warming induced by foehn winds in the lee of the smoky mountains. Weather and Forecasting, 17 (4), 907-915.

Gaffin, D. M., 2007: Foehn winds that produced large temperature differences near the southern appalachian mountains. Weather and Forecasting, 22 (1), 145-159.

Grün, B. and F. Leisch, 2008: FlexMix Version 2: Finite mixtures with concomitant variables and varying 
and constant parameters. Journal of Statistical Software, 28 (4), 1-35, URL http://www.jstatsoft.org/v28/ i04/.

Gutermann, T., 1970: Vergleichende Untersuchungen zur Fönhäufigkeit im Rheintal zwischen Chur und Bodensee. No. 18 in Veröffentlichungen der Schweizerischen Meteorologischen Zentralanstalt, City-Druck AG, Zürich.

Gutermann, T., B. Dürr, H. Richner, and S. Bader, 2012: Föhnklimatologie Altdorf: zie lange Reihe (1864-2008) und ihre Weiterführung, Vergleich mit anderen Stationen. Fachbericht 241, MeteoSchweiz.

Hastie, T., R. Tibshirani, and J. Friedman, 2009: The Elements of Statistical Learning. 2d ed., Springer-Verlag, New York.

Jackson, P. L., G. J. Mayr, and S. Vosper, 2013: Mountain Weather Research and Forecasting: Recent Progress and Current Challenges, chap. Dynamically-Driven Winds, 121-218. Springer-Verlag.

Leisch, F., 2004: FlexMix: A general framework for finite mixture models and latent class regression in R. Journal of Statistical Software, 11 (8), 1-18, URL http: //www . jstatsoft.org/v11/i08/.

Mayr, G. J. and L. Armi, 2008: Föhn as a response to changing upstream and downstream air masses. Quarterly Journal of the Royal Meteorological Society, 134, 1357-1369.

Mayr, G. J. and L. Armi, 2010: The influence of downstream diurnal heating on the descent of flow across the Sierras. Journal of Applied Meteorology and Climatology, 49, 1906-1912.

Mayr, G. J., et al., 2007: Gap flows: Results from the Mesoscale Alpine Programme. Quarterly Journal of the Royal Meteorological Society, 133, 881-896.

McLachlan, G. J. and D. Peel, 2000: Finite Mixture Models. John Wiley \& Sons.

Pelletier, J. D., 2013: A robust, two-parameter method for the extraction of drainage networks from high-resolution digital elevation models (DEMs): Evaluation using synthetic and real-world DEMs. Water Resources Research, 49, 75-89.

Prandtl, L., 1944: Führer durch die Strömungslehre, chap. 5, 326-330. 2d ed., Friedrich Vieweg \& Sohn.

R Core Team, 2013: R: A Language and Environment for Statistical Computing. Vienna, Austria, R Foundation for Statistical Computing, URL http://www. R-project.org/.
Vergeiner, J., 2004: South foehn studies and a new foehn classification scheme in the Wipp and Inn valley. Ph.D. thesis, Universität Innsbruck, URL http: //imgi.uibk.ac.at/sekretariat/dissertations/ Vergeiner_Johannes_2004_Diss.pdf.

Whiteman, C. D., 2000: Mountain Meteorology: Fundamentals and Applications. Oxford University Press, 376 pp.

Wilks, D. S., 2011: Statistical Methods in the Atmospheric Sciences, International Geophysics Series, Vol. 100. 3d ed., Academic Press, Oxford.

WMO, 1992: International Meteorological Vocabulary, Vol. 182. 2d ed., World Meteorological Organization, 784 pp. 


\subsection{Additional Results}

Some results which could not be treated in the presented article (section 3.1) in full detail, are presented in this section. First estimations of the necessary preprocessing procedure like filtering the wind sector and scaling of the speed distribution are discussed. Then all other tested models are shown.

\subsubsection{Wind-sector at Valley and Mountain Station}

The three successful mixture models presented in the article were tested for different wind sectors as filter in preprocessing (see Table 3.1). In contrast to the paper, for this analysis the data availability drops to $84 \%$, because wind of Sattelberg has to be included (compare Table 2.2). Expanding the wind sector at the valley station up to $180^{\circ}$ (valley axis \pm 90 ) affects the result only by about 0.1 percentage points in almost all cases. Leaving out the direction filter from the mountain station also affects the result only little. Only with M3 (using $\Delta \theta$ and $r h$ ), an increase of foehn frequency by 0.5 percentage points can be seen. So limitations to wind direction at the mountain station are not necessary and the wide wind sector at the valley station is sufficient.

The abolition of the mountain wind criteria allows to use $6 \%$ more data (see Table 2.2), because the wind measurements at Sattelberg had some problems with freezing of the sensor and shifts of direction (see section 2.2). So for all further analyses the larger data-set with availability of $91 \%$ can be used with the widest wind-sector.

\subsubsection{Scaling of Speed Distribution}

Since the mixture model treats the wind speed distributions as Gaussian ones, several scaling functions were tested (see Table 3.2) to transfer the typically non-

Table 3.1: Comparison of the three mixture models (see Table 1 in paper) for four different wind sectors as filter in preprocessing, with and without using crest station. Shown are relative annual foehn frequencies.

\begin{tabular}{|c|c|c|c|c|}
\hline \multicolumn{2}{|c|}{ Wind Sector $\left[^{\circ}\right]$} & \multicolumn{3}{|c|}{ Foehn Frequency [\%] } \\
\hline $\mathrm{dd}(\mathrm{SAT})$ & dd(ELB) & M1 & M2 & M3 \\
\hline $180 \pm 45$ & $133 \pm 45$ & 19.68 & 18.83 & 19.16 \\
\hline $180 \pm 45$ & $133 \pm 90$ & 19.79 & 18.85 & 19.28 \\
\hline - & $133 \pm 45$ & 19.69 & 18.76 & 19.64 \\
\hline - & $133 \pm 90$ & 19.76 & 18.70 & 19.81 \\
\hline
\end{tabular}


Table 3.2: Comparison of different scaling transformations for wind speed. Shown are relative annual foehn frequencies for the three mixture models (see Table 1 in paper). Note the extreme high fohen frequency from M1 with $\ln (f f+0.1)$ scaling.

\begin{tabular}{|c|c|c|c|}
\hline \multirow[t]{2}{*}{ Scaling } & \multicolumn{3}{|c|}{ Foehn Frequency [\%] } \\
\hline & M1 & M2 & M3 \\
\hline & 19.73 & 18.76 & 19.85 \\
\hline $\ln (f f+0.1)$ & 43.42 & 16.35 & 17.42 \\
\hline $\ln (f f+1)$ & 13.26 & 16.68 & 17.77 \\
\hline$\sqrt{f f}$ & 15.05 & 17.08 & 18.27 \\
\hline
\end{tabular}

Gaussian distribution (Wilks 2011) into more Gaussian ones. The natural logarithm and square root functions were tested. The major difference between the different scaling methods occurs with the M1 models, which only uses this wind distribution to separate foehn from down-valley winds. Scaling with natural logarithm function is very sensitive to the added offset within M1 and leads to very high or to very low foehn frequencies. If concomitant variables are included the models became more similar to the results of the unscaled models.

A comparison of all models with subjective expert classifications showed that the unscaled models gave to the best results. Also this model gives very similar results in all setups (M1-M3), while the other, scaled models show much higher variability with adding additional variables.

\subsubsection{Further Tested Models}

Many additional models were tested with plenty of variable combinations. They are listed in Table 3.3. Model M3 is taken as reference, because all investigations (case studies and comparison of climatology results) showed that M3 is the best one. When using just the valley station, none of those additional models (M4-6, M10-13) could improve the simplest one, M1. In the subjectively examined case studies, none surpassed M3. 
Table 3.3: List of other tested models, with used variables, relative foehn frequency (Foehn Freq.), differences to the reference frequency ( $\Delta$ Foehn Freq.), probability of detection (POD) and false alarm ratio (FAR). As reference the best model M3 is used. Abbreviations: $f f$ wind speed, $\Delta \theta$ difference in potential temperature to the crest station (SAT), rh relative humidity, $f x F$ gust factor , $\Delta M$ difference in mixing ratio to the crest station, $\frac{\Delta T}{x \mathrm{~h}}$ increase of temperature and $\frac{\Delta r h}{x \mathrm{~h}}$ relative humidity in $0.5,1$ or 2 hours.

\begin{tabular}{clcccc}
\hline \hline Models & Variables & Foehn Freq. [\%] & $\Delta$ Foehn Freq. & POD & FAR \\
\hline M1 & $f f$ & 19.59 & -0.04 & 92.48 & 7.32 \\
M2 & $f f, \Delta \theta$ & 18.54 & -1.08 & 93.64 & 0.89 \\
M3 & $f f, \Delta \theta, r h$ & $\mathbf{1 9 . 6 3}$ & 0.00 & 100.00 & 0.00 \\
M4 & $f f, r h$ & 23.51 & 3.88 & 98.64 & 17.65 \\
M5 & $f f, f x F$ & 29.26 & 9.63 & 98.30 & 34.05 \\
M6 & $f f, r h, f x F$ & 25.46 & 5.84 & 99.12 & 23.60 \\
M7 & $f f, \Delta \theta, f x F$ & 18.82 & -0.80 & 94.63 & 1.33 \\
M8 & $f f, \Delta M$ & 19.51 & -0.11 & 92.37 & 7.09 \\
M9 & $f f, \Delta \theta, \Delta M$ & 18.68 & -0.95 & 94.51 & 0.69 \\
\hline M10 & $f f, \frac{\Delta r h}{0.5 \mathrm{~h}}, \frac{\Delta T}{0.5 \mathrm{~h}}$ & 19.58 & -0.05 & 92.49 & 7.29 \\
M11 & $f f, \frac{\Delta r h}{1 \mathrm{~h}}, \frac{\Delta T}{1 \mathrm{~h}}$ & 19.59 & -0.04 & 92.57 & 7.26 \\
M12 & $f f, \frac{\Delta r h}{2 \mathrm{~h}}, \frac{\Delta T}{2 \mathrm{~h}}$ & 19.48 & -0.14 & 92.45 & 6.86 \\
M13 & $f f, \frac{\Delta r h}{1 \mathrm{~h}} * \frac{\Delta T}{1 \mathrm{~h}}$ & 19.61 & -0.02 & 92.54 & 7.36 \\
M14 & $f f, \Delta \theta, \frac{\Delta r h}{0.5 \mathrm{~h}}, \frac{\Delta T}{0.5 \mathrm{~h}}$ & 18.51 & -1.12 & 93.46 & 0.89 \\
M15 & $f f, \Delta \theta, \frac{\Delta r h}{1 \mathrm{~h}}, \frac{\Delta T}{1 \mathrm{~h}}$ & 18.56 & -1.07 & 93.66 & 0.96 \\
M16 & $f f, \Delta \theta, \frac{\Delta r h}{2 \mathrm{~h}}, \frac{\Delta T}{2 \mathrm{~h}}$ & 18.64 & -0.99 & 94.04 & 0.98 \\
M17 & $f f, \Delta \theta, \frac{\Delta r h}{1 \mathrm{~h}} * \frac{\Delta T}{1 \mathrm{~h}}$ & 18.51 & -1.11 & 93.50 & 0.87 \\
\hline
\end{tabular}




\section{Chapter 4}

\section{Methods and Results for a Complex Location (Innsbruck)}

In chapter 3, the theories of mixture models were explained and how they can be used for separation of two wind speed distributions at a station located in a foehn valley. This chapter applies mixture models for foehn analysis at a more complex location. After the problems resulting from such a location are described, three methods for different measurement setups will be presented. Case studies conclude the chapter.

\subsection{Problems Resulting from the Complex Loca- tion}

The topographic situation, and thus the corresponding wind systems in Innsbruck differ from the ones in the Wipp Valley. Three main wind systems at the used station of Innsbruck University reach strong speeds at least sometimes (see Fig. 4.1 (a) and

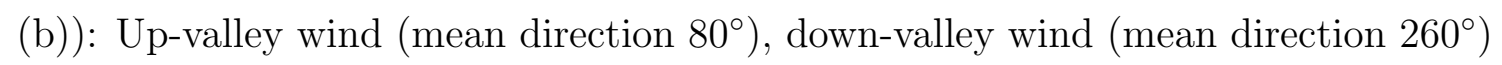
including the "pre-foehn west wind" (see section 2.1), and (south) foehn (mean direction $180^{\circ}$ ). All three wind systems are in a $180^{\circ}$ sector so that a $180^{\circ}$ sector as used in the Wipp Valley for filtering will be too wide. Additionally, north/west foehns can be observed, but they are very rare with a frequency of $0.7 \%$ (Haas 2006). Because of this rareness, the term "foehn" in Innsbruck is always used as shortening for "south foehn" in the following.

An additional complication is that the foehn direction strongly varies at Innsbruck as mentioned in section 2.1. In the western parts of the city (west of the Wipp Valley mouth), topography deflects foehn to blow from east, while on the eastern side (east from Wipp Valley) foehn comes from west. The advantage of the used station is that it is located right at the center of the Wipp Valley exit, so that the 
a)

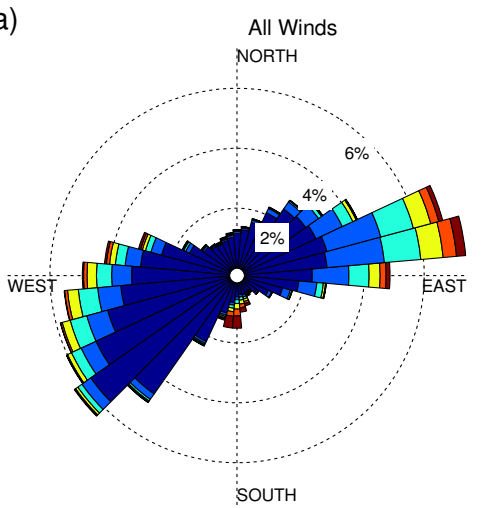

c)



b)

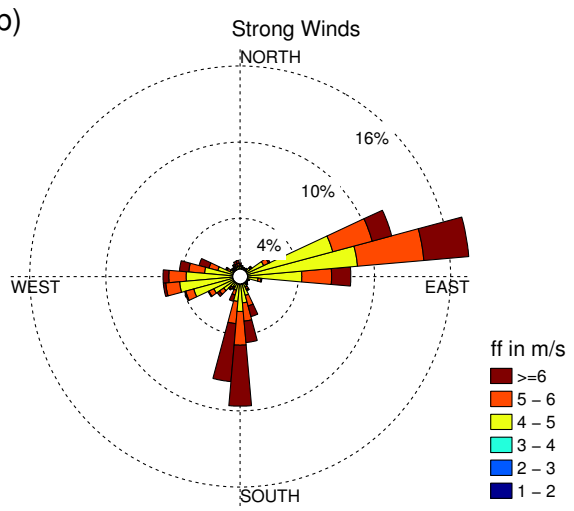

d)

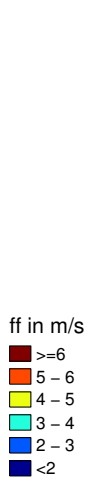

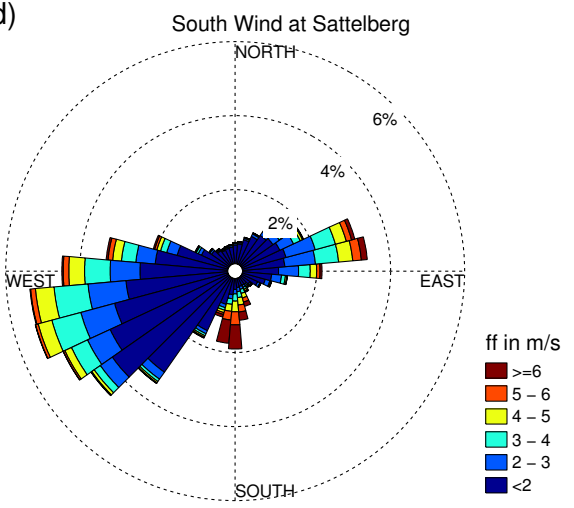

Figure 4.1: Wind roses for the station Innsbruck University. (a) all winds, (b) only stronger winds with speeds above $4 \mathrm{~m} \mathrm{~s}^{-1}$, (c) only for times with concomitant foehn at Ellbögen (analyzed with the model M3) and (d) only for times with south wind at Sattelberg.

foehn blows on average directly from the south. Nevertheless, foehn can deflected downward at the Nordkette to arrive as north wind (see section 2.1) at this station. Under special conditions the direction can even be east during foehn (see also case studies in section 4.3). That was already a major problem for the foehn classification in Innsbruck using the OFC method (Föst 2006).

With two other wind systems from similar sectors and of comparable strength to weak foehn cases, and a foehn sector larger than $180^{\circ}$, simple approaches used for Ellbögen have to be expanded.

Two procedures seem practical for automatic foehn detection: Since foehn in the upstream Wipp Valley is already classified, the overall data in Innsbruck could be reduced to the times when foehn was recorded in Ellbögen before mixture models are applied. For other locations, such an upstream foehn valley station might not exist, so it should be also investigated how foehn can be classified by using an upstream crest station. If no upstream stations are available, the last chance is to 

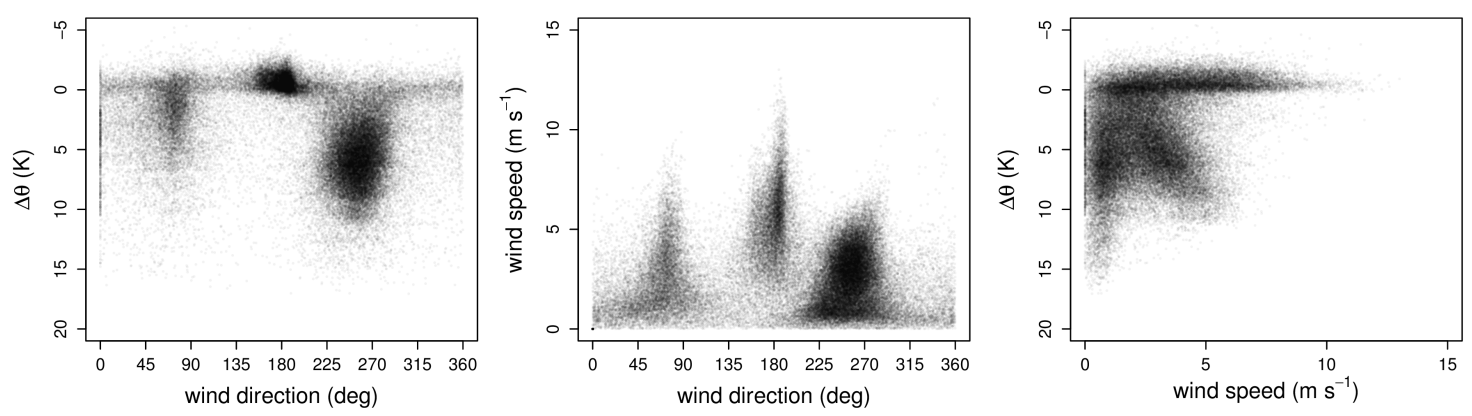

Figure 4.2: Scatterplots for Innsbruck while foehn was recorded in Ellbögen (by the model M3). The three crucial variables wind speed and direction and the difference in potential temperature to the upstream foehn station Ellbögen $(\Delta \theta)$ are shown. All three possible combinations of these variables are visualized. Left: direction $-\Delta \theta$, middle: direction - speed and right: speed $-\Delta \theta$ ).

try a similar approach to M1 with a tight foehn sector around the strong souths winds (see Fig. 4.1 (b)). But this is only possible at this location because the main foehn direction does not overlap with the other two wind systems. Nevertheless, this method would not capture the full variability of foehn as described above.

The first verification of all models based on these three approaches will compare them with results of the OFC for Innsbruck (Föst 2006). The criteria for the OFC were a wind speed at Innsbruck above $2 \mathrm{~m} \mathrm{~s}^{-1}$ from a direction between $20^{\circ}$ and $250^{\circ}$ and a $\Delta \theta$ to Sattelberg below $1 \mathrm{~K}$ (cf. Eq. 1.2). Additionally, at Sattelberg a southerly wind direction between $135^{\circ}$ and $225^{\circ}$ has to be observed. This classification led to a foehn frequency of $4.15 \%$. A comparison with the already classified foehn in Ellbögen (M3) shows that for 0.34 percentage points there was no foehn in Wipp Valley. An example is shown in Fig. 4.10. Since this is not physically possible, these 0.34 percentage points will be eliminated form the OFC for the first verification approaches. This corrected OFC will be called OFCc. However, even the $\mathrm{OFCc}$ is not perfect but misses foehn times as shown in the case studies (see section 4.3).

\subsection{Classification Schemes for Different Measure- ment Setups}

\subsubsection{Upstream Foehn Valley Station}

Usually foehn flows can be retraced for a valley station by analysis of topography. In the case of Innsbruck, a large part of the foehn air arrives from the Wipp Valley, where the station Ellbögen is located in the very northern part of this valley (see 
also topography in Fig. 2.1). It is impossible that foehn blows at Innsbruck but not at Ellbögen. Therefore only times with foehn at Ellbögen need to be considered for a diagnosis of foehn.

After this filtering, still three strong wind-systems and some, mostly down-valley orientated weak winds remain (see Fig. 4.1c). Fig. 4.2 shows all three remaining regimes: Weak wind speeds around $1 \mathrm{~m} \mathrm{~s}^{-1}$ with a small density maximum between 225 and $270^{\circ}$ (see middle part of Fig. 4.2) indicate the "normal" radiatively driven down-valley winds. The higher speed-maximum from a similar direction represents the so called "pre-foehn west wind". Hereby the speed is directly proportional to $\Delta \theta$ (right plot) and thus increases with stronger stability/inversions. Also remarkable is the slight shift in direction from southwest to west with increasing speed.

The density maximum of foehn winds is also well pronounced and can be seen best in the left part of Fig. 4.2, with a mean direction from south and low stability. Low stability $(\Delta \theta \leq 0)$ is also the limiting factor for foehn, because the wind can descend into valley only under mixed conditions. When $\Delta \theta$ is near or below zero, winds from (almost) all directions occur, which indicates that deflected foehn can reach the station from various directions and so makes it more difficult to distinguish foehn from other wind systems. Hereby the most unstable values for westerly directions are a bit more stable than from the other ones because during foehn situations at nights or cold season, cold air flows to Innsbruck from this direction. The density maximum for foehn winds is at $\Delta \theta \approx 0$, i.e. well mixed (adiabatic) conditions between the stations Ellbögen and Innsbruck (see right part of Fig. 4.2).

The smallest portion of all winds are the up-valley winds from easterly directions. They can be radiatively driven or caused by (shallow) cold air advection from the plain through the lower Inn Valley while this cold air does not reach the altitude of Ellbögen. Most of these winds are vertically stably stratified $(\Delta \theta \geq 0)$. The cases that have mixed conditions between Ellbögen and Innbruck could also be either radiatively driven up-valley wind or deflected foehn.

Several meaningful variables for distinguishing foehn can be derived from the Fig. 4.2. Most important seems to be $\Delta \theta$ between the foehn valley station and Innsbruck which could even be used as the primary variable instead of speed. Additionally, a direction information could be useful. Direction itself $(d d)$ could not be used in a statistical model, because it is cyclic. So the normalized zonal $u_{i}=u / f f$ and meridional $v_{i}=v / f f$ wind components are used ( $u$ is the component towards east and $v$ towards north). Also the variables speed ( $f f)$ and relative humidity $(r h)$ which are primary and concomitant classifiers respectively, for Ellbögen should be tested. Since there are three or even four wind systems (if distinguishing between radiatively foehn driven down-valley winds), models with three and four clusters could be sensible. For these multicluster models it makes sense to include the direction 
components because this would implicate one cluster per mean wind direction.

\section{Comparison of Models}

Comparing all these approaches with a long sample of case studies becomes too time-consuming. So they are summarized and compared to the corrected previous method (OFCc) in Table 4.1. For a more detailed examination, results of models were visualized in Fig. 4.3. Very similar looking plots were summarized in groups, and from each one the most sensible model is finally included in Fig. 4.3. If models were undistinguishable upon visual inspection or verification scores (cf. Table 4.1), the simplest one with the fewest variables was chosen for the plots.

Models using only wind speed are not able to detect foehn correctly (see Table 4.1). Most of them (MIE1, MIE2 and MIE3), analyze more than twice the foehn frequency of the OFCc, while scaling speed with the root function (MIE4) leads to one third less foehn than OFCc. A separation just by speed is not possible because of the big overlap of speeds from all three wind systems (compare central part of Fig. 4.2). Adding the difference of potential temperature to the upstream station Ellbögen, leads to much more reasonable results except of MIE7. So scaling with $\ln (f f+0.1)$ is not meaningful. Scaling with $\ln (f f+1)$ leads to pretty same results as no scaling (compare MIE1 with MIE2 and MIE5 with MIE6). Therefore only scaling with the square root function were pursued further.

The first section of more realistic models uses speed as primary variable with at least $\Delta \theta$ as concomitant (MIE5-MIE18, excluding MIE6 amd MIE7). The minimal model MIE5 captures the major strong foehn events but misses the weaker ones (see Fig. 4.3b), and therefore analyzes overall only $3.68 \%$ foehn frequency. The similar MIE8 (see Fig. 4.3c), which uses scaled speed, analyzes foehn from every direction with $\Delta \theta \leq 0$ and yields a higher foehn frequency of $4.79 \%$.

The multiple cluster models, which also include directional information, behave differently. While the three cluster model MIE11 (Fig. 4.3d) includes also the major part of the up-valley wind, the four cluster model MIE18 (Fig. 4.3e) analyzes only south wind. However, none of both extremes captures reality, which is something in between. Overall, only MIE8 from all those models seems to produce plausible results and will be examined in more detail in case studies.

The second main approach, using $\Delta \theta$ as primary variable (see MIE19 MIE32 in Table 4.1), leads to reasonable foehn frequencies between 4 and $7 \%$ without such extremes as in the previous approach.

The simplest model MIE19 (see Fig. 4.3f) uses just $\Delta \theta$ to capture all events as foehn with $\Delta \theta$ between -2.4 and $0.84 \mathrm{~K}$ while the minimum of $\Delta \theta$ is $-5.4 \mathrm{~K}$. The reason for the lower bound is that for values of $\Delta \theta$ below $-2.4 \mathrm{~K}$ the (fitted) density distribution for "no foehn" is larger than the one for foehn (see Fig. 4.4). This 
Table 4.1: List of tested models for the setup with an upstream foehn valley station. Listed are used variables, relative foehn frequency (F. Freq.), differences to the reference frequency ( $\Delta$ F. Freq.), probability of detection (POD) and false alarm ratio (FAR). As reference the corrected OFCc was used. Abbreviations: $f f$ wind speed, $\Delta \theta$ difference in potential temperature to the upper foehn valley station (ELB), rh relative humidity and $u_{i}, v_{i}$ normalized wind components. Concomitant variables are in rectangular brackets. If more than two clusters are used the number in front of " $\mathrm{x}$ " gives the amount of clusters.

\begin{tabular}{|c|c|c|c|c|c|}
\hline Models & Variables & F. Freq. [\%] & $\Delta \mathrm{F}$. Freq. & POD & FAR \\
\hline MIE1 & $f f$ & 11.59 & 7.81 & 100.00 & 67.44 \\
\hline MIE2 & $\ln (f f+1)$ & 12.30 & 8.52 & 100.00 & 69.32 \\
\hline MIE3 & $\ln (f f+0.1)$ & 12.02 & 8.25 & 99.95 & 68.62 \\
\hline MIE4 & $\sqrt{f f}$ & 2.47 & -1.31 & 43.77 & 33.05 \\
\hline MIE5 & $f f,[\Delta \theta]$ & 3.68 & -0.09 & 76.81 & 21.24 \\
\hline MIE6 & $\ln (f f+1),[\Delta \theta]$ & 3.62 & -0.15 & 79.24 & 17.45 \\
\hline MIE7 & $\ln (f f+0.1),[\Delta \theta]$ & 12.98 & 9.21 & 100.00 & 70.93 \\
\hline MIE8 & $\sqrt{f f},[\Delta \theta]$ & 4.79 & 1.02 & 87.28 & 31.22 \\
\hline MIE9 & $f f,[\Delta \theta, r h]$ & 3.75 & -0.02 & 78.87 & 20.66 \\
\hline MIE10 & $\sqrt{f f},[\Delta \theta, r h]$ & 4.57 & 0.79 & 87.30 & 27.88 \\
\hline MIE11 & $3 \mathrm{x}, f f,\left[\Delta \theta, u_{i}, v_{i}\right]$ & 5.74 & 1.98 & 95.69 & 37.23 \\
\hline MIE12 & $4 \mathrm{x}, f f,\left[\Delta \theta, u_{i}, v_{i}\right]$ & 4.08 & 0.31 & 85.40 & 21.16 \\
\hline MIE13 & $3 \mathrm{x}, f f,\left[\Delta \theta, u_{i}, v_{i}, r h\right]$ & 5.34 & 1.57 & 96.19 & 32.16 \\
\hline MIE14 & $4 \mathrm{x}, f f,\left[\Delta \theta, u_{i}, v_{i}, r h\right]$ & 4.03 & 0.26 & 85.44 & 20.06 \\
\hline MIE15 & $3 \mathrm{x}, \sqrt{f f},\left[u_{i}, v_{i}\right]$ & 5.34 & 1.56 & 95.89 & 32.18 \\
\hline MIE16 & $4 \mathrm{x}, \sqrt{f f},\left[\Delta \theta, u_{i}, v_{i}\right]$ & 2.86 & -0.90 & 67.44 & 11.25 \\
\hline MIE17 & $3 \mathrm{x}, \sqrt{f f},\left[\Delta \theta, u_{i}, v_{i}, r h\right]$ & 5.17 & 1.40 & 94.37 & 31.24 \\
\hline MIE18 & $4 \mathrm{x}, \sqrt{f f},\left[\Delta \theta, u_{i}, v_{i}, r h\right]$ & 2.92 & -0.84 & 68.01 & 12.33 \\
\hline MIE19 & $\Delta \theta$ & 5.90 & 2.12 & 92.47 & 40.84 \\
\hline MIE20 & $\Delta \theta,[r h]$ & 7.33 & 3.56 & 99.21 & 48.94 \\
\hline MIE21 & $\Delta \theta,[f f]$ & 5.29 & 1.52 & 91.71 & 34.58 \\
\hline MIE22 & $\Delta \theta,[f f, r h]$ & 7.12 & 3.35 & 99.13 & 47.47 \\
\hline MIE23 & $\Delta \theta,[\sqrt{f f}]$ & 5.13 & 1.36 & 91.79 & 32.48 \\
\hline MIE24 & $\Delta \theta,[\sqrt{f f}, r h]$ & 7.13 & 3.36 & 99.17 & 47.54 \\
\hline MIE25 & $3 \mathrm{x}, \Delta \theta,[f f]$ & 5.40 & 1.62 & 92.14 & 35.57 \\
\hline MIE26 & $3 \mathrm{x}, \Delta \theta,[f f, r h]$ & 5.79 & 2.02 & 95.19 & 38.00 \\
\hline MIE27 & $3 \mathrm{x}, \Delta \theta,\left[f f, u_{i}, v_{i}\right]$ & 3.90 & 0.13 & 80.47 & 22.19 \\
\hline MIE28 & $3 \mathrm{x}, \Delta \theta,\left[f f, u_{i}, v_{i}, r h\right]$ & 4.22 & 0.45 & 86.96 & 22.32 \\
\hline MIE29 & $3 \mathrm{x}, \Delta \theta,\left[\sqrt{f f}, u_{i}, v_{i}\right]$ & 3.92 & 0.15 & 80.90 & 22.18 \\
\hline MIE30 & $3 \mathrm{x}, \Delta \theta,\left[\sqrt{f f}, u_{i}, v_{i}, r h\right]$ & 4.14 & 0.37 & 86.28 & 21.45 \\
\hline MIE31 & $3 \mathrm{x}, \Delta \theta,\left[u_{i}, v_{i}\right]$ & 5.07 & 1.30 & 89.06 & 33.86 \\
\hline MIE32 & $3 \mathrm{x}, \Delta \theta,\left[u_{i}, v_{i}, r h\right]$ & 4.46 & 0.69 & 88.16 & 25.47 \\
\hline
\end{tabular}


(a)


(b)
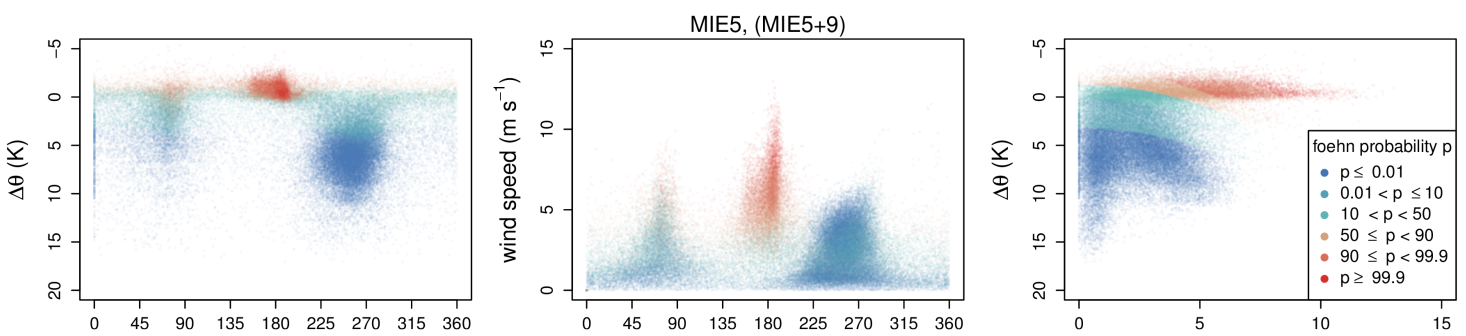

(c)
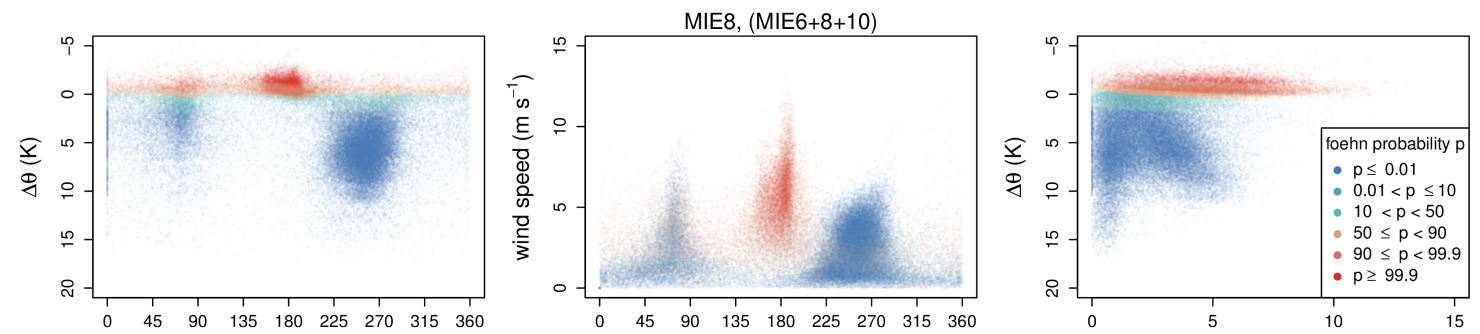

(d)
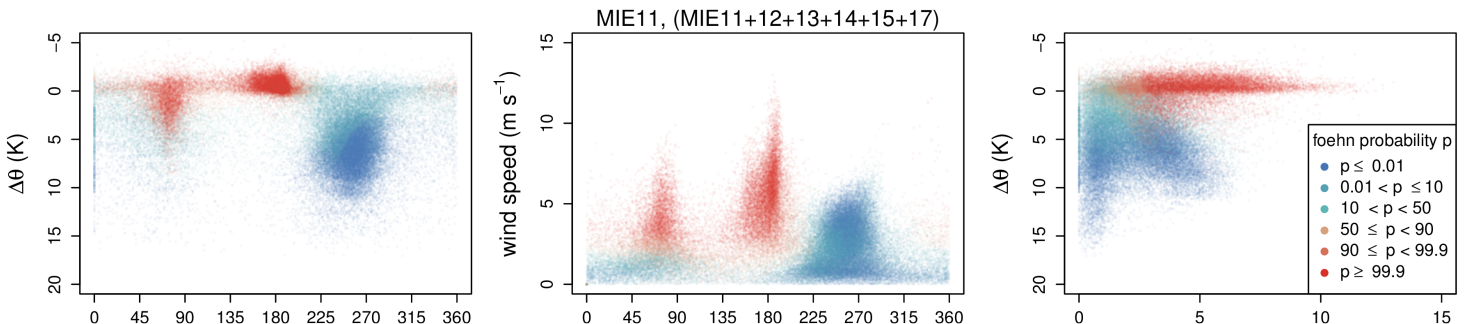

(e)
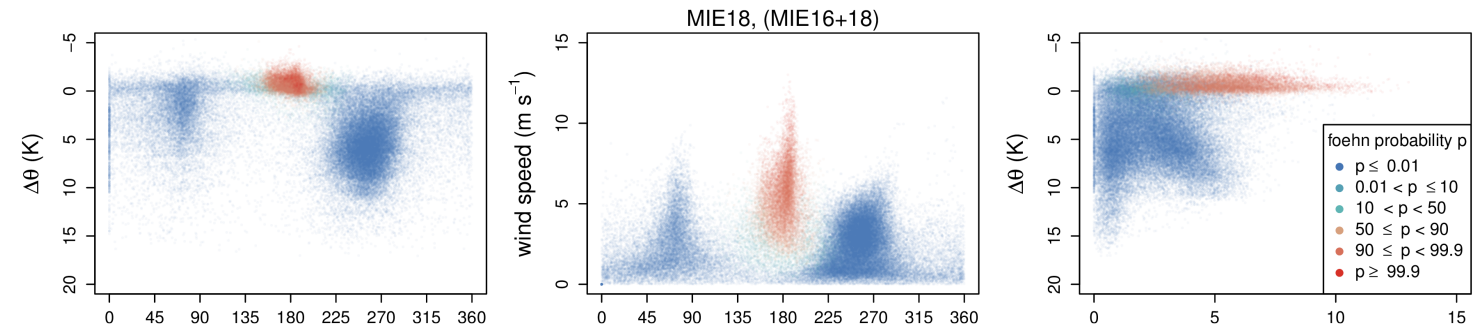

(f)
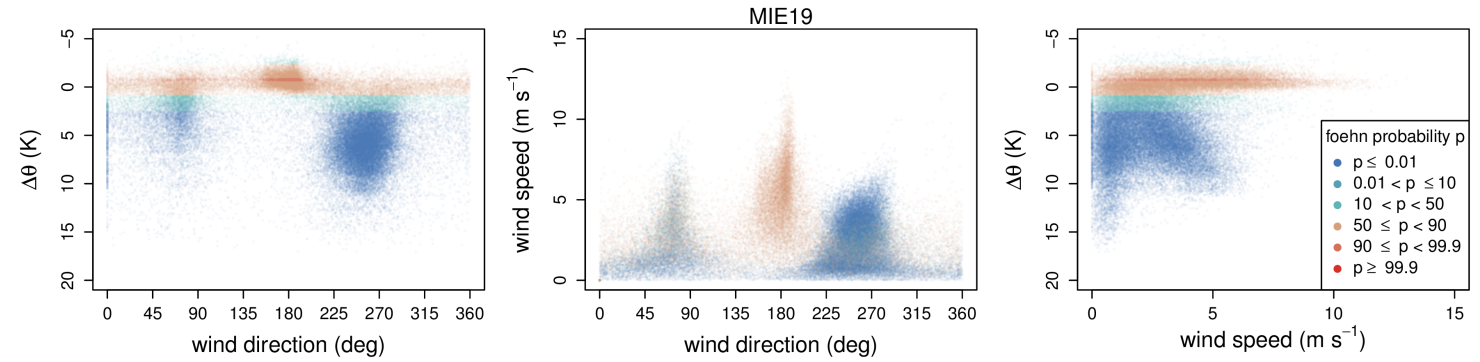
(g)
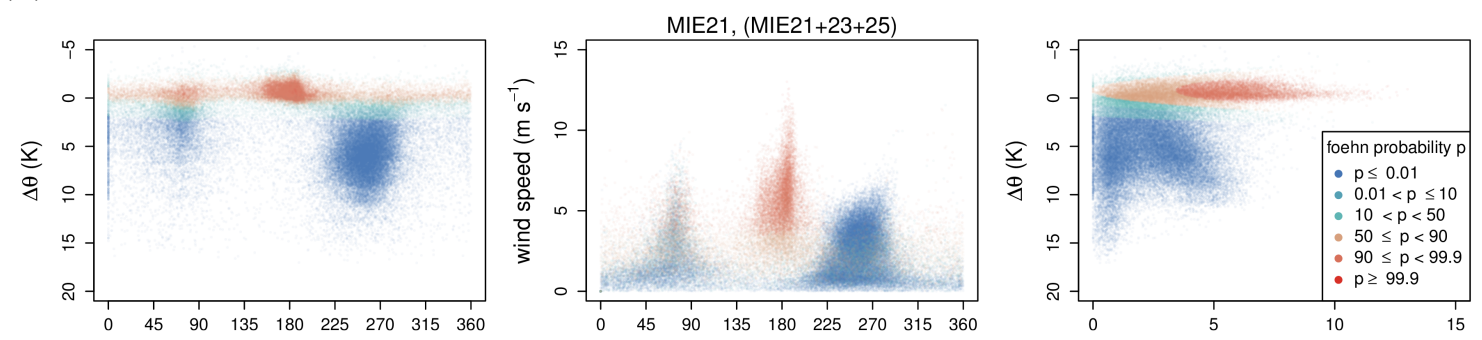

(h)


(i)
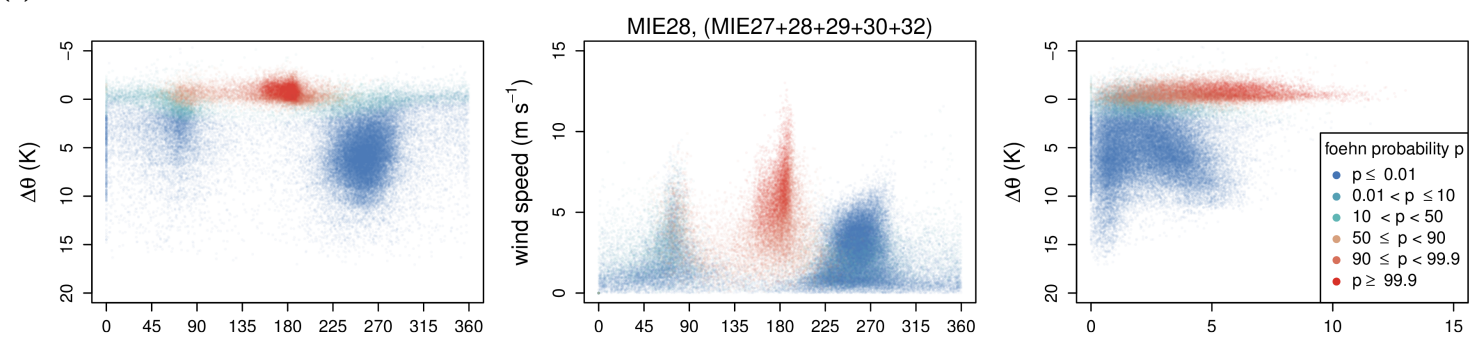

(j)
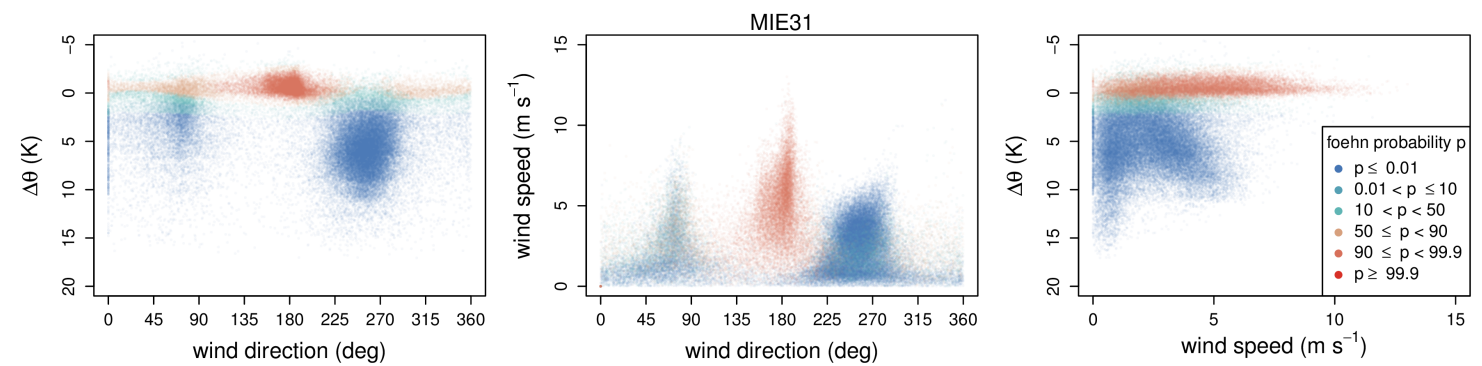

Figure 4.3: Likelihood for foehn (colors) in Innsbruck, analyzed with OFC and different mixture models, using many variable combinations (see Table 4.1). For each group of very similar looking model plots (acronyms in brackets), one representative model is shown. Since all data are visualized when foehn was recorded in Ellbögen, there is no difference between OFC and the corrected OFCc. The same variable combinations like in Fig. 4.2 are plotted. Note that higher foehn probabilities are plotted on the top of the lower ones.

density distribution leads to a maximal foehn probability of $90.1 \%$ for $\Delta \theta=-0.76 \mathrm{~K}$. Examinations in case studies of those extreme low values $(\Delta \theta \leq-4 \mathrm{~K})$ showed that such cases occur on late summer afternoons, when showers or thunderstorms move northward during a foehn situation. With those showers, the precipitated cold air moves from south to north and reaches first Ellbögen, while Innsbruck is still in the warmer air, which leads to those extremely low values of $\Delta \theta$. However the model excludes also values of $\Delta \theta$ between $-4 \mathrm{~K}$ and $-2.4 \mathrm{~K}$, which occur mostly during 

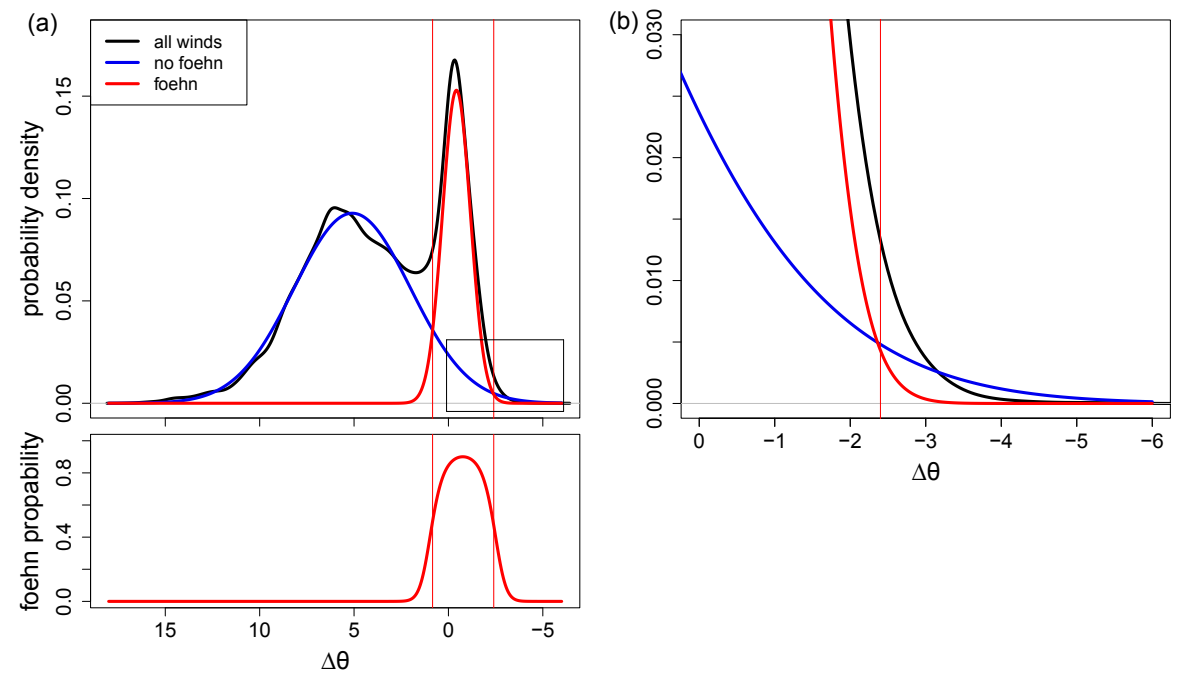

Figure 4.4: Probability densities for $\Delta \theta$ between Innsbruck and Ellbögen during foehn in Ellbögen. Shown are the measured distribution (black line) and the fitted distributions for foehn (red line) and no foehn (blue line) for mixture model MIE19, which uses only $\Delta \theta$ as input (cf. Table 4.1). The vertical red lines indicate the interval with foehn probability $\geq 50 \%$. (a) includes whole distributions of $\Delta \theta$ with fohn probability (MIE19) below. The part in the black rectangle is enlarged in (b).

deep foehn events. Overall, $0.5 \%$ of the filtered time and $0.1 \%$ of the whole data-set are below the limit of $-2.4 \mathrm{~K}$ (with foehn at Ellbögen). Scaling of $\Delta \theta$ with the square root shifts the lower limit down to $-3.6 \mathrm{~K}$ but also increases the upper limit to $1.2 \mathrm{~K}$, which leads to a foehn frequency of $6.4 \%$. If the natural logarithm is used for scaling, the lower limit disappears and the upper limit increases to $2 \mathrm{~K}$, which causes a foehn frequency above $7 \%$. All those scaling methods worsen the results because they include too many stable cases.

Adding speed as concomitant (MIE21, see Fig. 4.3g) does not change much, but higher speeds are now favored with higher foehn probabilities and foehn frequency is reduced by 0.6 percentage points. Models, which also include relative humidity and do not use direction information (group MIE22, see Fig. 4.3h) overestimate the foehn frequency with around $7 \%$, because too many stable cases with significant positive values of $\Delta \theta$ (down-valley and up-valley winds) are included.

In contrast, including relative humidity with models which use direction information with three clusters (MIE28 group, see Fig. 4.3i), only has minor effects. This group is the most similar one to the OFCc (compare with Fig. 4.3a) with a POD of $87 \%$ and a FAR of $22 \%$. The major difference to OFCc is that MIE28 includes fewer down-valley and up-valley winds. Model MIE31 (see Fig. 4.3j) does not use wind speed but only $\Delta \theta$ and direction, which enables it to include also some weak winds from different directions under mixed conditions with $\Delta \theta \approx 0$. However, this 
model only excludes the lowest values of $\Delta \theta$ which are associated with convective outflows.

The models using $\Delta \theta$ as primary variable MIE19, MIE21, MIE28 and MIE31 seem to yield most reasonable results. They were compared together with MIE8 in $30+$ cases-studies. All have advantages in some cases and disadvantages in other ones. Each one captures the foehn cases better than the OFC. Overall MIE19 $(\Delta \theta)$ and MIE31 ( $\Delta \theta$ and direction) seem to be the best ones (see also section 4.3). MIE19 (5.90\% foehn frequency) classifies most foehn case completely, but also includes few up-valley wind cases, which occur mostly during spring and summer when the valley wind system is strongly developed and weak foehn blows in the Wipp Valley. MIE31 (5.07\% foehn frequency) have fewer of those misclassifications, but also do not capture some foehn events, especially the deflected cases completely. (Subsection 4.3 compares also both models in some exemplary cases studies.)

Overall MIE19 is the best model of this group. It use only the difference of potential temperature between the Ellbögen and Innsbruck $(\Delta \theta)$, which decides whether the foehn flow can descend to Inn Valley. This model captures well deflected foehn, an miss only the rare cases when potential temperature in Innsbruck is much higher than in the upstream Wipp Valley. So MIE19 is chosen to serve as reference for farther approaches instead of the OFCc.

\subsubsection{Upstream Crest Station}

Without such a helpful upstream station as Ellbögen where foehn can be easily classified and used as filter for the farther downstream station, a mountain station can be exploited. The approach is similar: Foehn at the leeward valley station Innsbruck is only possible when wind at the crest was from the south. South wind at the crest occurred twice often as foehn at Ellbögen. Figs. 4.1c and d show the two distributions.

The same mixture models were tested as with the up-valley foehn station Ellbögen. They are summarized in Table 4.2. The first four, which use only speed are left out because of poor performance. Instead of them, five models with the primary variable $\Delta \theta$ and four clusters are included since they differ from results with three clusters (in contrast to using Ellbögen where these differences were negligible). For verification, the best model of the previous approach is used as reference (MIE19) instead of the OFCc. Additionally, the part of foehn frequencies with no foehn in Ellbögen (as diagnosed with M3) is shown. This value is a good indicator for the plausibility of the results, since such cases are physically impossibly.

From the information in Table 4.2 it can be seen that that many models lead to unreasonable results. All two-cluster models, which do not use any directional 
information (MIS1 - MIS10 and MIS19 - 24) analyze more than twice as much foehn as the reference model MIE19 and record foehn in Innsbruck without foehn in the Wipp Valley for around 5 percentage points. All models with more than approximately one percentage frequency without foehn in Ellbögen (MIS15, MIS17, MIS25, MIS26, MIS28, MIS30, MIS32, MIS33) were also excluded from further, more detailed examinations.

The remaining models were again grouped by similarity and one representative result is shown in Fig. 4.5. MIS11 uses three clusters with speed as primary variable and $\Delta \theta$ and direction information as concomitants. It includes only data with high speeds and low stability, i.e. strong foehn cases, and a few strong upvalley winds (see Fig. 4.5a). Using an additional cluster increases the POD, but also includes more (stable) up-valley winds (MIS12, see Fig. 4.5b). If the wind speed is scaled with the square root function (MIS16), the model becomes very strict and analyzed only the obvious correct foehn events (see Fig. 4.5c). Almost no foehn cases were analyzed when no foehn was recorded in Wipp Valley (0.04\%) and the FAR is very low with $4.63 \%$. However, all those models are not able to capture deflected foehns.

Using $\Delta \theta$ as primary variable, the sector of included direction widens. MIS27 uses speed and direction information as concomitant variables and captures almost $60 \%$ of foehn with a still low FAR. Note that MIS31, which does not use speed yields very similar results. Some directions are included from the sector between $80^{\circ}$ and $220^{\circ}$, with a clear maximum from south (see Fig. $4.5 \mathrm{~d}$ ). Overall this model misses to classify 2.11 percentage points compared to reference MIE19. If relative humidity is added additionally to this three cluster model, the analyzed foehn frequency doubles (see MIS28 in Table 4.2). When four clusters are used with these co-variables (speed, direction, relative humidity), the frequencies becomes similar to the ones analyzed with the reference model. This model MIS35 has the lowest difference with only 0.34 percentage points less foehn than the reference. But the identical periods of common foehn with the reference are only $74 \%$ of all foehn and 0.77 percentage points are even analyzed when foehn is impossible (no foehn at Ellbögen, "ÆF. ELB" in Table 4.2). Fig. 4.5e shows, that now some deflected foehns are captured from all directions. But a few southerly winds with $\Delta \theta$ around $2 \mathrm{~K}$, i.e. shallow foehn, are missing. If a similar model without speed (MIS37) is run, the results worsen a little: compare MIS35 to MIS37 in Table 4.2. 
Table 4.2: List of tested models for the setup with an upstream crest station. Same as Table 4.1, but reference is now MIE19 (Table 4.1) and $\Delta \theta$ refers to Sattelberg. Additionally, the column " $\notin \mathrm{F}$. ELB" gives the percentage points of cases when the model analyzed foehn in Innsbruck but no foehn in Ellbögen was recorded.

\begin{tabular}{|c|c|c|c|c|c|c|}
\hline Models & Variables & F. Freq. [\%] & $\Delta \mathrm{F}$. Freq. & $\notin$ F. ELB & POD & FAR \\
\hline MIS5 & $f f,[\Delta \theta]$ & 17.87 & 11.97 & 5.48 & 88.35 & 70.84 \\
\hline MIS6 & $\ln (f f+1),[\Delta \theta]$ & 17.64 & 11.76 & 5.40 & 87.33 & 70.81 \\
\hline MIS7 & $\ln (f f+0.1),[\Delta \theta]$ & 14.12 & 8.24 & 4.08 & 89.17 & 62.76 \\
\hline MIS8 & $\sqrt{f f},[\Delta \theta]$ & 16.43 & 10.55 & 4.63 & 89.05 & 68.04 \\
\hline MIS9 & $f f,[\Delta \theta, r h]$ & 18.15 & 12.27 & 5.62 & 90.09 & 70.73 \\
\hline MIS10 & $\sqrt{f f},[\Delta \theta, r h]$ & 16.77 & 10.89 & 4.83 & 90.11 & 68.31 \\
\hline MIS11 & $3 \mathrm{x}, f f,\left[\Delta \theta, u_{i}, v_{i}\right]$ & 2.99 & -2.89 & 0.19 & 44.77 & 11.73 \\
\hline MIS12 & $4 \mathrm{x}, f f,\left[\Delta \theta, u_{i}, v_{i}\right]$ & 4.33 & -1.55 & 0.61 & 57.05 & 22.24 \\
\hline MIS13 & $3 \mathrm{x}, f f,\left[\Delta \theta, u_{i}, v_{i}, r h\right]$ & 2.95 & -2.93 & 0.20 & 44.03 & 11.90 \\
\hline MIS14 & $4 \mathrm{x}, f f,\left[\Delta \theta, u_{i}, v_{i}, r h\right]$ & 4.25 & -1.63 & 0.60 & 56.20 & 22.03 \\
\hline MIS15 & $3 \mathrm{x}, \sqrt{f f},\left[u_{i}, v_{i}\right]$ & 5.99 & 0.11 & 1.22 & 71.08 & 30.07 \\
\hline MIS16 & $4 \mathrm{x}, \sqrt{f f},\left[\Delta \theta, u_{i}, v_{i}\right]$ & 3.10 & -2.78 & 0.04 & 50.08 & 4.63 \\
\hline MIS17 & $3 \mathrm{x}, \sqrt{f f},\left[\Delta \theta, u_{i}, v_{i}, r h\right]$ & 6.16 & 0.28 & 1.38 & 71.04 & 31.98 \\
\hline MIS18 & $4 \mathrm{x}, \sqrt{f f},\left[\Delta \theta, u_{i}, v_{i}, r h\right]$ & 3.05 & -2.83 & 0.04 & 49.35 & 4.54 \\
\hline MIS19 & $\Delta \theta$ & 41.99 & 36.11 & 24.47 & 96.09 & 86.50 \\
\hline MIS20 & $\Delta \theta,[r h]$ & 12.14 & 6.25 & 4.00 & 93.84 & 54.39 \\
\hline MIS21 & $\Delta \theta,[f f]$ & 19.05 & 13.17 & 6.36 & 86.71 & 73.16 \\
\hline MIS22 & $\Delta \theta,[f f, r h]$ & 11.51 & 5.63 & 3.53 & 93.09 & 52.30 \\
\hline MIS23 & $\Delta \theta,[\sqrt{f f}]$ & 19.06 & 13.18 & 6.37 & 86.84 & 73.13 \\
\hline MIS24 & $\Delta \theta,[\sqrt{f f}, r h]$ & 11.52 & 5.64 & 3.53 & 93.11 & 52.34 \\
\hline MIS25 & $3 \mathrm{x}, \Delta \theta,[f f]$ & 7.14 & 1.25 & 1.12 & 85.98 & 28.94 \\
\hline MIS26 & $3 \mathrm{x}, \Delta \theta,[f f, r h]$ & 10.27 & 4.39 & 2.78 & 92.60 & 46.84 \\
\hline MIS27 & $3 \mathrm{x}, \Delta \theta,\left[f f, u_{i}, v_{i}\right]$ & 3.78 & -2.11 & 0.17 & 58.38 & 8.80 \\
\hline MIS28 & $3 \mathrm{x}, \Delta \theta,\left[f f, u_{i}, v_{i}, r h\right]$ & 10.25 & 4.37 & 2.80 & 92.60 & 46.73 \\
\hline MIS29 & $3 \mathrm{x}, \Delta \theta,\left[\sqrt{f f}, u_{i}, v_{i}\right]$ & 3.75 & -2.13 & 0.16 & 58.16 & 8.65 \\
\hline MIS30 & $3 \mathrm{x}, \Delta \theta,\left[\sqrt{f f}, u_{i}, v_{i}, r h\right]$ & 10.16 & 4.28 & 2.74 & 92.50 & 46.31 \\
\hline MIS31 & $3 \mathrm{x}, \Delta \theta,\left[u_{i}, v_{i}\right]$ & 3.64 & -2.24 & 0.14 & 56.46 & 8.45 \\
\hline MIS32 & $3 \mathrm{x}, \Delta \theta,\left[u_{i}, v_{i}, r h\right]$ & 10.31 & 4.43 & 2.88 & 92.83 & 46.91 \\
\hline MIS33 & $4 \mathrm{x}, \Delta \theta,[f f, r h]$ & 6.10 & 0.21 & 0.99 & 77.15 & 25.36 \\
\hline MIS34 & $4 \mathrm{x}, \Delta \theta,\left[f f, u_{i}, v_{i}\right]$ & 3.87 & -2.01 & 0.18 & 59.32 & 9.51 \\
\hline MIS35 & $4 \mathrm{x}, \Delta \theta,\left[f f, u_{i}, v_{i}, r h\right]$ & 5.54 & -0.34 & 0.77 & 73.99 & 21.30 \\
\hline MIS36 & $4 \mathrm{x}, \Delta \theta,\left[u_{i}, v_{i}\right]$ & 3.63 & -2.25 & 0.14 & 56.31 & 8.47 \\
\hline MIS37 & $4 \mathrm{x}, \Delta \theta,\left[u_{i}, v_{i}, r h\right]$ & 5.29 & -0.59 & 0.71 & 71.18 & 20.59 \\
\hline
\end{tabular}


(a)
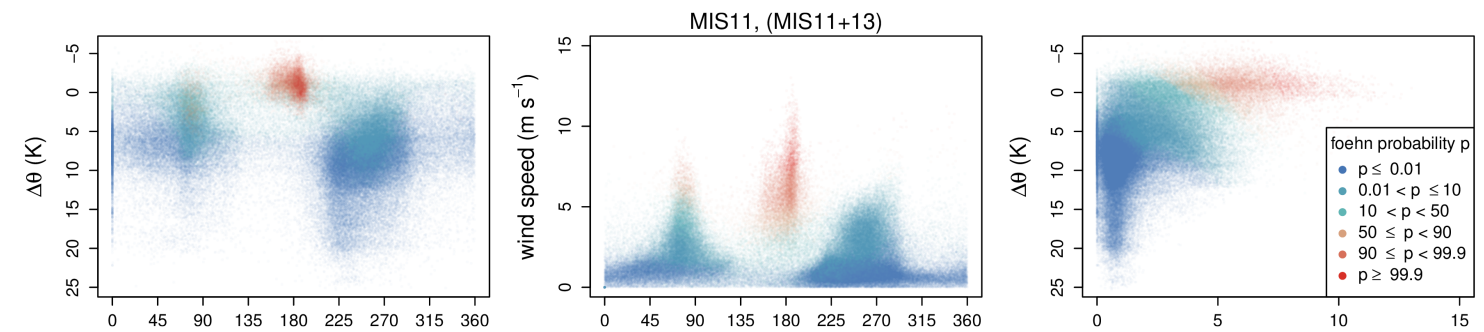

(b)
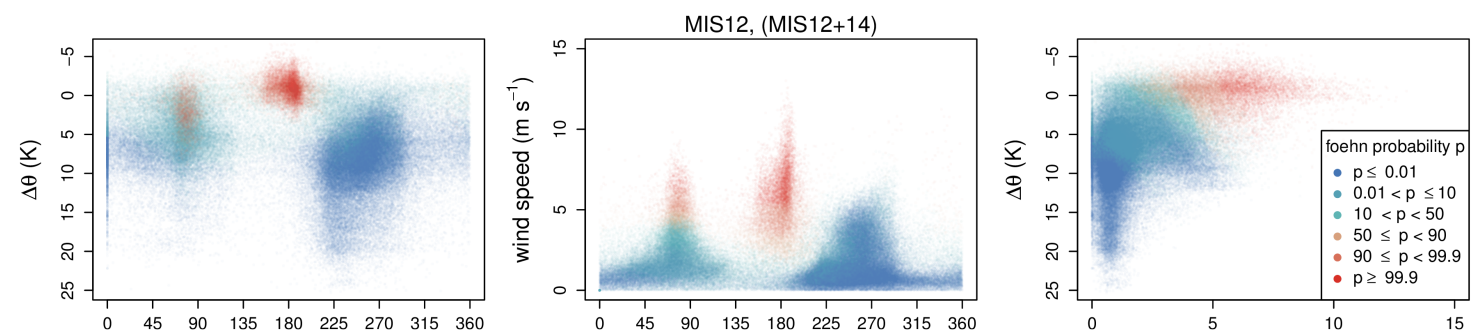

(c)
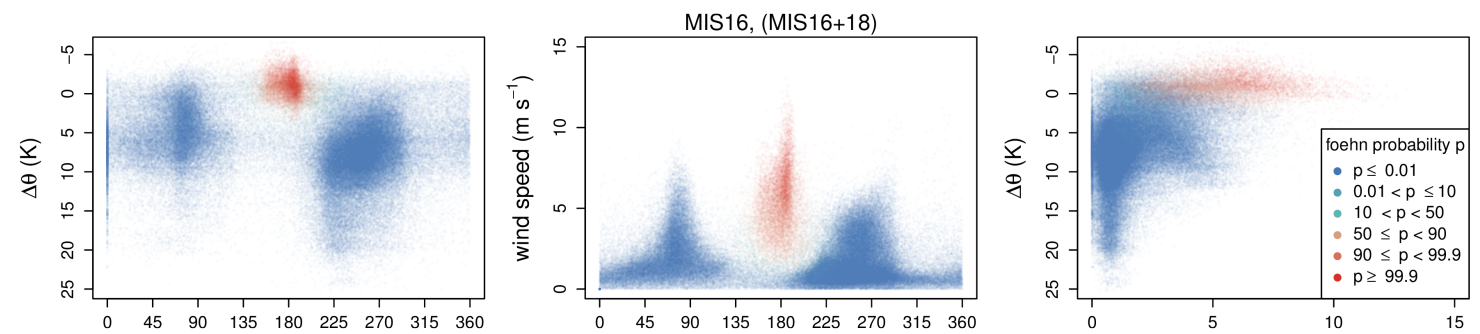

(d)
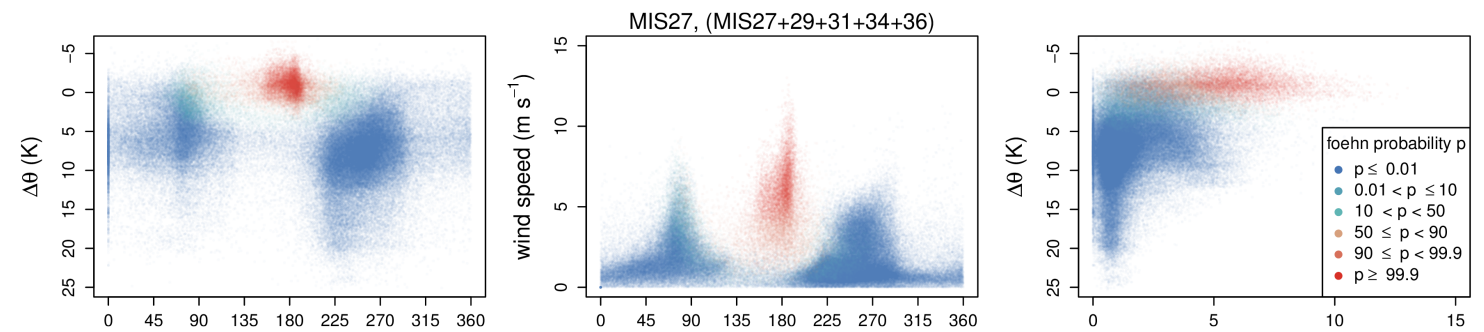

(e)
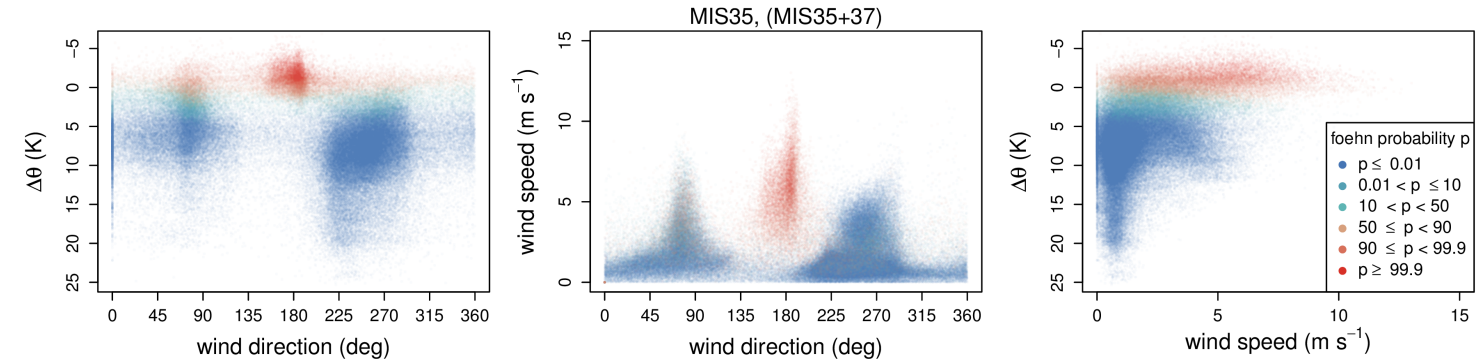

Figure 4.5: Likelihood for foehn (colors) in Innsbruck, analyzed with different mixture models, using many variable combinations (see Table 4.2). The very similar looking model plots are summarized in groups (in brackets) and for each one a representative model is shown. The data are visualized when south wind was measured at Sattelberg. Same variable combinations as in Fig. 4.2 are plotted, but $\Delta \theta$ refers now to Sattelberg. Note that higher foehn probabilities are plotted on the top of the lower ones. 


\subsubsection{Only Valley Station}

If no upstream station is available, the last remaining possibility is a classification method as used in Ellbögen (see Chapter 3), but with a tight foehn wind sector. As shown in Fig. 4.1b, the usual (south) foehn direction can be distinguished from the other two wind systems. The minima in direction frequencies for wind speeds above $4 \mathrm{~m} \mathrm{~s}^{-1}$ on both sides of the south direction form the limits which are used to filter. So the models were run for data which fulfill the condition $130^{\circ} \leq d d_{I B K} \leq 210^{\circ}$. Overall $7.8 \%$ of all winds occurs from this sector and $4.08 \%$ additionally have foehn at Ellbögen. Winds that occurs from this sector are foehn winds with strong speeds and down-slope winds with weak speeds (the speed distribution is very similar to Fig. 2 in the article in chapter 3), which enables it to distinguish them just by this single speed variable.

The four models using only speed (MI1 - MI4) and the same approaches as used in Ellbögen (MI02 - MI05) are summarized in Table 4.3. As for Ellbögen, the approaches using upstream stations are also able to separate foehn from downslope winds properly (see Fig. 4.6). Note that the amount of no-foehn winds is here much lower than in the Wipp Valley, because the direction sector which is here used excludes the down-valley winds. The foehn frequency is around $3.6 \%$ from this wind-sector.

Different scaling functions for speed were tested. As in previous results for Innsbruck, scaling with $\ln (f f+1)$ and the square root, respectively, makes no difference. MI3 which uses $\ln (f f+0.1)$ has the highest speed limit and thus the lowest foehn frequency. The un-scaled MI1 has almost the same foehn frequency as the more complicated models MI03 - MI05. This confirms the result of the study for the

Table 4.3: List of tested models for valley station Innsbruck with constricted direction sector $130^{\circ} \leq d d_{I B K} \leq 210^{\circ}$. As in Table 4.2, MIE19 is still used as reference. Additionally, the thresholds of wind speed are included ( $f f$-limit) for models using only speed from the valley station Innsbruck to separate foehn from other winds.

\begin{tabular}{clccccc}
\hline \hline Models & Variables & $f f$-limit $\left[\mathrm{m} \mathrm{s}^{-1}\right]$ & F. Freq. [\%] & $\Delta$ F. Freq. & POD & FAR \\
\hline MI1 & $f f$ & 1.7 & 3.62 & -2.26 & 53.17 & 13.35 \\
MI2 & $\ln (f f+1)$ & 2.4 & 3.17 & -2.71 & 50.13 & 6.81 \\
MI3 & $\ln (f f+0.1)$ & 3.4 & 2.64 & -3.24 & 43.01 & 4.06 \\
MI4 & $\sqrt{f f}$ & 2.4 & 3.17 & -2.72 & 50.06 & 6.74 \\
\hline MI02 & $f f,\left[\Delta \theta_{E L B}\right]$ & - & 3.93 & -1.97 & 54.39 & 18.40 \\
MI03 & $f f,\left[\Delta \theta_{E L B}, r h\right]$ & - & 3.66 & -2.24 & 54.69 & 11.85 \\
MI04 & $f f,\left[\Delta \theta_{S A T}\right]$ & - & 3.58 & -2.32 & 54.87 & 9.53 \\
MI05 & $f f,\left[\Delta \theta_{S A T}, r h\right]$ & - & 3.60 & -2.30 & 55.01 & 9.84 \\
\hline
\end{tabular}



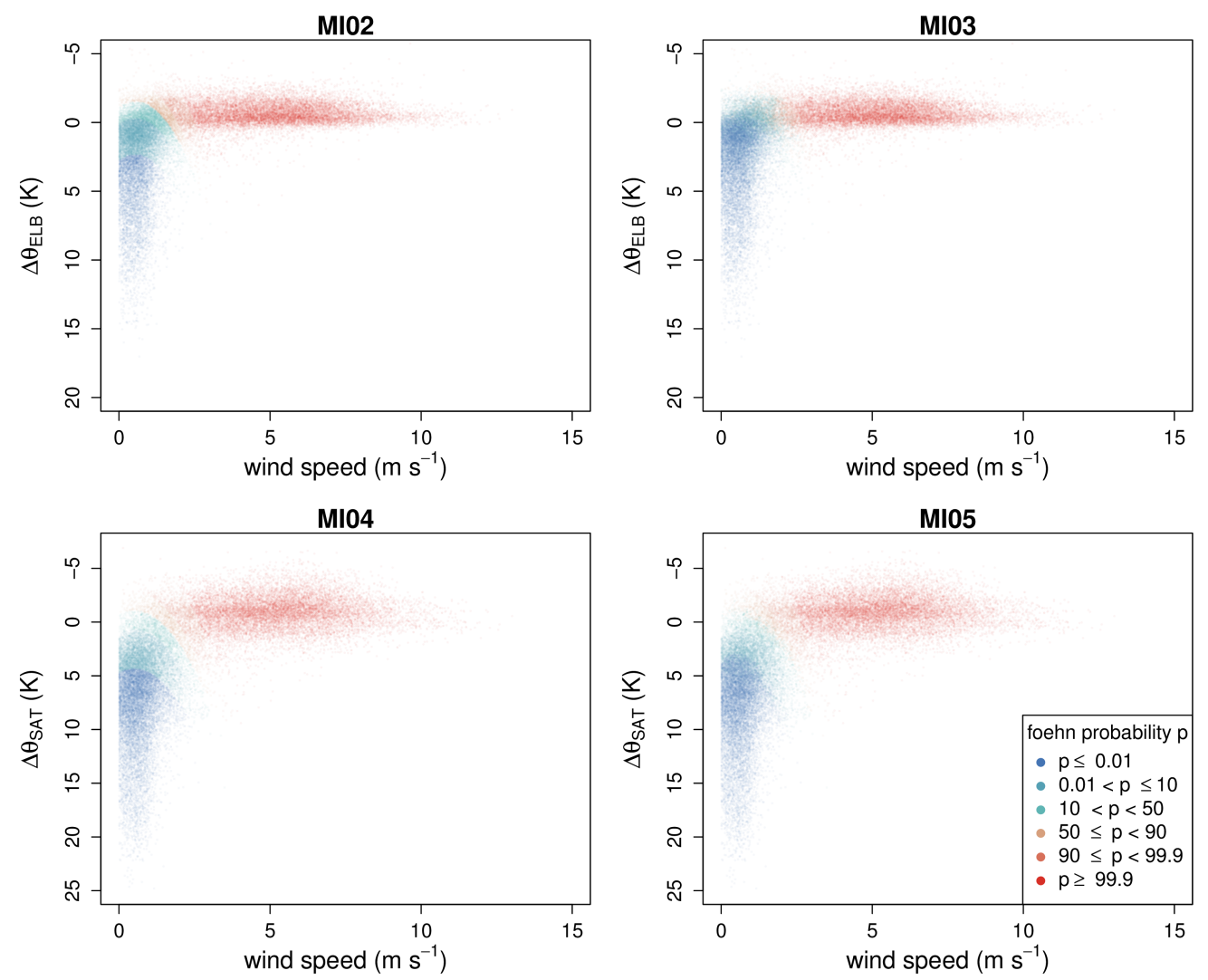

Figure 4.6: Likelihood of foehn (colors) for wind speed and potential temperature difference $\left(\Delta \theta=\theta_{\text {upstream station }}-\theta_{\text {valley }}\right)$ combinations for wind from the predefined foehn wind sector $130^{\circ} \leq d d_{I B K} \leq 210^{\circ}$. Each point represents a 10 min mean. Top (MI02 and MI03): Ellbögen is used as the upstream station, bottom (MI04 and MI05): Sattelberg.

simple station Ellbögen.

Compared to the best model MIE19, the models MI1 and MI4 capture half of all foehn events in Innsbruck. With these approaches it is not possible to classify the complete range of foehn in Innsbruck, because the preprocessing already excludes all deflected foehns with directions differing from south. Limiting the direction sector for the results of MIE19 leads to a foehn frequencies 3.4\%. This is in the range of results from models MI1 and MI4.

Preprocessing with wind direction leads to similar results as MIS16. MIS16 analyzed $3.10 \%$ overall foehn frequency (see Table 4.2) and limits implicitly the foehn sector to $140-220^{\circ}$ (compare left panel of Fig. 4.5c). The model is similarly constructed as the ones of this section with speed as main variable and $\Delta \theta$ as concomitant. The difference is that it includes the directions directly as variable in the mixture model $\left(u_{i}\right.$ and $\left.v_{i}\right)$. So the direction sector is chosen automatically instead of by preprocessing. Model MIS27 (3.78\% foehn frequency) is also very similar (Fig. 4.5d) but it also includes few cases with directions down to $80^{\circ}$.

The presented foehn classification setups can capture the full range of deflected 
Table 4.4: Summary of OFC and best statistical models for the station Innsbruck with two major different measurement setups with an easy classifiable foehn station Ellbögen (MIE) and with only a upstream crest station Sattelberg (MIS). Shown are the used reference stations, the variables, and the resulting relative foehn frequencies. For description of variables see Table 4.1. Note that the models marked with ${ }^{*}$ can capture only direct foehn.

\begin{tabular}{cclc}
\hline \hline Models & upstream Station & Variables & F. Freq. [\%] \\
\hline OFC & Sattelberg & $d d, f f, \Delta \theta$ & 4.15 \\
MIE19 & Ellbögen & $\Delta \theta$ & 5.90 \\
MIE31 & Ellbögen & $3 \mathrm{x}, \Delta \theta,\left[u_{i}, v_{i}\right]$ & 5.07 \\
MIS27* & Sattelberg & $3 \mathrm{x}, \Delta \theta,\left[f f, u_{i}, v_{i}\right]$ & 3.78 \\
MIS35* $^{*}$ & Sattelberg & $4 \mathrm{x}, \Delta \theta,\left[u_{i}, v_{i}, r h\right]$ & 5.54 \\
\hline
\end{tabular}

foehn (MIE19) or only direct foehn from south (e.g. MIS16, MIS27, MI12-MI15). Ultimately it depends on the user, which one is preferred. Deflected foehn fulfills the WMO definition of foehn completely, because the wind descends on the lee side down into the valley, although on a detour. For some applications, however only direct foehn might be of interest.

\subsection{Case Studies}

After the most reasonable models were extracted from a multitude of combinations of variables by statistical comparison in section 4.2 , they were examined for individual cases. There the best models of the two main approaches (with reference station Ellbögen and Sattelberg) could be selected and compared to the earlier method OFC. Table 4.4 summarizes these models. Note that MI1 is very similar to MIS27 and thus not included in the case studies.

Four cases were chosen, which cover all different (south) foehn manifestations at Innsbruck. They illustrate the features of foehn at this location and show how the different mixture model approaches behave.

\subsubsection{Classical Foehn Case 25 April 2012}

The foehn case of the 25 April 2012 (see Fig.4.7) is an example of a typical foehnday in Innsbruck. In the morning around 09 UTC the foehn starts in the Wipp Valley. In the late morning when the air in Inn Valley warms to the (potential) temperature of the foehn flow a classical foehn breakthrough can be seen. Wind shifts to south with a strong increase of speed accompanied by an abrupt warming 


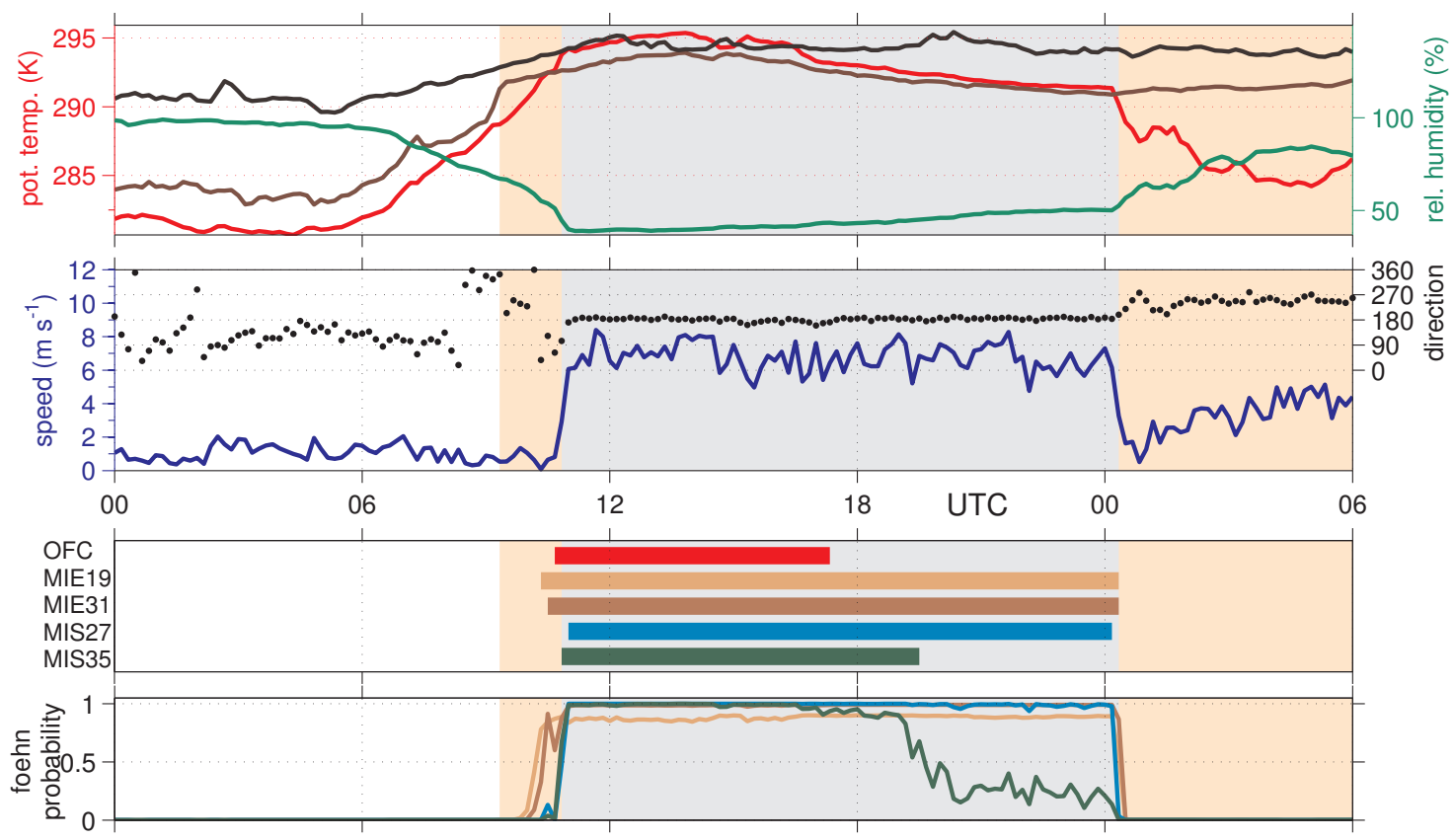

Figure 4.7: Time series from 00 UTC 25 April 2012 to 06 UTC 26 April 2012 for the Valley Station Innsbruck with (first row) potential temperature (red line) and relative humidity (green line) and the potential temperatures of the upstream crest stations Sattelberg (black line) and the upstream foehn valley station Ellbögen (brown line). Second row: wind direction (black dotted line) and wind speed (blue line) for Innsbruck. Third row: Periods of foehn diagnosed by each mixture model MIE19, MIE31, MIS27 and MIS35 (cf. Table 4.4) having a foehn probability $\geq 50 \%$, and the objective foehn classification (OFC). Fourth row: Foehn probabilities from those mixture models with same colors as in third row. Periods of foehn in the upstream Wipp Valley (Ellbögen) classified with M3 are shaded light orange in the background of all rows, while the gray shading indicates the manually analyzed periods of foehn in Innsbruck, which include also foehn in Wipp Valley.

with a steep decrease of relative humidity. The onset is captured by all models. The models using Ellbögen as reference analyze it some decaminutes earlier than those with Sattelberg, because the potential temperature of the lower upstream station is reached a bit earlier. In the evening the potential temperature difference between both valley stations and crest station increases, which is caused by mixing-in of could air from upstream side valleys or/and because the foehn becomes shallower. Thus the criterion for $\Delta \theta$ of OFC is no longer fulfilled already before 18 UTC. Because of this, the OFC captures only the half time of this foehn event. Also MIS35 misses the foehn two hours later, but still indicates a foehn probability of around $25 \%$. This behavior could already be seen from Fig. 4.5e (left panel), where the south winds with $\Delta \theta$ values above around $2 \mathrm{~K}$ are not included. All other models capture 
the whole foehn till the end, which can be clearly seen shortly after 00 UTC, with strong decrease of temperature and an increase in relative humidity, while the wind weakens and shifts to west. Nocturnal cooling in the foehn-free part of Inn Valley west of Innsbruck causes this ending. This cold air flows eastward (down-valley) and undercut the warmer foehn. With further cooling, the difference in potential temperature becomes larger, and the down-valley wind strengthens caused by foehn aloft (pre-foehn west wind). This behavior could already be seen in the right panel of Fig. 4.2.

\subsubsection{Foehn Case with deflected foehn on 07/08 November 2011}

The foehn event in Innsbruck from 09 UTC 07 November to 20:30 UTC 08 November 2011 with a short foehn pause $(1.5 \mathrm{~h})$ during the night is characterized by many periods with deflected foehn from various directions (see Fig. 4.8). Since the potential temperature of Innsbruck remains the same, or even a bit higher than at Ellbögen and the relative humidity also remained unchanged, the descending foehn air must still reach the station Innsbruck, especially during night. Notable is that between 00 and 04 UTC the directions remains unchanged from northwest, while the foehn lifts off for $1.5 \mathrm{~h}$ and set on again. In contrast to these northwestern foehn winds from down-valley wind direction, the period between 07 and 09 UTC 08 November

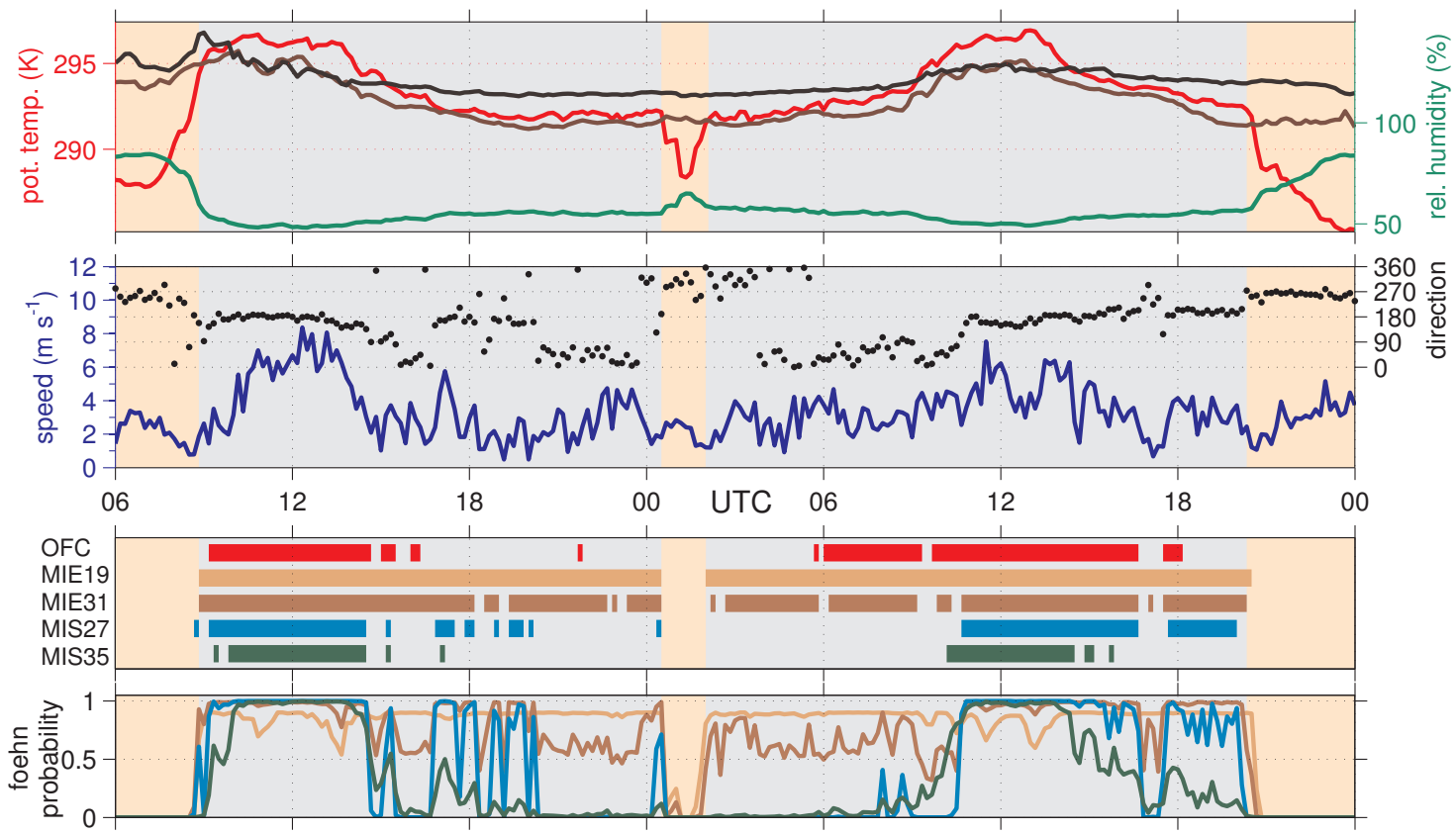

Figure 4.8: As Fig. 4.7, but for 06 UTC 07 November 2011 to 00 UTC 09 November 2011. 
shows that foehn can also reach the valley station from up-valley wind direction (80 $\left.-110^{\circ}\right)$.

Model MIE19, which uses only the potential temperature difference to Ellbögen captures the whole foehn period perfectly. But noticeable are the decreasing foehn probabilities during those times, when the potential temperature of Innsbruck exceeds the one of Ellbögen by several degrees (13:30 UTC 07 November, 11:30 UTC and 13 UTC 08 November). These decreased foehn probabilities within those low values of $\Delta \theta$ are caused by the fitted distributions from this models as shown in Fig. 4.4. In these cases potentially warmer air from aloft turbulently mixes into the (lower) foehn flow on the way from Ellbögen to Innsbruck and so causes the very low values of $\Delta \theta$.

Model MIE31, which also includes direction, reduces the foehn probability significantly, when the foehn does not come directly from south (see fourth row in Fig. 4.8). For some short periods this leads even to a foehn probabilities below $50 \%$.

The models with Sattelberg as reference (MIS27 and MIS35) have much greater problems to analyze this foehn event completely. They diagnose only winds directly from south as foehn, and reduce the foehn probabilities for other directions to almost zero. MIS35, which uses one cluster more than MIS27 and additionally includes relative humidity, captures clearly less foehn than MIS27.

Overall models with Ellbögen as reference (MIE19 and MIE31) diagnose this foehn event considerably better than the OFC does. MIS27 has overall the same amount of foehn time as OFC, but with temporal differences. MIS35 is even worse than OFC.

\subsubsection{Weak Foehn Cases on 04/05 December 2011}

The foehn cases on 04 and 05 December 2011 are difficult to classify even for a human expert (see Fig. 4.9). The first event on the afternoon of 04 December shows the onset only by a very slight shift in direction from west to a more southerly direction, accompanied by a speed increase and typical foehn signals in temperature and humidity. Since the potential temperature remains always lower than at the upstream stations, air at Innsbruck is presumably a mixture of foehn and the cold air in valley. The following foehn periods during night to 05 December show in general the same characteristics. A (short) exception is the time around 22 UTC, when the south component is more clearly pronounced.

Only MIE19 is able to recognize this foehn events. It analyzes all foehn periods with foehn probabilities around 70\% except of the last short period around 01 UTC on 05 December. Model MIE31 indicates increased foehn probabilities during most times of this event, but rarely exceeds the threshold of $50 \%$. Models which use Sat- 


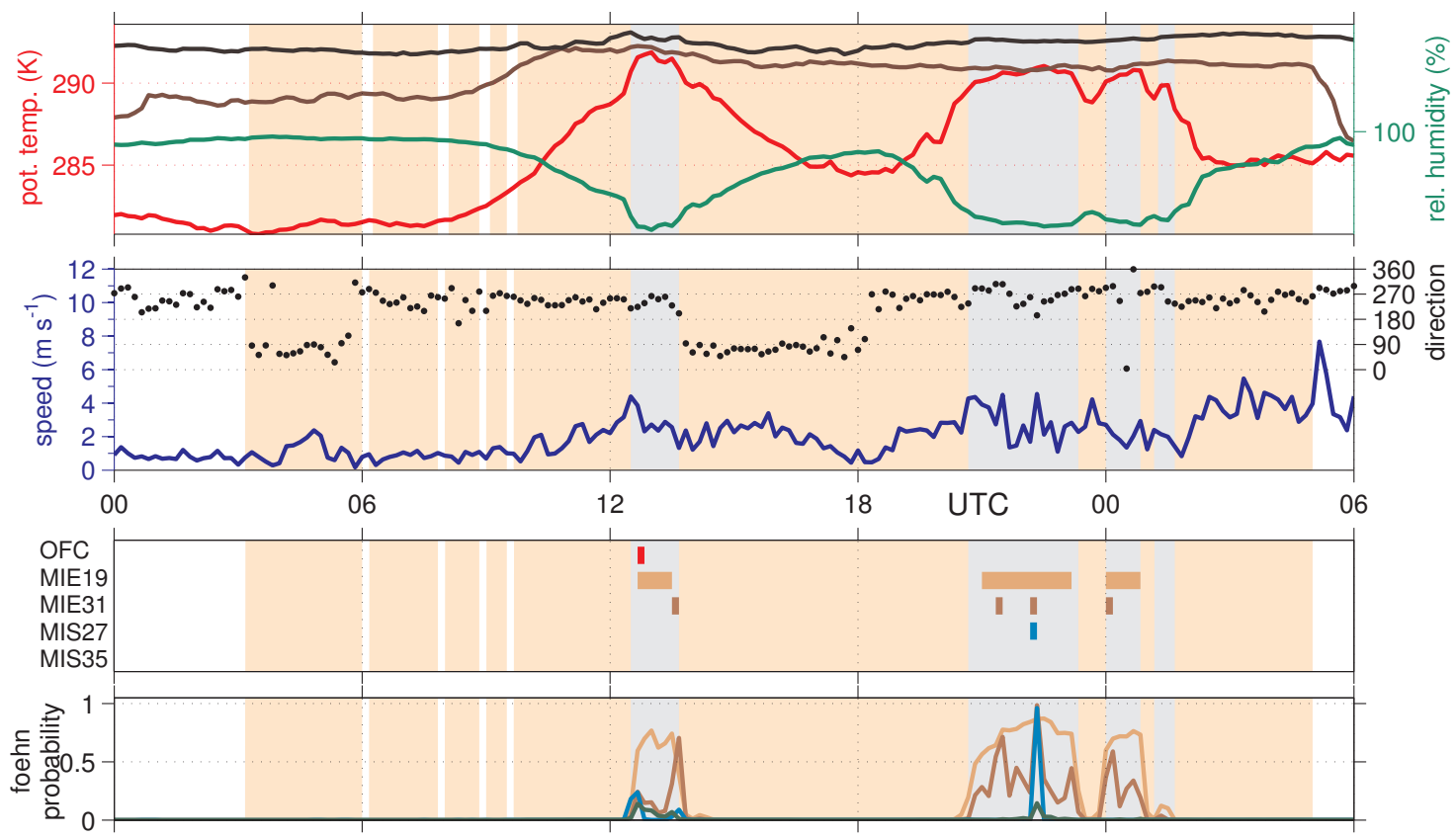

Figure 4.9: As Fig. 4.7, but for 00 UTC 04 December 2011 to 06 UTC 05 December 2011.

telberg as reference (MIS27 and MIS35) miss them almost completely, only MIS27 analyzes a very short period with foehn direction from south (22 UTC 04 December) correctly.

Compared to the OFC, which captures only a very short period at the beginning of the first period, MIE19 and MIE31 capture more, MIS27 the same amount of foehn, and only MIE35 less.

\subsubsection{Misclassification of Up-valley Wind 02 April 2012}

On 02 April 2012 foehn does not reach Innsbruck (see Fig.4.10). In late afternoon weak foehn begins in the Wipp Vally, while strong radiatively driven up-valley wind persists in Innsbruck with average wind speeds of up to $6 \mathrm{~m} \mathrm{~s}^{-1}$. Even when the potential temperature in Innsbruck is higher than those of both (in foehn direction) upstream stations, the foehn can not descend into the the Inn Valley, because the up-valley wind is so strong that it forces the weak foehn to separate at the edge of Wipp Valley.

Such situations occur especially during spring and summer and cause problems for all automatic foehn classification methods. The models, which use only data when foehn was recorded in Ellbögen (MIE19 and MIE31), miss-classify the whole late afternoon after foehn begins in Wipp Valley, while MIE31 which also use direction as input, misclassifies around one hour less. MIS27 achieves the best results 


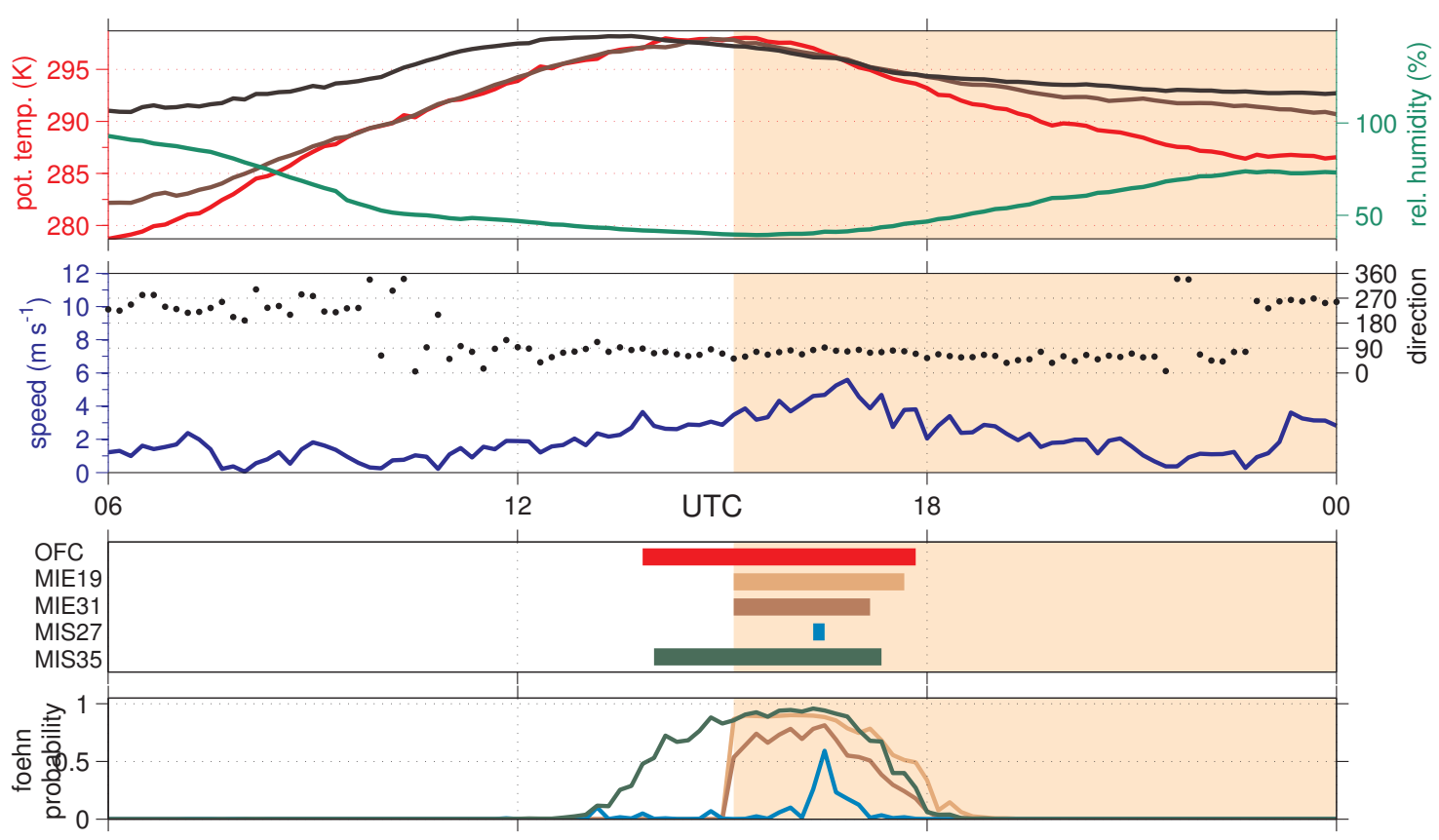

Figure 4.10: As Fig. 4.7, but for 06 UTC 02 April 2012 to 00 UTC 03 April 2012.

since it separates foehn directions to be only from south (compare scatter-plot in Fig. 4.5d) and thus only mistakes a short period after 16 UTC with a foehn probability slightly above 50\%. In contrast to this the model MIS35 miss-classifies the largest amount of up-valley wind as foehn, even if there was no foehn in Wipp Valley. Nevertheless all of those mixture model have fewer misclassifications than the OFC has. 


\section{Chapter 5}

\section{Climatology of Föhn for Ellbögen and Innsbruck}

A statistical and case study-based evaluation yielded the mixture models M3 and MIE19 as the best approaches for stations Ellbögen (chapter 3) and Innsbruck (chapters 4). M3 separates foehn from down-valley winds in Wipp Valley by using speed with concomitants $\Delta \theta$ (to Sattellberg) and relative humidity. For Innsbruck, MIE19 uses $\Delta \theta$ (to Ellbögen) to distinguish whether foehn descends from the Wipp Valley to the Inn Valley. These classifications will be used to compile statistics for the Wipp Valley from 1 January 2000 till 1 January 2013, and Innsbruck from 1 January 2002 till 1 January 2012. Additionally, direct and deflected foehn is compared for Innsbruck.

\subsection{Postprocessing}

As mentioned in chapter 3, the applied method is not able to distinguish the shortlived convective outflows and frontal passages from foehn. An examination of the analyzed foehn events shows that there are 2789 cases of very short events in Ellbögen and 805 in Innsbruck with durations of less than one hour. A survey with case studies showed that the major part of these cases is associated with convective outflows or frontal passages. Another considerable part of those short periods was observed with temporal strengthening of down-valley winds in Ellbögen, and a well-mixed valley atmosphere on summer evenings with up-valley winds in Innsbruck, which were incorrectly classified as foehn. Since only a minor part of these short events represents correctly analyzed foehns, all analyzed events with durations below one hour are eliminated from the dataset prior to the climatological investigations.

This correction leads only to little changes in foehn frequencies but has clear effects on the number of analyzed foehn days. The foehn frequency is reduced by 
1.25 percentage points at Ellbögen and by 0.49 points at Innsbruck . In contrast to this minor effect (reduction by 6 and $8 \%$, respectively), the average foehn days per year are reduced by 21 both in Ellbögen and Innsbruck (reduction by 14 and 32\%, respectively).

So the final results of foehn frequencies are $18.61 \%$ for the station Ellbögen in the Wipp Valley and 5.65\% for Innsbruck University in the Inn Valley.

\subsection{Annual Foehn Days}

The strong variations in data availability (see Fig. 2.5 in chapter 2) makes it almost impossible to create a comparable statistic of days with foehn per year. The analyzed development of foehn days per year from 2001 to 2012 is shown in Fig. 5.1, where also the availability of required variables for foehn diagnostics is included.

For calculation of average foehn days per year, the results are first normalized for each year with the corresponding data availability and than averaged. This leads to 138.7 days per year with at least one hour of foehn at Ellbögen and 66.7 days per year at Innsbruck. So Ellbögen has twice as many foehn days as Innsbruck, and three times as high a relative foehn frequency. This difference results from the much longer duration of foehn events in the Wipp Valley than at Innsbruck (compare Fig. 5.1).

The longest continuous foehn periods were $6.76 \mathrm{~d}$ at Ellbögen from 1730 UTC 2 November 2011 till 1130 UTC 9 November 2011, and 2.44 d at Innsbruck from 0750 UTC 9 Jun 2010 till 1810 UTC 11 Jun 2010.

\subsection{Annual and Daily Foehn Frequency Distribu- tion}

The distributions of foehn frequencies show strong seasonal and daily variability.

At Ellbögen two well pronounced maxima are in spring (April, 29.5\%) and autumn (November, 27.3\%) (see Fig. 5.2a). Foehn is rarest during the summer months (Jun - September) with frequencies around 11\% resulting from usually weak gradients of temperature and pressure at this season. A second, weaker and shorter minimum is in January and February with frequencies of 16.1 and $18.1 \%$, respectively.

The daily cycle of foehn frequency at Ellbögen is much lower than the annual one. The frequency varies from $14.9 \%$ at 08 UTC to $21.7 \%$ at 16 UTC, where both extreme values are shifted by around $3 \mathrm{~h}$ from spring to autumn. This shows that could pools rarely are able to prevent the foehn flow from descending to this 
(a)

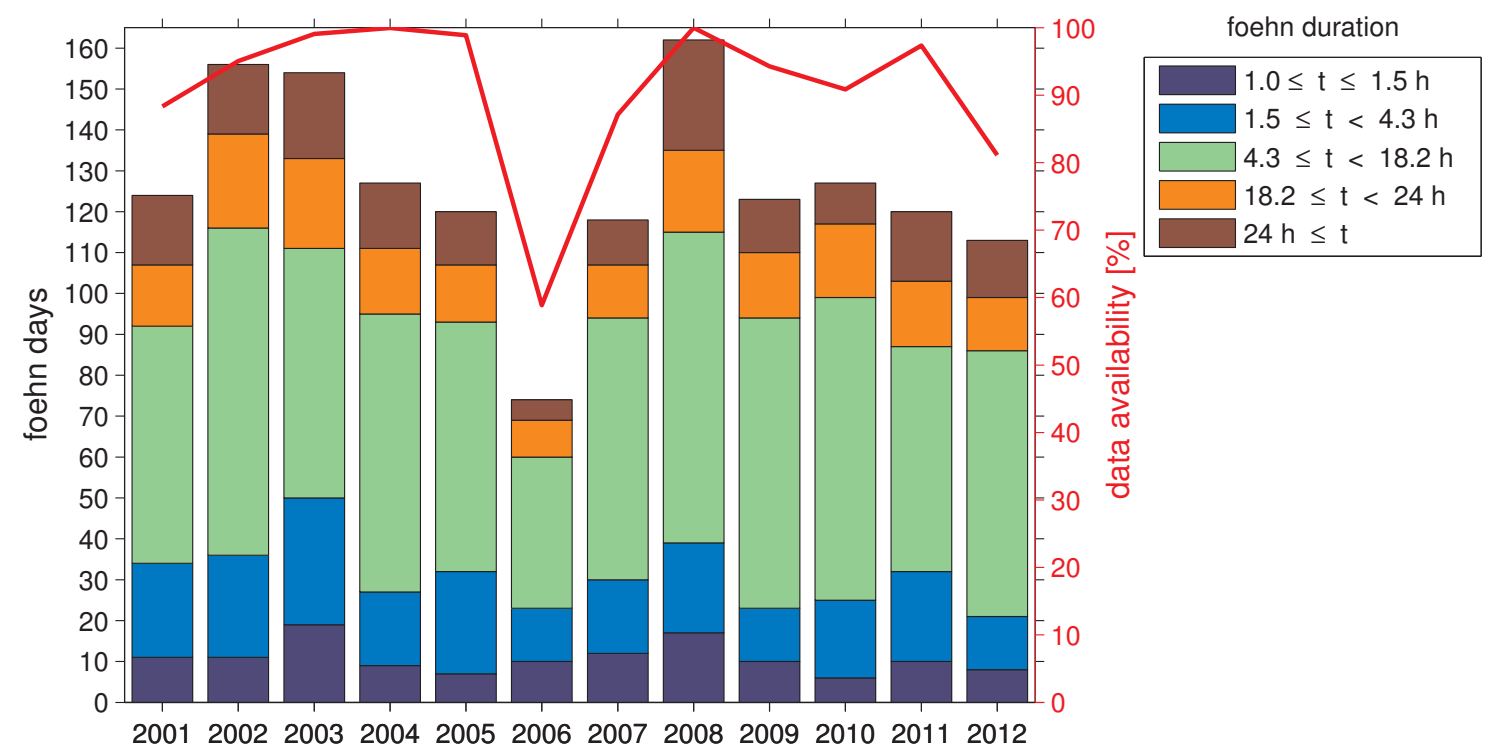

(b)



Figure 5.1: Series of temporal development of days with foehn (with at least one hour of uninterrupted foehn per day) in Ellbögen (a) and Innsbruck (b) from 2001 to 2012. The foehn days are separated into five classes at 10, 25, 75 and 90 quantiles, with respective duration thresholds given in the legend. Note that the foehn hours are counted for calender days and not per foehn events. The red line (right axis) shows the availability of data which were used for this foehn diagnosis.

$1.1 \mathrm{~km}$ amsl-located station about $500 \mathrm{~m}$ above the Inn Valley floor.

At Innsbruck, both cycles are more strongly pronounced than at Ellbögen (see Fig. 5.2b). In December and January foehn is very rare with a frequency of $1.2 \%$. The foehn-richest season is the spring, especially the months April and May with 
(a)
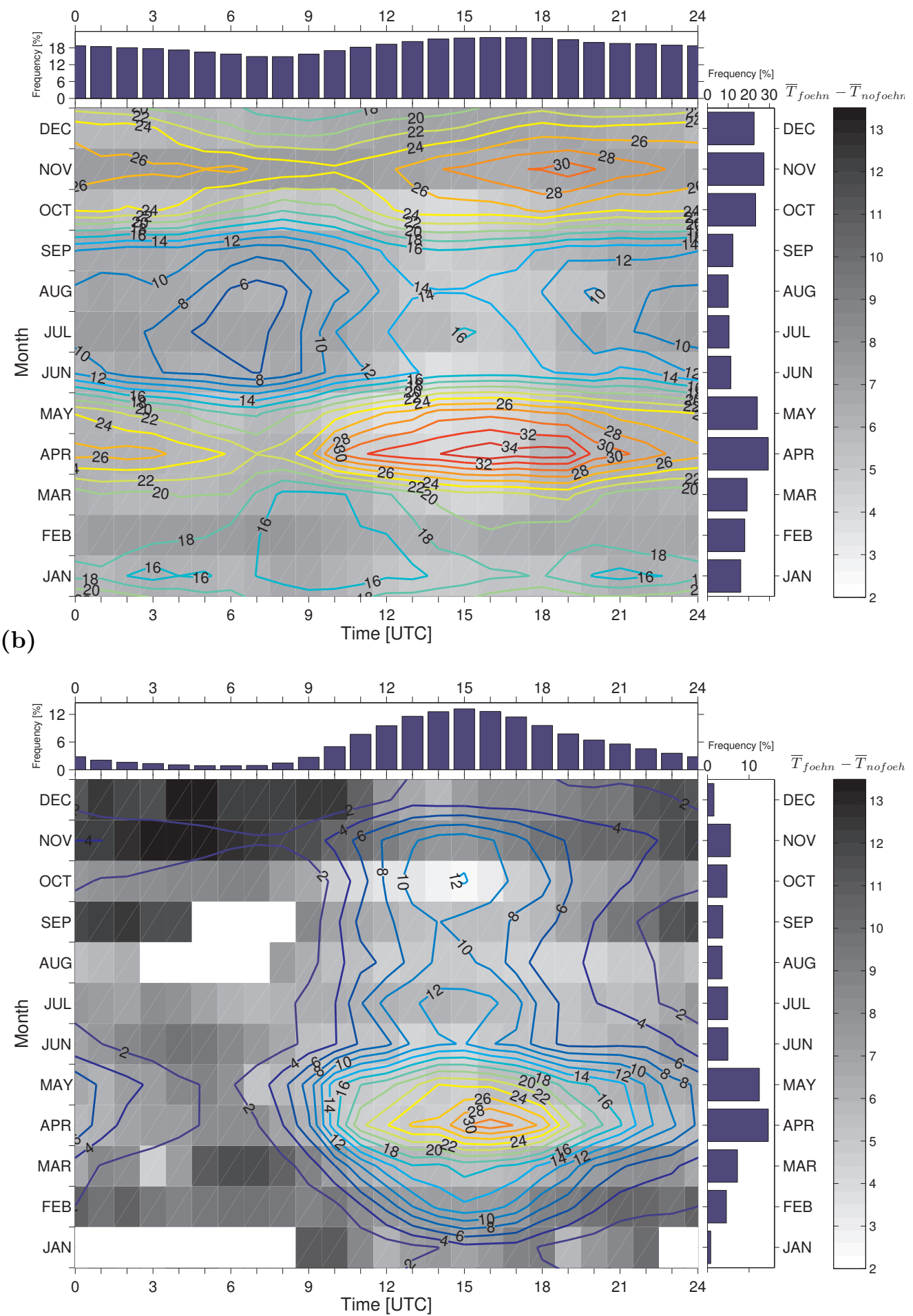

Figure 5.2: Annually and daily distribution of foehn frequency (contour lines) with temperature effect (gray background shading) at Ellbögen (a) and Innsbruck (b). The temperature effect $(\mathrm{K})$ is the difference of average temperature with foehn from the average temperature without foehn for each month and hour (see also Equation 5.2). White color shows times without foehn at the period of investigation. Additionally, annually and daily cycles of foehn frequencies are included for all hours and months, respectively. 
$14.6 \%$ and $12.5 \%$ foehn time, respectively. In the other months (February, June November) the frequency is around $5 \%$.

The diurnal variations are also strong. During the early morning hours 0507 UTC foehn is observed less then $1 \%$ of all times, while in the late afternoon (14-16 UTC) foehn occurs for around $13 \%$ of all observations.

During afternoons of the warm season (April - September) foehn frequency is only around 4 percentage points lower at Innsbruck than at Ellbögen, while at the other times - especially during nights and winter - the frequency is several times higher at Ellbögen than at Innsbruck. This shows that Innsbruck is most of time (13\%) decoupled form the foehn flow due to too low potential temperatures. It takes mostly till noon to heat the Inn Valley to the potential temperature of the foehn flow, so that it can descend. In spring the foehn starts around 3 hours earlier than during other seasons (see strongest gradient of foehn frequency in Fig. 5.2b).

\subsection{Temperature Effects}

To determine the temperature effect of foehn, the average difference of temperatures for all measurements and for measurements without foehn were computed for each months and each hour and then averaged. Mathematically this can be written as

$$
T_{\text {effect }}=\frac{1}{12 \cdot 24} \sum_{m=1}^{12} \sum_{h=1}^{24}\left(\bar{T}_{m, h}^{a}-\bar{T}_{m, h}^{n}\right)
$$

where $\bar{T}_{m, h}$ is the mean temperature for month $m$ at hour $h$. The upper index $a$ stands for all measurements and $n$ for measurements without foehn. Note that $a=$ $n+f$, where $f$ gives the measurements with foehn. The average temperature $\bar{T}_{m, h}^{a}$ depends on the amount of foehn at the corresponding time $(m, h)$ and thus on the corresponding foehn frequency $F_{m, h}$. For a comparison of temperatures independent from foehn frequencies, the Equations 5.1 can be rewritten to

$$
T_{\text {effect }}=\frac{1}{12 \cdot 24} \sum_{m=1}^{12} \sum_{h=1}^{24}\left(F_{m, h} \cdot(\underbrace{\left.\bar{T}_{m, h}^{f}-\bar{T}_{m, h}^{n}\right)}_{\Delta \bar{T}_{m, h}})\right.
$$

where $\Delta \bar{T}_{m, h}$ comes which is plotted in Fig. 5.2.

Foehn increases the average annual temperature $\left(T_{\text {effect }}\right)$ by about $+1.00 \mathrm{~K}$ at Ellbögen and $+0.36 \mathrm{~K}$ at Innsbruck. The absolute values of $\Delta \bar{T}_{m, h}$ are higher at Innsbruck than at Ellbögen (see Fig. 5.2), but due to the higher foehn frequencies, the overall temperature effect is larger in the Wipp Valley.

For Innsbruck, if all periods with foehn at Ellbögen are taken into account (that means including also the pre-foehn west wind), the temperature effect increases to 
$+0.67 \mathrm{~K}$. That shows that also foehn aloft causes warming (net $+0.31 \mathrm{~K}$ ) of the same magnitude as with foehn at the ground. But note that the overall frequency of this state $(12.96 \%)$ is twice as high as the foehn frequency $(5.65 \%)$ at Innsbruck. Consequently also the differences of temperatures during foehn aloft and no foehn are on average half as high as the values of comparing foehn at the ground with no foehn.

Temperature of foehn is compared in detail in Fig. 5.2. For each hour and each month, the difference between the average foehn temperature and the average nofoehn temperature is shown (see $\Delta \bar{T}_{m, h}$ in Equation 5.2). The average temperature is for every time warmer with foehn than without.

At Ellbögen, $\Delta \bar{T}_{m, h}$ varies between $+3 \mathrm{~K}$ at 13 UTC May and $+7 \mathrm{~K}$ at $08 \mathrm{UTC}$ February (Fig. 5.2a). In general the larger values are during nights and cold season, while the differences are lower in the afternoon.

At Innsbruck, the variations of $\Delta \bar{T}_{m, h}$ are much stronger (Fig. 5.2b) than at Ellbögen. During nights, especially in November and December, the foehn is more than $10 \mathrm{~K}$ warmer than the average temperature without foehn. The maximum is $+13.4 \mathrm{~K}$ at 05 UTC November. The smallest differences are at late afternoons with a minimum of $+2.4 \mathrm{~K}$ at 15 UTC October.

The foehn frequency shows a clear dependence on $\Delta \bar{T}_{m, h}$ at Innsbruck. At the times, when the average temperature at Inn Valley is high, i.e. at afternoons due to radiation, and thus the difference to the upstream foehn temperature is low, foehn can descend frequently to Innsbruck. For this reason, the foehn frequencies at Innsbruck reach almost the values of Ellbögen during afternoons between March and September (compare Fig. 5.2). The largest differences of foehn frequencies between both stations are during nights and the cold season, when the foehn is much warmer then the Inn Valley, which is filled with radiatively cooled air.

\subsection{Foehn Begin and Ending Times}

Foehn begins and ends at preferred times at Innsbruck but not at Ellbögen. During the cold season from November till March the foehn at Ellboegen (see Fig. 5.3 a and b) begins almost at any time of the day with the same frequency. For the rest of the year foehn onsets are more frequent around noon than at other times. The endings of foehn are rarest around 12 UTC, with a shift of this minimum towards 09 UTC in summer.

In contrast to Ellbögen, the density distributions of onset and ending times have clear maxima at Innsbruck (see Fig. $5.3 \mathrm{c}$ and d). Foehn begins most frequent around 12 UTC, while the onsets are $1-2 \mathrm{~h}$ later in winter (December and January) and earlier in spring (March - May) and autumn (September - November). These 

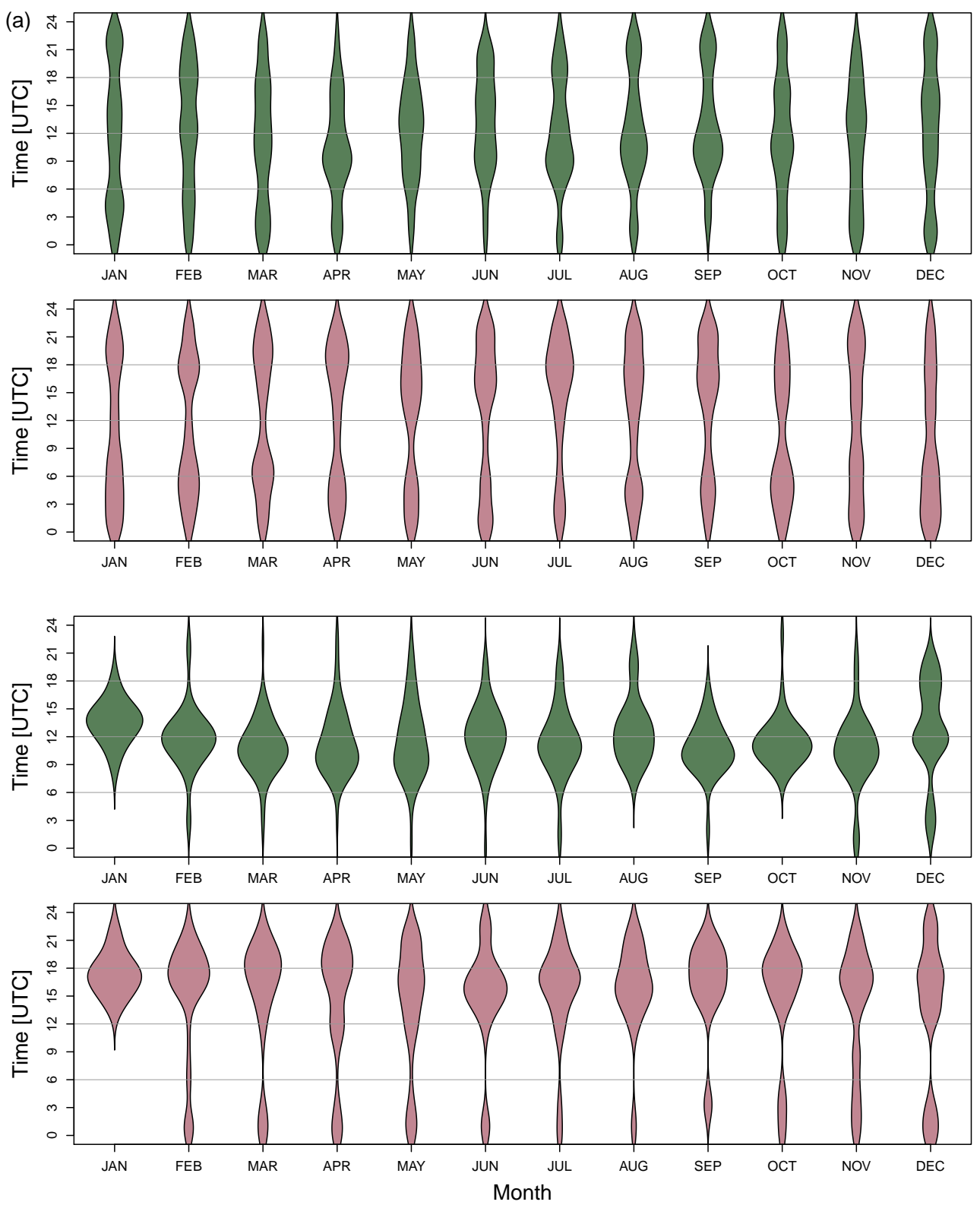

Figure 5.3: Annual distribution of foehn onset (green, a and c) and ending (red, b and d) times for Ellbögen $(\mathrm{a}, \mathrm{b})$ and Innsbruck $(\mathrm{c}, \mathrm{d})$. The data is visualized in bean plots which show the density distributions of foehn onsets and ending for each month.

times are favored for foehn onsets because the Inn Valley must be warmed till the temperature of foehn is reached (cf. Fig. 5.2b). Foehn ends most frequently around 18 UTC when the Valley air cools below the (potential) temperature of the foehn flow. The endings of foehn are $1-2 \mathrm{~h}$ earlier in summer (July - August) and winter (December and January) than in other seasons. 




Figure 5.4: Distribution of wind direction density at Innsbruck during foehn analyzed with the model MIE19 (red line). Additionally, the distribution of all winds at Innsbruck with speeds above $4 \mathrm{~m} \mathrm{~s}^{-1}$ is included (black, thin line), which was used to determine the direct foehn wind sector marked by vertical black lines.

\subsection{Comparison: Deflected - Direct Foehn}

As discussed in section 4.1, south foehn at Innsbruck can be deflected and reach the Inn Valley from various directions (see Fig. 5.4). For some applications, only direct foehn from the south might be of interest.

For comparing direct with deflected foehn, wind measurements are needed. Using wind measurements reduces the data availability from $85.7 \%$ to $72.9 \%$ due a wind sensor failure from winter 2008 till summer 2009 (see also section 2.2). For a consistent comparison model MIE19 ${ }^{1}$ is used with a direction-filter in postprocessing: $130^{\circ} \leq d d_{I B K} \leq 210^{\circ}$. For this data-set, the overall foehn frequency using MIE19, is $5.70 \%$ for all foehn winds and $3.35 \%$ for direct foehn with the southerly direction filter. The amount of foehn days (with at last one hour of uninterrupted foehn) is reduced also by almost the half, from 569 to 304 days over the period from 2002 till 2012 for all foehn and direct foehn, respectively. The series of foehn days during the period of investigation is summarized in Table 5.1.

\footnotetext{
${ }^{1}$ For direct foehn the mixture models MI1, MI12-MI15, MIE18, MIS16 or MIS27 could also be used.
} 
Table 5.1: Comparison of foehn days with at least one hour of uninterrupted duration from all directions, including deflected foehn (all foehn) and only south direction (direct foehn). Data availability (data avail.) is included for all variables needed for mixture model MIE19 and wind direction at Innsbruck.

\begin{tabular}{r|cccccccccc}
\hline \hline year & 2002 & 2003 & 2004 & 2005 & 2006 & 2007 & 2008 & 2009 & 2010 & 2011 \\
\hline data avail. & 94.7 & 98.3 & 98.7 & 98.7 & 59.0 & 84.9 & 0 & 47.7 & 99.6 & 82.7 \\
all foehn & 76 & 68 & 59 & 58 & 38 & 66 & 0 & 21 & 62 & 49 \\
direct foehn & 45 & 41 & 43 & 32 & 19 & 42 & 0 & 9 & 39 & 34 \\
\hline
\end{tabular}




\section{Chapter 6}

\section{Discussion and Conclusion}

This study showed that statistical mixture models can be used to diagnose foehn automatically and assign an uncertainty to the diagnosis at stations in simple as well as complex topography. The method is objective and requires in general only the foehn direction sector as manual input.

At the station Ellbögen (1080 m amsl) in the Wipp Valley (simple topography), wind speed suffices to get accurate results of foehn frequency. Thereby the mixture models estimates parameters for speed-density distributions of down-valley winds and foehn, which comes from a predefined wide foehn wind sector of $\pm 90^{\circ}$ from the valley axis. This enables it to separate both winds and calculate the certainty that one measurement belongs to one of these groups.

Including additional physically meaningful concomitant variables to the mixture model improves the accuracy of the results and reduces the uncertainty of classification. The most important concomitant is the difference of potential temperature between a station at the upstream crest and the valley station, because the adiabatic descent is a major property of foehn flows. Relative humidity refines this result, while other tested variables do not lead to any improvement.

For station Innsbruck University (580 m amsl) in a more complex topography, the same approach classifies direct foehn successfully. At this location the Wipp Valley flows through a steep step of approximate $200 \mathrm{~m}$ perpendicular into the Inn Valley, with the around $2.4 \mathrm{~km}$ high "Nordkette" at the opposite valley side. Since the "Nordkette", however, deflects foehn emerging from the Wipp Valley, deflected foehn is almost as frequent as direct foehn. These deflected cases can not be captured by this method.

This problem can be solved, when an upstream foehn valley station like Ellbögen is available. Instead of the direction filter, the data set is reduced to those times when foehn is registered at Ellbögen and thus foehn in general is possible at Innsbruck. Whether foehn can descend from Ellbögen further downwards to the Inn Valley depends on the stratification, which is given by the difference of potential 
temperature between these stations $(\Delta \theta)$. This enables a mixture model using only $\Delta \theta$ as primary variable to diagnose foehn properly (MIE19).

Altogether 32 different models with combinations of $\Delta \theta$, speed, direction and relative humidity and different numbers of clusters were tested for the setup with Ellbögen and 37 with Sattelberg (precondition of wind from $180^{\circ} \pm 90^{\circ}$ at crest) as reference. None of them was better than MIE19. The best of the 37 models from the classification setup with Sattelberg leads to similar results as those models using the simple setup which was used at Ellbögen. Thus it makes only sense to use a foehn valley stations as reference for pre-filtering data when the main foehn direction can be distinguished from other strong wind systems at valley.

Since these methods are not able to distinguish convective outflows and fronts from foehn, a post-processing is needed. It was found that just eliminating all analyzed foehn periods shorter than one hour eliminates almost all such situations.

Results of the best models lead to foehn frequencies of $18.61 \%$ at the station Ellbögen in Wipp Valley (1 January 2000 till 1 January 2013) and 5.65\% at Innsbruck University in the Inn Valley (from 1 January 2002 till 1 January 2012). Foehn increases the average annual temperature at Ellbögen by $1.00 \mathrm{~K}$ and $0.36 \mathrm{~K}$ at Innsbruck, respectively. Ortner (2010) found a similar warming of $0.3 \mathrm{~K}$ for Innsbruck in analysis of climate foehn observations. Foehn aloft causes a warming of $0.31 \mathrm{~K}$, which is caused by increase turbulent mixing through stronger wind speeds at Inn Valley (especially the pre-foehn west wind). The net effect of the warm and dry aloft foehn layer on the long-wave downward radiation is not clear. A higher temperature increases the radiation, while a lower humidity decreases the emissivity.

The annual and daily distribution of foehn frequency (cf. Fig. 5.2) is strongly connected to the differences of foehn temperatures to no-foehn temperatures. Overall this result is very similar to the one of Föst (2006) (cf. Fig. 1.5), with the exception that Föst analyzed at Ellbögen clearly higher foehn frequencies during nights from January to March.

At Innsbruck foehn onsets most frequent around 12 UTC, after the valley is warmed radiativelly and ends around 18 UTC (cf. Fig. 5.3) with decreasing temperature in the valley (cf. Fig. 5.2b). At Ellbögen the density distributions of beginning and ending times show only little variations, which indicates that could pools and daily cycle of radiations have only a marginal influence on foehn in the Wipp Valley.

At both stations (Ellbögen and Innsbruck) the new method outperforms the previous method OFC (Vergeiner 2004; Drechsel and Mayr 2008; Föst 2006). The mixture models also analyze the onsets and the endings better and with fewer interruptions. At Innsbruck, also deflected foehn is captured and many misclassifications of up-valley winds (with the OFC) are eliminated by using the condition of simultaneous foehn at the upstream station in the Wipp Valley. 
Another advantage of foehn diagnosis with mixture models is the faster application compared to the former methods (Gutermann 1970; Vergeiner 2004; Drechsel and Mayr 2008; Dürr 2008). Since it uses unsupervised learning, no sample of manually pre-classified foehn periods is needed as for the method of Gutermann (1970). Also no criteria (except of the foehn direction sector) have to be manually estimated as for the OFC and the method from Dürr (2008).

Finally, mixture models provide an additional useful information about the (un-)certainty of the diagnosis. Some cases with foehn-probabilities around $50 \%$ might be interpreted as a mixture of foehn and no-foehn air (cf. case study in Fig. 4.9). In contrast to the probabilistic approach of Strobl (2009), no additional work of estimating the annual cycle of down-valley wind periods is required.

Mixture models can distinguish foehn and no-foehn, when the two density distributions (of speed or $\Delta \theta$ ) are statistically distinguishable. For the wind speed method (simple topography), the average speeds of downslope and down-valley winds have to be lower than for foehn.

The major problem of automatic foehn diagnosis methods is the verification since the truth is not known. Even a classification by different human experts leads to differences. Since for an unsupervised classification it is unknown which measurement belongs to which group, the results have to be checked indirectly. To assess the results, scatterplots of all combinations of the important variables (speed, $\Delta \theta$, and in some cases also direction) are helpful, because unreasonable results can be easily recognized. When foehn classification is applied for two or more stations in one region, the analysis can also be checked for consistency, e.g. that a downstream station can not have a foehn when a upstream station has no foehn. But to decide finally which model is the best one, detailed human-expert analysis of many case studies is indispensable.

It will be important to test this classification method at other locations. Separating foehn from down-valley winds by using wind speed distribution should work at many direct foehn valleys similar to the Wipp Valley. At more complex topographies foehn could be easily classified by using $\Delta \theta$ as primary variable if an upstream foehn station is available. Otherwise, more complex approaches including direction could be tried.

A further investigations should also compare the accuracy of this unsupervised classification method with the method from Dürr (2008). Since Dürr's method was applied in many valleys of the northern Switzerland, the easiest way for comparison would be a application of mixture models for the same stations as Dürr's.

Such an automatic foehn diagnosis enables many further investigations. For example it could be investigated whether foehn observations fit to current conceptual models of foehn. Also research on influence of foehn on temperature, precipitation 
and air quality are possible.

Finally, mixture model could be used for operational real time weather analyses. Since the model parameters are fitted once for a station, the foehn probability can easily be computed in real time. 


\section{Bibliography}

Afanasyev, Y. and W. Peltier, 2001a: On breaking internal waves over the sill in Knight Inlet. Proc. Roy. Soc. A, 457, 2799-2825.

Afanasyev, Y. and W. Peltier, 2001b: Reply to comment on the paper 'on breaking internal waves over the sill in Knight Inlet'. Proc. Roy. Soc. A, 457, 2831-2834.

Armi, L., 1986: The hhydraulic of two floflow layers with different densities. J. Fluid Mech., 163, 27-58.

Armi, L. and D. Farmer, 2002: Stratified flow over topography: Bifurcation fronts and transition to the uncontrolled state. Proc. Roy. Soc. A, 458, 513-538.

Armi, L. and G. J. Mayr, 2007: Continuously stratified flows across an Alpine crest with a pass: Shallow and deep föhn. Quart. J. Roy. Meteor. Soc., 133, 459-477.

Armi, L. and G. J. Mayr, 2011: The descending stratified flow and internal hydraulic jump in the lee of the Sierras. J. Appl. Meteor. Climatol., 50, 1995-2011.

Berg, H., 1951: Der Föhn im nördlichen Alpen- und Voralpengebiet. Ber. DWD US-Zone, Bd. 5, 35, 117-124.

Clark, T. and R. Farley, 1984: Severe downslope windstorm calculations in two and three spatial dimensions using anelastic interactive grid nesting: A possible mechanism for gustiness. J. Atmos. Sci., 41, 329-350.

Clark, T. and W. Peltier, 1977: On the evolution and stability of infinite amplitude mountain waves. J. Atmos. Sci., 34, 1715-1730.

Conrad, V., 1936: Handbuch der Klimatologie, chap. Die klimatologischen Elemente und ihre Abhängigkeit von terrestrischen Einflüssen, 1146-1166. Bornträger.

Cummins, P., 2000: Stratified flow over topography: time-dependent comparisons between model solutions and observations. Dyn. Atmos. Oceans, 33, 43-72.

Defant, A., 1910: Zur Theorie der Berg- und Talwinde. Meteor. Z., 4,--. 
Defant, A., 1949: Zur Theorie der Hangwinde, nebst Bemerkungen zur Theorie der Berg- und Talwinde. Arch. Meteor. Geophys. Bioklimatol., Serie B, 1, Serie A.

Dörnbrack, R. K. J., A. Heise, 2006: Wellen und Rotoren. Promet, 32, 18-24.

Drechsel, S. and G. J. Mayr, 2008: Objective forecasting of foehn winds for a subgridscale Alpine valley. Wea. Forecasting, 23, 205-218.

Dreiseitl, E., H. Feichter, H. Pichler, R. Steinacker, and I. Vergeiner, 1980: Windregimes an der Gabelung zweier Alpentäler. Arch. Meteor. Geophys. Bioklimatol., Serie B, 28 (3), 257-275, doi:10.1007/BF02245357, URL http://dx.doi. org/10.1007/BF02245357.

Dürr, B., 2008: Automatisiertes Verfahren zur Bestimmung von Föhn in Alpentälern. Arbeitsbericht 223, MeteoSchweiz. URL http://www . meteoschweiz.admin.ch/web/de/forschung/publikationen/alle_ publikationen/ab_223.Par.0001.DownloadFile.tmp/ab223.pdf.

Durran, D. R., 1986: Another look at downslope windstorms. part i: The development of analogs to supercritical flow in an infinitely deep, continuously stratified fluid. J. Atmos. Sci., 43, 2527-2543.

Ekhart, E., 1949: Zum Innsbrucker Föh. Meteor. Rundsch., 2, 276-280.

Farmer, D. and L. Armi, 1999: Stratified flow over topography: the role of smallscale entrainment and mixing in flow establishement. Proc. Roy. Soc. A, 455, $3221-3258$.

Farmer, D. and L. Armi, 2001: Stratified flow over topography: models versus observations. Proc. Roy. Soc. A, 457, 2827-2830.

Ficker, H., 1943: Föhn und Föhnwirkungen: der gegenwärtige Stand der Frage. Leipzig: Becker \& Erler, 112 pp.

Föst, F., 2006: Eine objektive Föhnklimatologie für das Wipp- und Inntal. Diplomarbeit, Freie Universität Berlin und Innsbruck, URL http://imgi.uibk.ac . at/sekretariat/diploma_theses/Foest_Fritz_2006_Dipl.pdf.

Frey, 1957: Zur Diagnose des Föhns. Meteor. Rundsch., 10, 181-185.

Georgelin, M., E. Richard, M. Petitdidier, and D. A., 1994: Impact of subgrid-scale program parameterization on the simulation of orographic flows. Mon. Wea. Rev., 122, 1509-1522. 
Gohm, A. and G. J. Mayr, 2005: Numerical and observational case study of a deep Adriatic bora. Quart. J. Roy. Meteor. Soc., 131, 1363-1392.

Grubišić, V., et al., 2008: The terrain-induced rotor experiment. Bull. Amer. Meteor. Soc., 89 (10), 1513-1533, doi:10.1175/2008BAMS2487.1, URL http://dx.doi. org/10.1175/2008BAMS2487.1.

Gutermann, T., 1970: Vergleichende Untersuchungen zur Föhnhäufigkeit im Rheintal zwischen Chur und Bodensee. No. 18 in Veröffentlichungen der Schweizerischen Meteorologischen Zentralanstalt, City-Druck AG, Zürich.

Haas, G., 2006: Nordföhn und Niederschlag in Innsbruck. Diplomarbeit, Universität Innsbruck, URL http://imgi.uibk.ac.at/sekretariat/diploma_ theses/Haas_Georg_2006_Dipl.pdf.

Hann, J., 1879: Zur Theorie der Berg- und Talwinde. Meteor. Z., 14, 444-448.

Hastie, T., R. Tibshirani, and J. Friedman, 2009: The Elements of Statistical Learning. Springer Series in Statistics, Springer New York Inc., New York, NY, USA.

Huppert, H. and J. Miles, 1969: Lee waves in a stratified flow Part 3: Semi-elliptical obstacles. J. Fluid Mech., 35, 481-496.

Jackson, P. L., G. J. Mayr, and S. Vosper, 2013: Mountain Weather Research and Forecasting: Recent Progress and Current Challenges, chap. Dynamically-Driven Winds, 121-218. Springer-Verlag.

Klemp, J. and D. R. Durran, 1987: Numerical modeling of bora winds. Meteor. Atmos. Phys., 36, 215-227.

Klemp, J. and D. Lilly, 1978: Numerical simulation of hydrostatic mountain waves. J. Atmos. Sci., 35, 78-107.

Kneringer, P., 2011: Objektive Föhnklimatologie im Raum Boulder, Colorado. M.S. thesis, Universität Innsbruck.

Küttner, J., 1938: Moazagotl und Föhnwelle. Beitr. Phys. Atmos., 25, 79-114.

Lackmann, G. M. and J. E. Overland, 1989: Atmospheric structure and momentum balance during a gap-wind event in Shelikof Strait, Alaska. Mon. Wea. Rev., 117, 1817-1833.

Lilly, D., 1979: A severe downslope windstorm and aircraft turbulence event induced by a mountain wave. J. Atmos. Sci., 95, 241-261. 
Lin, Y. and W. T.A., 1996: Flow regimes and transient dynamics of two-dimensional stratified flow over an isolated mountain ridge. J. Atmos. Sci., 53, 139-158.

Long, 1953: Some aspects of the flow of stratified fluids. i. a theoretical investigation. Tellus, 5, 42-58.

Long, 1954: Some aspects of the flow of stratified fluids. ii. experiments with a two-fluid system. Tellus, 6, 97-115.

Markowski, P. and R. Yvette, 2010: Mesoscale Meteorology in Midlatitudes. WileyBlackwell, 430 pp.

Mayr, G. J. and L. Armi, 2008: Föhn as a response to changing upstream and downstream air masses. Quart. J. Roy. Meteor. Soc., 134, 1357-1369.

Mayr, G. J. and L. Armi, 2010: The influence of downstream diurnal heating on the descent of flow across the Sierras. J. Appl. Meteor. Climatol., 49, 1906-1912.

Mayr, G. J., et al., 2004: Gap flow measurements during the Mesoscale Alpine Programme. Meteor. Atmos. Phys., 86, 99-119.

Mayr, G. J., et al., 2007: Gap flows: Results from the Mesoscale Alpine Programme. Quart. J. Roy. Meteor. Soc., 133, 881-896.

Obenland, 1956: Untersuchung der Föhstatistik des Oberallgäus. Ber. DWD, Bd.4, 23, 37 .

Olafsson, H. and B. P., 1997: The effect of rotation and surface friction on orographic drag. J. Atmos. Sci., 54, 193-210.

Ortner, A., 2010: Detaillierte Statistik des Südföhn in innsbruck: Einfluss des Südföhns auf die Temperatur. M.S. thesis, University Innsbruck.

Peltier, W. and T. Clark, 1979: The evolution and stability of finite-amplitude mountain waves. part ii: Surface wave drag and severe downslope windstorms. $J$. Atmos. Sci., 36, 1498-1529.

Peltier, W. and T. Clark, 1983: Nonlinear mountain waves in two and three spatial dimensions. Quart. J. R. Meteorol. Soc., 109, 527-548.

Pippan, C., 2000: Umgang mit einem heterogenen, hochaufgelösten Meßnetz während der Feldphase des Mesoscale Alpine Programme. M.S. thesis, University Innsbruck. 
Plavcan, D., G. J. Mayr, and A. Zeileis, 2014: Automatic and probablilistic foehn diagnosis with a statistical mixture model. J. Appl. Meteor. Climatol., 53, in press.

Pollack, O., 1911: Der Föhn in Salzburg. Meteor. Z., 28, 93-95.

Reiter, 1958: Klima von Innsbruck. Stadtmagistrat Innsbruck, Statist. Amt., 2. Sonderveröffent., - .

Richard, E., P. Mascart, and E. Nickerson, 1989: On the role of surface friction in downslope windstorms. J. Appl. Meteor., 28, 241-251.

Richner, H. and P. Hächler, 2013: Mountain Weather Research and Forecasting: Recent Progress and Current Challenges, chap. Understanding and Forecasting Alpine Foehn, 219 - 260. Springer.

Schütz, J. and F. Steinhauser, 1955: Neue Föhnuntersuchungen aus dem Sonnblickgebiert. Arch. Meteor. Geophys. Bioklimatol., Serie B, 6, 207-224.

Seibert, 1982: The south foehn cases at Innsbruck during the ALPEX Special Observing Period (SOP). GARP-ALPEX, 7, 155-166.

Seibert, 1985: Fallstudien und statistische Untersuchungen zum Südföhn im Raum Tirol. Ph.D. thesis, Universität Innsbruck.

Smith, R. B., 1985: On severe downslope winds. J. Atmos. Sci., 42, 2597-2603.

Smith, R. B. and Grønås, 1993: Stagnation points and bifurcation in 3-d mountain air-flow. Tellus, 45A, 28-43.

Steinacker, R., 1984: Area-height distribution of a valley and its relation to the valley wind. Contrib. Atmos. Phys., 57, 64-71.

Strobl, A., 2009: Eine Südföhn-Statistik für das Oberinntal und ein Vergleich mit dem Wipptal. Diplomarbeit, Universität Innsbruck, URL http://imgi .uibk.ac . at/sekretariat/diploma_theses/Strobl_Anton_2009_Dipl.pdf.

Ungeheuer, H., 1952: Zur Statistik des Föhns im Voralpengebiet. Ber. DWD USZone, Bd. 6, 38, 117-120.

Verant, W., 2006: Föhnklimatologie für Südtirol und das Aostatal. Diplomarbeit, Universität Innsbruck, URL http://imgi.uibk.ac.at/sekretariat/diploma_ theses/Verant_Werner_2006_Dipl.pdf. 
Vergeiner, J., 2004: South foehn studies and a new foehn classification scheme in the Wipp and Inn valley. Ph.D. thesis, Universität Innsbruck, URL http://imgi.uibk.ac.at/sekretariat/dissertations/ Vergeiner_Johannes_2004_Diss.pdf.

Wagner, A., 1932b: Neue Theorie des Berg- und Talwinds. Meteor. Z., 49, 329-341.

Weissmann, M., F. J. Braun, L. Gantner, G. J. Mayr, S. Rahm, and O. Reitebuch, 2005: The alpine mountain-plain circulation: Airborne doppler lidar measurements and numerical simulations. Mon. Wea. Rev., 133 (11), 3095-3109, doi:10.1175/MWR3012.1, URL http://dx.doi.org/10.1175/MWR3012.1.

Whiteman, C. D., 2000: Mountain Meteorology: Fundamentals and Applications. Oxford University Press, 376 pp.

Widmer, R., 1966: Statistische Untersuchungen über den Föhns im Reusstal und Versuch einer objektiven Föhnprognose für die Station Altdorf. Vierteljahrsschrift Naturforsch. Ges. Zürich, 111, 331-375, URL http://www .agf .ch/doc/Widmer_ 1966.pdf.

Wilks, D. S., 2011: Statistical Methods in the Atmospheric Sciences, International Geophysics Series, Vol. 100. 3d ed., Academic Press, Oxford.

WMO, 1992: International Meteorological Vocabulary, Vol. 182. 2d ed., World Meteorological Organization, 784 pp.

Yoshino, M., 1976: Bora studies: A historical review and problems today. M.M. Yoshino Ed., 3-18.

Zanella, 1982: Il Foehn nel Pedemonte Emiliano. Atti del primo convegno di meteorologia appenninica, Reggio Emillia, -, 221-237.

Zängl, G., 2003: Deep and shallow south foehn in the region of Innsbruck: Typical features and semi-idealized numerical simulations. Meteor. Atmos. Phys., 83, 237261.

Zängl, G., 2004: A reexamination of the valley wind system in the Alpine Inn Valley with numerical simulations. Meteor. Atmos. Phys., 87 (4), 241-256, doi:10.1007/ s00703-003-0056-5, URL http://dx.doi .org/10 .1007/s00703-003-0056-5. 


\section{Acknowledgments}

The major thanks belong to my first supervisor Georg Johann Mayr, who enabled me to work on my favor and very interesting topics foehn and mountain meteorology. He supported me with very good ideas and help, especially for publishing the core part of this work. Also in busy times he found time to discuss my questions.

Many thanks belong also to Achim Zeileis, who supported me as second supervisor in statistical aspects. He provided the statistical solution for our classification problem.

I like to thank also the Institute for Meteorology and Geophysics of Innsbruck, which provided the data that were necessary for this study.

Finally, i thank also to the Austrian Science Fund (FWF): L615-N10, which financed the publishing cost of our article. 


\title{
Curriculum Vitae
}

\author{
David Plavcan \\ Schneeburggasse 6 \\ 6020 Innsbruck \\ Born on March 1988 in Znojmo, Czech Republic
}

\section{Education and Professional training:}

2012-2014 Master thesis under the guidance of Ao. Prof. Dr. Mayr, Institute of Meteorology and Geophysics, University of Innsbruck: "Automatic and Probabilistic Diagnosis of Foehn with a Statistical Mixture Model".

2011-2014 Master study at the University of Innsbruck. Master of Natural Science in Atmospheric Science.

2011 Bachelor thesis under the guidance of Assoz. Prof. Dr. Gohm, Institute of Meteorology and Geophysics, University of Innsbruck: "Nebelklimatologie und -klassifikation von Innsbruck".

2008-2011 Bachelor study at the University of Innsbruck. Bachelor of Natural Science in Geo- and Atmospheric Science.

1998-2007 Adalbert-Stifter-Gymnasium, Passau Matura.

TEACHING EXPERIENCE:

2012-2014 Tutor for "Einführung in die Meteorologie" and "Einführung in die Klimatologie" (Bachelor degree courses Atmospheric science)

2011-2012 Tutor for "Wetterbesprechung" (Bachelor and Master degree course Atmospheric science)

2010-2011 Tutor for "Einführung in die Meteorologie" and "Einführung in die Klimatologie" (Bachelor degree courses Atmospheric science) 
PRACTICAL EXPERIENCE:

July \& August $2013 \quad$ Practical training with AustroControl Innsbruck (Verification of winter services forecasts)

July \& August $2012 \quad$ Practical training with Office of the Tyrolean regional government, section forest protection, department air quality (Influence of Foehn on Air Quality in Innsbruck)

since winter 2010/2011 Weather forecast for the Four Hills Tournament (Ski Jumping World Cup) in Innsbruck Bergisel

FURTHER SKILLS:

Programming Matlab, R, Fortran 95, EULAG, $\mathrm{LT}_{\mathrm{E}} \mathrm{X}$

Languages $\quad$ German, English, French, Slovak 